\title{
Physics and current understanding of X-ray storage phosphors
}

DER UNIVERSITÄT-GESAMTHOCHSCHULE PADERBORN

ZUR ERLANGUNG DER LEHRBERECHTIGUNG

(VENIA LEGENDI)

FÜR DAS FACH

EXPERIMENTALPHYSIK

vorgelegte Habilitationsschrift

von

STEFAN SCHWEIZER

MAI 2000 (Eröffnung des Habilitationsverfahrens)

NOVEMBER 2000 (Habilitationsvortrag)

DEZEMBER 2000 (Abschluss des Habilitationsverfahrens) 


\section{Table of Contents}

$\begin{array}{ll}\text { Introduction } & 1\end{array}$

1 Experimental fundamentals 5

1.1 Magneto-optical measurement techniques .................................................. 5

1.1.1 Magnetic circular dichroism of the optical absorption ..................... 5

1.1.2 Optical detection of electron paramagnetic resonance (EPR) and electron nuclear double resonance (ENDOR) …………………...... 8

1.1.3 Cross-relaxation spectroscopy ………………………………..... 10

1.2 Conventional EPR and ENDOR …………………………………..... 11

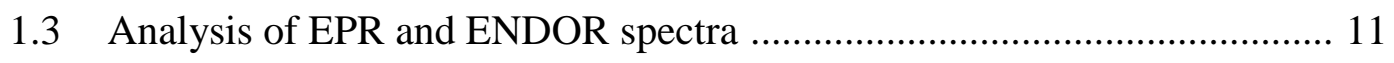

1.3.1 The spin Hamiltonian ……………………….......................... 11

1.3.2 Analysis of EPR spectra ……………………….................... 15

1.3.3 Analysis of ENDOR spectra ……………………………….... 15

1.3.4 Calculation of powder EPR and ENDOR spectra ........................ 16

2 X-ray storage phosphors $\quad 19$

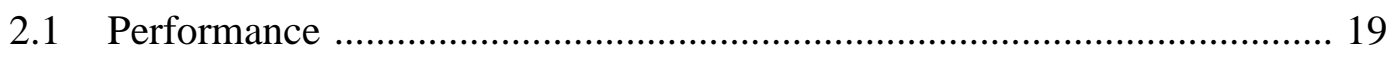

2.2 Spatial resolution of X-ray storage phosphor image plates ....................... 21

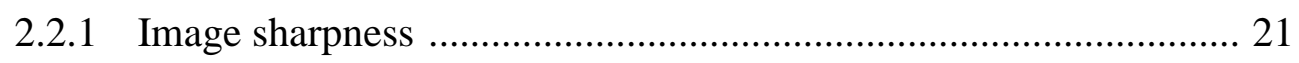

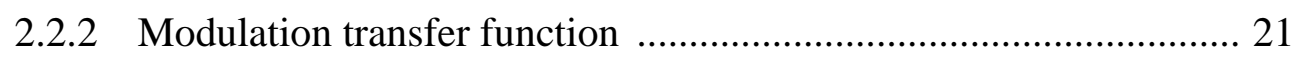

2.2.3 Description of imaging processes via Fourier transformation ........ 24

2.2.4 Measurement of the spatial resolution and the modulation transfer function ......................................................................... 25

2.3 Read-out process of X-ray storage phosphor image plates ……………..... 27 
3 The X-ray storage phosphor BaFBr: $\mathrm{Eu}^{2+} \quad 31$

$3.1 \quad$ Stoichiometric $\mathrm{BaFBr}$..................................................................... 31

3.1.1 Generation of electron trap centres .............................................. 31

3.1.2 Generation of hole trap centres …………………………….... 33

3.1.3 PSL active hole trap centres ..................................................... 35

3.2 Non-stoichiometric $\mathrm{BaFBr}$.............................................................. 38

3.2.1 Photostimulated luminescence …………………….................... 40

3.2.2 Identification of fluorine antisites with MAS-NMR ...................... 41

3.2.3 Identification of electron and hole trap centres with EPR ............. 43

3.2.4 Generation of electron and hole trap centres ................................. 45

3.3 Red-shift of the PSL excitation upon $\mathrm{Ca}^{2+}$ or $\mathrm{Sr}^{2+}$ doping ........................ 49

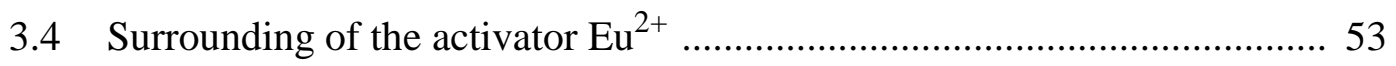

3.4.1 EPR and ENDOR of crystalline BaFBr: $\mathrm{Eu}^{2+}$................................ 53

3.4.2 EPR and ENDOR of powdered BaFBr:Eu ${ }^{2+}$............................... 54

3.4.3 Influence of the production process ............................................... 56

$4 \quad$ Alkali halides and elpasolites $\quad 59$

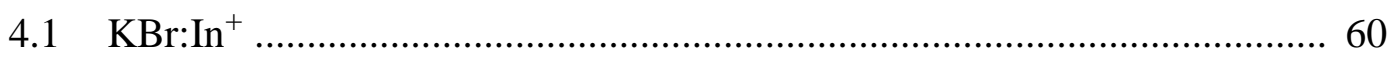

4.1.1 Generation of electron and hole trap centres ................................. 62

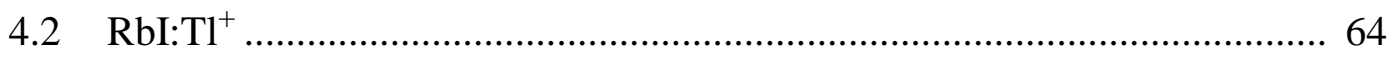

4.2.1 Generation of electron and hole trap centres ................................ 64

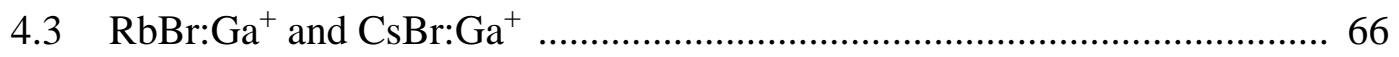

4.3.1 Sample preparation ................................................................. 66

4.3.2 Generation of electron and hole trap centres .................................. 67

4.3.3 Generation of $\left(\mathrm{Ga}^{2+}\right)^{\mathrm{I}}$ and $\left(\mathrm{Ga}^{2+}\right)^{\mathrm{II}}$ centres in $\mathrm{RbBr}: \mathrm{Ga}^{+} \ldots \ldots \ldots \ldots \ldots . . . . .68$

4.3.4 PSL experiments with $\mathrm{RbBr}: \mathrm{Ga}^{+}$and $\mathrm{CsBr}: \mathrm{Ga}^{+}$......................... 71

4.3.5 Optimal activator concentration and $\mathrm{Ga}^{+}$aggregation ................... 73

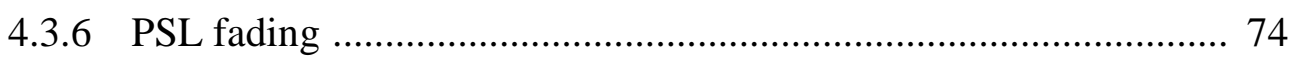

4.3.7 Red-shift of the PSL excitation ...................................................... 76

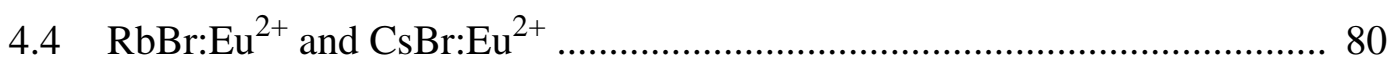

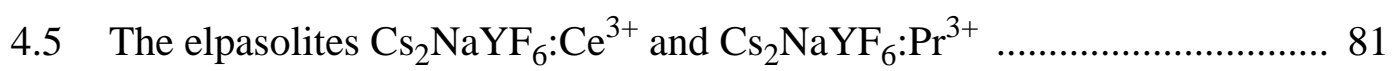


$5 \quad$ Glasses and glass ceramics $\quad 87$

5.1 Production of fluorozirconate glasses and glass ceramics ....................... 87

5.2 X-ray diffraction on fluorozirconate glasses and glass ceramics .............. 88

5.3 Photoluminescence and PSL of fluorozirconate glasses and glass

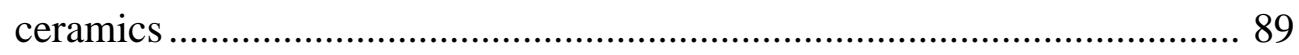

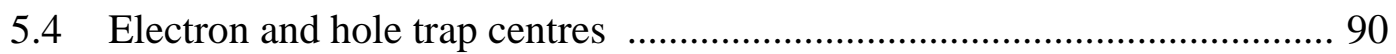

$\begin{array}{ll}\text { Summary } & 93\end{array}$

$\begin{array}{ll}\text { References } & 97\end{array}$ 


\section{Introduction}

In the beginning of radiation diagnostics, conventional photographic films were used for X-ray imaging. Due to their poor sensitivity to X-rays, high doses had to be used for the imaging process in medical radiography. Significant progress was achieved by the use of a combination of intensifying screens coated with a scintillator layer and a photographic film. The scintillator screen plays the role of an X-ray to optics converter (X-ray luminescence), and the film is as before the image storing part of the system. The latent $\mathrm{X}$-ray image becomes visible after appropriate chemical processing of the film.

In contrast to the X-ray scintillators, where the X-ray energy is directly converted into visible light, $\mathrm{X}$-ray storage phosphors store the radiation image in proportion to its intensity distribution in a storage phosphor screen. The screen is coated with X-ray storage phosphor crystallites which are imbedded in an organic binder. Upon X-irradiation, complementary defects (electron and hole trap centres) are generated in these crystallites. The electron of the electron trap centre can be stimulated afterwards and it recombines with the complementary hole trap centre. The recombination energy is often transferred to a doped activator which emits light of a characteristic photon energy. This process is called photostimulated luminescence (PSL).

Since the sensitivity of the X-ray storage phosphors exceeds that of the scintillator-filmsystem by at least one order of magnitude, the applied X-ray dose can be reduced significantly. For the best X-ray storage phosphors the dose dependence shows linearity for more than five orders of magnitude. Under- and over-exposures caused by the S-shaped sensitivity characteristics of all the photographic films including the scintillator-filmsystem can thus be avoided. The image is digitised directly and can be archived easily. Due to the scattering effects of the stimulation light during the read-out process, the spatial resolution of X-ray storage phosphor screens is still inferior compared to that of scintillator-film-systems. 
For practical use in commercial X-ray imaging systems the requirements for X-ray storage phosphors are somewhat different from those for scintillator-film based systems. Besides a high X-ray absorption, which can be achieved by the incorporation of elements with high mass number, the generated complementary defects should be thermally stable at room temperature, to make sure that the image information is stored until it is read out, possibly several hours later. The wavelength of the stimulation light should be in a spectral range which is clearly separated from the spectral range of the emitted light of the activator. Moreover, it would be advantageous if the stimulation light was in a spectral range where low-cost lasers are available as light sources. The emission of the activator should be in a spectral range where it can be detected easily and sensitively. The radiative life time of the activator as well as the bleaching time of the defects determine the time necessary for the read-out process. The re-usability of such X-ray storage phosphor screens is an important advantage. It should thus be possible to erase all defects in the crystallites after the read-out process has been accomplished.

The so far best-known X-ray storage phosphor is $\mathrm{BaFBr}$ doped with $\mathrm{Eu}^{2+}$ as activator [1]. In spite of many efforts to understand the information storage and read-out processes, no complete understanding has yet been achieved (see e.g., [2, 3, 4, 5]). The lower spatial resolution of commercially-used X-ray imaging systems based on $\mathrm{BaFBr}$ is partially due to the matlockite structure of the crystallites in the storage phosphor layer. During the read-out process the stimulation light is not only scattered due to the different refractive indices of the organic binder and the phosphor crystallites, but also due to the statistical distribution of the birefringent crystallites in the screen. Optically isotropic crystals such as e.g. cubic alkali halides would possibly minimise the scattering effects in the storage phosphor layer. It is thus a challenge to find optically isotropic storage phosphor materials which have the same performance as $\mathrm{BaFBr}: \mathrm{Eu}^{2+}$.

One of the suitable cubic alkali halides is $\mathrm{KBr}: \mathrm{In}^{+}$, which was shown to have storage and PSL properties [6]. From the practical point of view it will not be a very important system due to its low X-ray stopping power. $\mathrm{RbI}: \mathrm{Tl}^{+}$has, in principle, very good storage and PSL properties [7]. However, the stored image fades away at room temperature within minutes, so that a very fast read-out process has to be initiated immediately after taking the image. It has been shown that the alkali halides $\mathrm{RbBr}: \mathrm{Ga}^{+}$and $\mathrm{CsBr}: \mathrm{Ga}^{+}$have excellent figures of merit as X-ray storage phosphors [8]. They are optically isotropic and therefore very promising. The elpasolite $\mathrm{Cs}_{2} \mathrm{NaYF}_{6}: \mathrm{Ce}^{3+}$ is also comparable to $\mathrm{BaFBr}: \mathrm{Eu}^{2+}$ with respect to X-ray conversion and necessary stimulation energy [9]. 
The observation that upon X-irradiation the electron and hole trap centres are always created with a spatial correlation to the activator is of particular interest for the functioning of the storage phosphors. It is statistically not very probable that for low medical doses the photostimulated electron of the electron trap centre and a hole of the hole trap centre recombine near an activator. A phosphor does not function, unless electron and hole trap centres are generated near the activator. The reason for this spatial correlation of the radiation damage centres with the activator is so far not understood and represents a very interesting, fundamental open question.

In chapter 1 the experimental fundamentals of the measurement techniques used are described. Chapter 2 deals with the characterisation of X-ray storage phosphors such as performance and spatial resolution, as well as the experimental setup for the read-out process.

In chapter 3 one finds a detailed description of the information storage and read-out process in the $\mathrm{X}$-ray storage phosphor $\mathrm{BaFBr}: \mathrm{Eu}^{2+}$ emphasising the generation mechanism and structure of electron and hole trap centres, whilst alternative systems such as alkali halides and elpasolites, and glasses or glass ceramics are described in chapter 4 and 5 , respectively. 


\section{Chapter 1}

\section{Experimental fundamentals}

The main experimental method used to analyse the nature of the generated electron and hole trap centres, which are the basis of the information storage and read-out processes, is electron paramagnetic resonance (EPR), because electron and hole trap centres are paramagnetic before they recombine in the photostimulated luminescence process. For detailed defect investigations, electron nuclear double resonance (ENDOR) is also needed. However, because of low defect concentration conventional EPR and ENDOR are often not sensitive enough. Therefore, optically detected EPR and ENDOR techniques have to be applied. Their basis is the detection of changes of the magnetic circular dichroism of the optical absorption (MCDA) induced by EPR/ENDOR transitions. In the following only a brief description can be given of the most important methods. For further details the reader is referred to e.g. [10].

\subsection{Magneto-optical measurement techniques}

\subsubsection{Magnetic circular dichroism of the optical absorption}

The magnetic circular dichroism of the optical absorption (MCDA) is the difference between the absorption of right and left circularly polarised light. The light is propagated parallel to an external magnetic field $\mathbf{B}$ in which the sample is situated. The MCDA is defined by

$$
\varepsilon=\frac{\omega d}{2 c}\left(k_{\mathrm{r}}-k_{1}\right)
$$


where $k_{\mathrm{r}}$ and $k_{1}$ are the absorption indices for right and left circularly polarised light, $d$ the thickness of the crystal, $\omega$ the angular frequency of the light and $c$ the speed of light. The measured quantities are the energy dependent absorption coefficients $\alpha(E)$. With

$$
k(E)=\frac{\hbar c}{2 E} \alpha(E)
$$

and $E=\hbar \omega$ equation (1.1) becomes

$$
\varepsilon=\frac{d}{4}\left(\alpha_{\mathrm{r}}-\alpha_{1}\right)
$$

Assuming an exponential decay of the light intensity within the crystal, according to Lambert-Beer's law the measured light intensity is

$$
I_{\mathrm{r}, 1}=I_{\mathrm{o}} \exp \left(-\alpha_{\mathrm{r}, 1} d\right)
$$

where $I_{\mathrm{o}}$ is the intensity of the incident light and thus the sum of the incident right and left circularly polarised light. Transformation of equation (1.4) leads to

$$
\alpha_{\mathrm{r}, \mathrm{l}}=\frac{1}{d} \ln \frac{I_{\mathrm{o}}}{I_{\mathrm{r}, 1}} .
$$

Insertion of this result into equation (1.3) one obtains

$$
\varepsilon=\frac{1}{4} \ln \frac{I_{\mathrm{r}}}{I_{1}}
$$

With the average intensity $I_{\mathrm{a}}=\left(I_{\mathrm{r}}+I_{1}\right) / 2$ and the intensity difference $\Delta I=I_{\mathrm{r}}-I_{1}$ equation (1.6) becomes

$$
\varepsilon=\frac{1}{4} \ln \frac{1+\frac{\Delta I}{2 I_{\mathrm{a}}}}{1-\frac{\Delta I}{2 I_{\mathrm{a}}}} .
$$

Assuming $\Delta I \ll I_{\mathrm{a}}$, i.e. $d\left(\alpha_{\mathrm{r}}-\alpha_{1}\right) \ll<$, equation (1.7) simplifies to

$$
\varepsilon \approx \frac{\Delta I}{4 I_{\mathrm{a}}}=\frac{I_{\mathrm{r}}-I_{1}}{2\left(I_{\mathrm{r}}+I_{1}\right)}
$$

The MCDA consists of a paramagnetic and a diamagnetic part.

$$
\varepsilon(B, T)=\varepsilon_{\mathrm{dia}}(B)+\varepsilon_{\mathrm{para}}(B, T)
$$


The paramagnetic part is both temperature and magnetic field dependent. The diamagnetic part, which is caused by non-resolved Zeeman splittings of the excited states [11], is temperature independent, but also proportional to the external magnetic field value $B$.

For $S=1 / 2$ systems the paramagnetic MCDA is proportional to the polarisation $P$ of the ground state. The polarisation $P$ can be calculated using the Langevin function

$$
\varepsilon_{\text {para }} \propto P=\frac{n_{-}-n_{+}}{n_{-}+n_{+}}=\tanh \frac{g \mu_{\mathrm{B}} B}{2 k T} .
$$

$n_{+}$and $n_{-}$are the occupation numbers of the $m_{S}= \pm 1 / 2$ states, $g$ is the Lande $g$-factor, $\mu_{\mathrm{B}}$ the Bohr magneton, $B$ the magnetic field value and $T$ the temperature. For $S>1 / 2$ systems the polarisation $P$ is given by the Brillouin function (see e.g., [10]).

Figure 1.1 schematically represents the circularly polarised transitions for an alkali atom model, which is often used to describe the MCDA of an F centre (electron trapped in an anion vacancy) in alkali halides [12]. The excited state is split by the spin-orbit interaction into a $J=1 / 2$ and a $J=3 / 2$ state. The degeneracy is lifted by the applied magnetic field B. Neglecting the Zeeman splittings of the excited states one absorption band is observed for right and one for left circularly polarised light. The intensity is equal for both bands. Both absorption bands, the separation of which is determined by the spinorbit interaction, are identical in their respective shapes which are taken to be Gaussians in this model. Phonon-broadening of the transitions is taken into account via the "rigid shift" approximation [13]. For the selection rule $m_{J}= \pm 1$ and a small spin-orbit interaction compared to the half-width of the right and left circular absorption bands this leads to a derivative-like structure of the resulting MCDA (see e.g., [10]). 


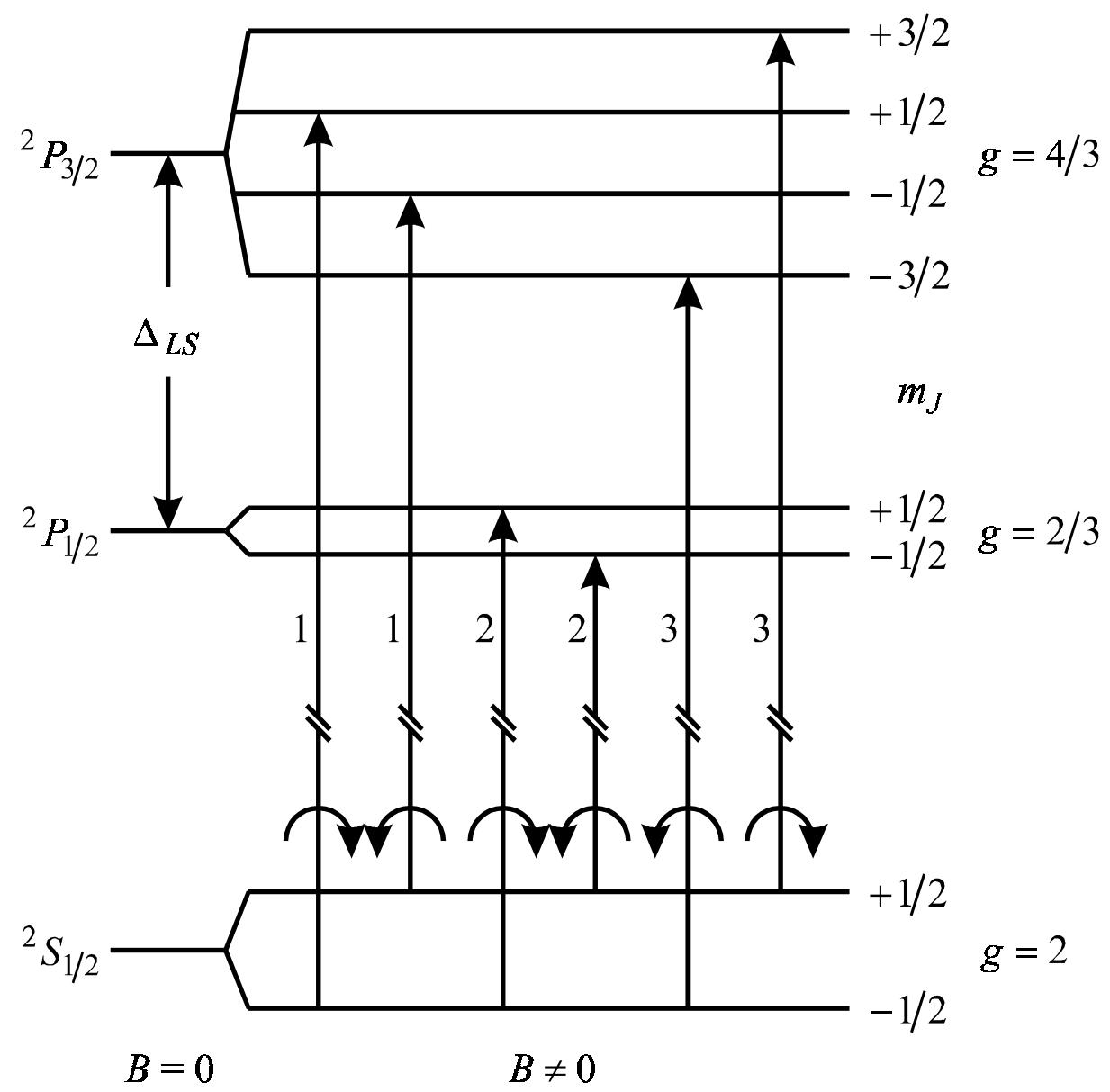

Figure 1.1 Schematic diagram of the energy levels in the alkali atom model to explain the MCDA of an F centre [12]. The $\Delta m_{J}=+1$ transitions absorb right, and the $\Delta m_{J}=-1$ transitions, left circularly polarised light. The energy difference between the $S$ and the $P$ states amounts to several $\mathrm{eV}$, the spin-orbit splitting $\Delta_{L S}$ to several meV up to $1 \mathrm{eV}$ depending on the nature of the anions. The numbers on the transition arrows indicate the relative transition probabilities.

\subsubsection{Optical detection of electron paramagnetic resonance (EPR) and electron nuclear double resonance (ENDOR)}

As described above the paramagnetic part of the MCDA is proportional to the spin polarisation of the ground state. Perturbing the thermal equilibrium occupation of the Zeeman levels at a fixed optical wavelength by applying a resonant and partly saturating electron paramagnetic resonance (EPR) transition, the spin polarisation is changed and, 


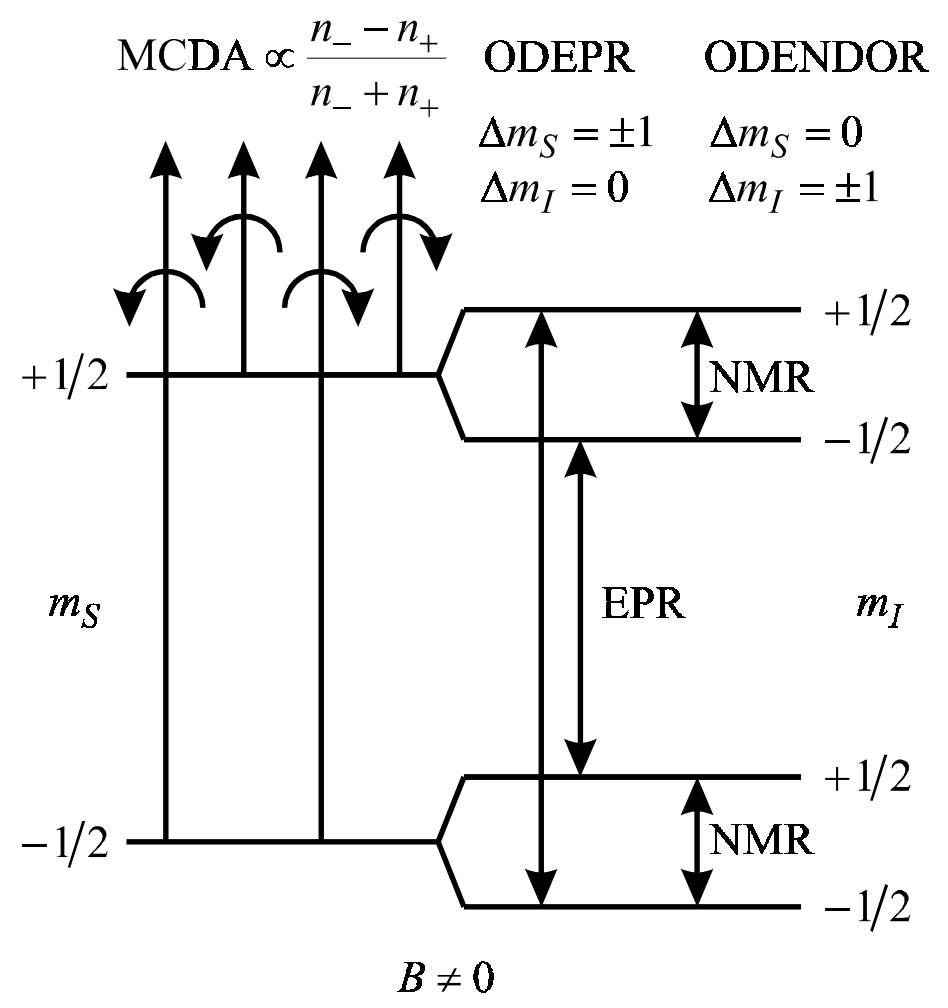

Figure 1.2 Schematic diagram of the energy levels of a paramagnetic centre having $S=1 / 2$ and $I=1 / 2$ to explain optically detected EPR and ENDOR.

according to equation (1.10), the paramagnetic MCDA decreases (figure 1.2). In an optically detected EPR experiment the changes of the detected MCDA are measured. A fixed optical wavelength and a fixed saturating microwave field are used and the external magnetic field is swept through the resonance conditions. EPR lines due to defects are then observed as changes in the magnetic field dependent MCDA signal (MCDAdetected EPR) at this optical wavelength. This technique, the optical detection of EPR, can increase the sensitivity considerably depending though on the optical transition probability (oscillator strength) and the spin-orbit splitting of the excited states. Moreover, the coupling of MCDA and EPR allows the assignment of optical transitions to paramagnetic defects. In particular, it is possible to separate superimposed MCDA bands, which are due to different defects, by their distinct MCDA-detected EPR spectra. When recording the wavelength-dependent ODEPR effect under resonant conditions, the MCDA "excitation" spectrum of a defect is obtained. This procedure is known as "tagged" MCDA (see e.g., [10]). 
In addition to the EPR transitions the ground state spin polarisation can be affected by applying simultaneously a resonant radio frequency (rf) field to induce NMR transitions. The NMR transitions between hyperfine (hf) or superhyperfine (shf) Zeeman levels also change the spin polarisation. Therefore also electron nuclear double resonance (ENDOR) can be detected optically via the change of the MCDA. Information about the defect structure can be obtained from the measured hf and shf interaction (see e.g., [10]).

\subsubsection{Cross-relaxation spectroscopy}

For the functioning of the storage phosphors it is necessary that the X-ray induced electron and hole trap centres are generated not too far from another and they are also spatially correlated to the activators. To investigate this experimentally one can use crossrelaxation spectroscopy. The cross-relaxation probability between two spin systems assuming a dipole-dipole interaction is given by [14]

$$
R_{i j}=\hbar^{-2}\left|\mathscr{H}_{i j}\right|^{2} g_{\alpha \beta}
$$

with

$$
\left|\mathscr{H}_{i j}\right|^{2}=g_{i}^{2} g_{j}^{2} \beta^{4}\left(3-\cos ^{2} \vartheta_{i j}\right)^{2} / r_{i j}^{6}
$$

and

$$
g_{\alpha \beta}=\int g_{\alpha}\left(v^{\prime}\right) g_{\beta}\left(v^{\prime \prime}\right) \delta\left(v^{\prime}-v^{\prime \prime}\right) \mathrm{d} v^{\prime} \mathrm{d} v^{\prime \prime},
$$

where $g_{\alpha \beta}$ is the overlap integral of the shape function of the EPR lines of both defects types, $\alpha$ and $\beta$, which can be determined experimentally from the EPR spectra. The indices $i$ and $j$ characterise the individual defect of each type taking part in the crossrelaxation (CR), with a separation $r_{i j}$ between defects $i$ and $j$ and an angle $\vartheta_{i j}$ between the $i j$ connecting line and the magnetic field. $\beta$ is the gyromagnetic ratio in the CGS system and $g_{i}$ and $g_{j}$ are the electronic $g$ factors.

According to equation (1.11) the cross-relaxation probability depends significantly on the separation between the two interacting spin-systems. Thus, it is possible to determine the distribution of the separations between different paramagnetic defects, however, only in case of diluted spin-systems. The dynamical behaviour of the spin polarisation of a paramagnetic defect can then be calculated by a set of rate equations describing the occupations of the Zeeman levels. The occupations are influenced by EPR transitions and spin-lattice relaxations. If two spin systems are coupled by CR, addi- 
tional terms due to $\mathrm{CR}$ enter the rate equations, which become non-linear. For a high concentration of paramagnetic defects the cross-relaxation effects are mainly determined by the average distance between the interacting spin-systems. In this case one does not obtain any further information about the distribution of separations of the different spin-systems. For details see e.g., [15].

\subsection{Conventional EPR and ENDOR}

In contrast to optically detected EPR, the EPR transitions in conventional experiments are detected via microwave absorption. In ENDOR the detection of NMR transitions is achieved via the change of the partly saturated EPR effect. To observe an ENDOR effect, the EPR transition has to be saturated partly by applying sufficiently high microwave power. The rf-induced NMR transition leads to a partial desaturation of the EPR, which is compensated by an increased microwave absorption (figure 1.3). The latter is detected (see e.g., [10]). In stationary ENDOR experiments [16] one can make use of a cross-relaxation probability $T_{\mathrm{x}}^{-1}$, which allows the stationary observation of the rfinduced desaturation of the EPR transition.

\subsection{Analysis of EPR and ENDOR spectra}

\subsubsection{The spin Hamiltonian}

For the analysis of EPR and ENDOR spectra an appropriate spin Hamiltonian is used (see e.g., [10]), which allows the calculation of the energy levels of the spin system. The spin Hamiltonian operator $\mathscr{H}$ is the sum of several operators: The electron Zeeman operator $\mathscr{H}_{\mathrm{EZ}}$, the fine-structure operator $\mathscr{H}_{\mathrm{FS}}$, the hyperfine structure operator $\mathscr{H}_{\mathrm{HF}}$, the superhyperfine structure operator $\mathscr{H}_{\mathrm{SHF}}$, the nuclear Zeeman operator $\mathscr{H}_{\mathrm{NZ}}$, and the nuclear quadrupole operator $\mathscr{H}_{\mathrm{Q}}$.

$$
\underset{\mathscr{H}_{\mathrm{EZ}}}{\mathscr{H}=\mu_{\mathrm{B}} \mathbf{S} \cdot \mathbf{g} \cdot \mathbf{B}+\sum_{k=2}^{2 S} \sum_{q=-k}^{k} b_{k}^{q} O_{k}^{q}(\mathbf{S})+\sum_{i}\left\{\mathbf{I}_{i} \cdot \mathbf{A}_{i} \cdot \mathbf{S}_{i}-\mu_{\mathrm{n}} \mathbf{I}_{i} \cdot \mathbf{g}_{\mathrm{n}, i} \cdot \mathbf{B}+\mathbf{I}_{i} \cdot \mathbf{Q}_{i} \cdot \mathbf{I}_{i}\right\}}
$$

with B magnetic field vector,

$\mu_{\mathrm{B}} \quad$ Bohr magneton, 
(a)

(b) $m_{S} \quad m_{I}$

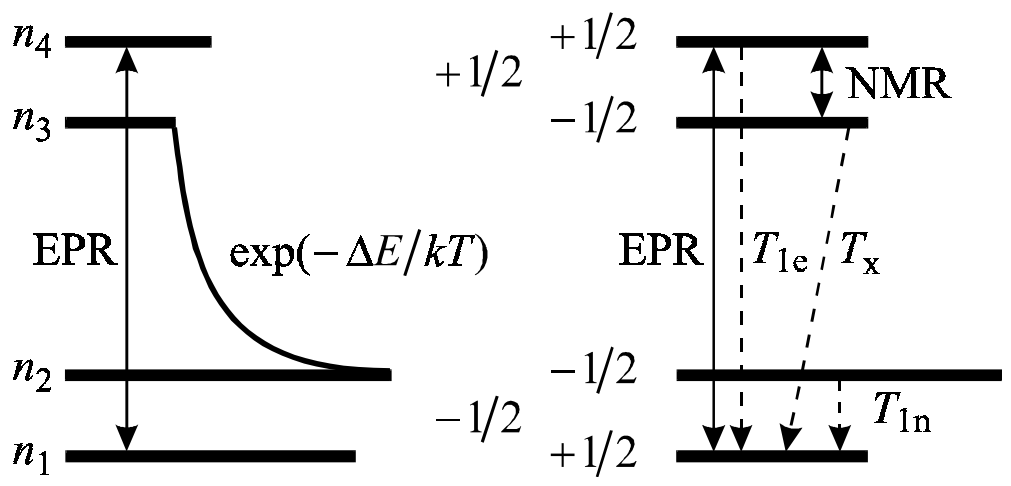

Figure 1.3 Schematic diagram explaining the EPR and ENDOR effect of a simple system having $S=1 / 2$ and $I=1 / 2$. The relative occupation of levels $1-4$ is marked by their lengths considering a non-saturated EPR transition (figure 1.3a) and the stationary occupation for saturated EPR and NMR transitions, including possible relaxation mechanisms (figure 1.3b).

$\mu_{\mathrm{n}} \quad$ nuclear magneton,

S electron spin operator,

$\mathbf{I}_{i} \quad$ nuclear spin operator of nucleus $i$,

g electron $g$ tensor,

$\mathbf{g}_{\mathrm{n}, i} \quad$ nuclear $g$ tensor of nucleus $i$,

$b_{k}^{q} \quad$ Stevens parameter,

$O_{k}^{q} \quad$ Stevens operator,

$\mathbf{A}_{i} \quad$ hyperfine or superhyperfine structure tensor of nucleus $i$,

$\mathbf{Q}_{i} \quad$ quadrupole tensor of nucleus $i$.

The electron Zeeman term $\mathscr{H}_{\text {EZ }}$ describes the magnetic interaction between the electron spin $\mathbf{S}$ and the external magnetic field $\mathbf{B}$, the nuclear Zeeman term $\mathscr{H}_{\mathrm{NZ}}$ the interaction between the nuclear spin $\mathbf{I}$ and the magnetic field $\mathbf{B}$. The fine-structure term $\mathscr{H}_{\mathrm{FS}}$ is a sum of Stevens operators [17] and describes the spin-spin interaction within a spin system having $S>1 / 2$. Due to time reversal symmetry the sum indices $q$ are even numbers. The use of Stevens operators in the fine-structure term has the advantage that they obey certain symmetry restrictions, i.e. some of the Stevens parameters vanish for certain point group symmetries. For $S \leq 3 / 2$ the fine-structure expression can be reduced to $\mathbf{S} \cdot \mathbf{D} \cdot \mathbf{S}$. The interaction between the electron spin $\mathbf{S}$ and the nuclear spin $\mathbf{I}$ of the 
central nucleus or a neighbour nucleus is described by the hyperfine (hf) or superhyperfine (shf) structure term $\mathscr{H}_{\mathrm{HF} / \mathrm{SHF}}$. The quadrupole term $\mathscr{H}_{\mathrm{Q}}$ contains the interaction between the nuclear quadrupole moment of a nucleus having $I>1 / 2$ and the electric field gradient at its site.

The hf or shf tensor $\mathbf{A}$ can be split into an isotropic part $a$ and a traceless anisotropic part B.

$$
\mathbf{A}=a \cdot \mathbf{E}+\mathbf{B},
$$

where $\mathbf{E}$ is the $3 \times 3$ unit matrix. Since the trace of the anisotropic hf or shf tensor is zero, the tensor can be described in its principal axes system by the two independent interaction parameters

$$
b=\frac{B_{z z}}{2}
$$

and $\quad b^{\prime}=\frac{B_{x x}-B_{y y}}{2}$.

The scalar $a$, the so-called Fermi contact interaction constant, is proportional to the unpaired spin density at the site of a nucleus in a one-particle approximation for the centre wave function $\psi(\mathbf{r})[13]$.

$$
a=\frac{2}{3} \mu_{\mathrm{o}} g_{\mathrm{e}} \mu_{\mathrm{B}} g_{\mathrm{n}} \mu_{\mathrm{n}} \cdot|\psi(0)|^{2},
$$

where $\mu_{\mathrm{o}}$ is the permeability of a vacuum. The matrix elements of the anisotropic part $\mathbf{B}$ are given by [13]

$$
B_{i k}=\frac{1}{4 \pi} \mu_{\mathrm{o}} g_{\mathrm{e}} \mu_{\mathrm{B}} g_{\mathrm{n}} \mu_{\mathrm{n}} \cdot \int\left\{\frac{3 x_{i} x_{k}}{r^{5}}-\frac{\delta_{i k}}{r^{3}}\right\}|\psi(\mathbf{r})|^{2} \mathrm{~d} \mathbf{r} .
$$

The quadrupole tensor $\mathbf{Q}$, which does not vanish for nuclei with spin $I>1 / 2$, is defined by

$$
Q_{i k}=\left.\frac{e Q}{2 I(2 I-1)} \cdot \frac{\partial^{2} V}{\partial x_{i} \partial x_{k}}\right|_{r=0}
$$

with $e$ elementary charge,

$Q \quad$ quadrupole moment of a nucleus,

$V \quad$ electric potential at the site of a nucleus. 


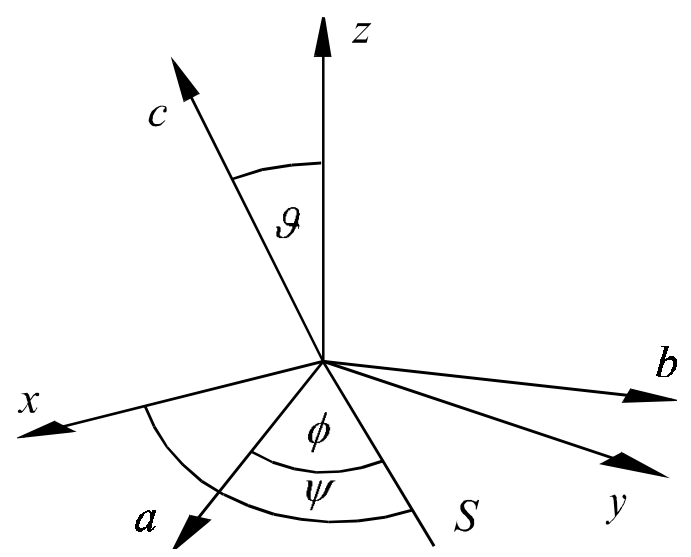

Figure 1.4 Definition of the Euler angles describing the tensor orientations. $a, b$, and $c$ are the crystal axes, whereas $x, y$, and $z$ are the principal axes of the tensor. The $a b$ plane cuts the $x y$ plane along line $S$.

The quadrupole tensor $\mathbf{Q}$ is also traceless and can be described analogously to the anisotropic hf or shf tensor in its principal axes system by the two parameters

$$
q=\frac{Q_{z^{\prime} z^{\prime}}}{2}
$$

and $\quad q^{\prime}=\frac{Q_{x^{\prime} x^{\prime}}-Q_{y^{\prime} y^{\prime}}}{2}$.

The $z$ axis of the hf, shf or quadrupole tensor's principal axes system is to be aligned along the direction of the largest interaction by definition. Consequently, $b$ and $q$ yield the axially symmetric parts of each tensor, whereas $b^{\prime}$ and $q^{\prime}$ describe the deviation from axial symmetry.

Since the principal axes system of the interaction tensors $(x, y, z)$ does often not coincide with the crystalline axes system or the laboratory system $(a, b, c)$, the relative position of the tensor principal axes system can be described by Euler angles (figure 1.4).

The exact determination of the energy levels of a spin system requires a full diagonalisation of the appropriate spin Hamiltonian. For a rough estimation perturbation theory of first or second order is often helpful, provided that one term of the Hamiltonian dominates. For example if $\mathscr{H}_{\mathrm{EZ}} \gg \mathscr{H}_{\mathrm{SHF}}$ the interaction for a simple $S=1 / 2$ system with isotropic electronic and nuclear $g$-factors and one neighbour nucleus is given in first order perturbation theory by 


$$
E=m_{S} g \mu_{\mathrm{B}} B+m_{S} m_{I} W_{\mathrm{SHF}}-m_{I} g_{\mathrm{n}} \mu_{\mathrm{n}} B+\frac{1}{2} W_{\mathrm{Q}}\left\{m_{I}^{2}-\frac{I(I+1)}{3}\right\}
$$

with $\quad W_{\mathrm{SHF}}=a+b \cdot\left(3 \cos ^{2} \vartheta-1\right)+b^{\prime} \cdot \sin ^{2} \vartheta \cdot \cos (2 \phi)$

and

$$
W_{\mathrm{Q}}=3 q \cdot\left(3 \cos ^{2} \vartheta^{\prime}-1\right)+3 q^{\prime} \cdot \sin ^{2} \vartheta^{\prime} \cdot \cos \left(2 \phi^{\prime}\right)
$$

$\vartheta$ and $\vartheta^{\prime}$ are the angles between the $z$ axis of the respective principal axes system and the magnetic field vector, $\phi$ and $\phi^{\prime}$ the angles between the $x$ axis and the projection of the magnetic field vector into the $x y$ plane of the respective principal axes system (see e.g., [10]).

\subsubsection{Analysis of EPR spectra}

EPR spectra are analysed by determining the energy differences between the levels for which transitions obeying the selection rules $\Delta m_{S}= \pm 1$ and $\Delta m_{I}=0$ occur. For a $S=1 / 2$ system equation (1.19) yields the energy positions of the allowed EPR transitions according to first order perturbation theory.

$$
h v_{\mathrm{EPR}}=g \mu_{\mathrm{B}} B+m_{I} W_{\mathrm{SHF}}
$$

In an EPR experiment the microwave frequency is fixed while the magnetic field is swept. Thus equation (1.20) has to be solved for the corresponding resonant magnetic fields. The interaction matrices can be obtained by rotating the magnetic field vector in two perpendicular planes (or rotating the crystal relative to the fixed magnetic field). The angular dependencies usually yield much more resonances than needed for the determination of the spin Hamiltonian parameters. Therefore, the interaction tensors are adjusted to the observed resonances in an iterative procedure where the weighted sum of the deviation squares of the measured and the calculated resonances is minimised.

\subsubsection{Analysis of ENDOR spectra}

ENDOR transitions obey the selection rules $\Delta m_{S}=0$ and $\Delta m_{I}= \pm 1$. According to equation (1.19) first order theory yields

$$
h v_{\mathrm{ENDOR}}=\left|m_{S} W_{\mathrm{SHF}}-g_{\mathrm{n}} \mu_{\mathrm{n}} B+m_{Q} W_{\mathrm{Q}}\right|
$$


with

$$
m_{Q}=\left(m_{I}+m_{I}{ }^{\prime}\right) / 2
$$

$m_{I}$ and $m_{I}{ }^{\prime}$ represent the nuclear spin states between which the ENDOR transition occurs. By analogy to the EPR analysis also here the corresponding interaction matrices are obtained by recording ENDOR angular dependencies for a rotation of the magnetic field vector in two perpendicular planes and fitting the interaction parameters to the experimental data afterwards.

According to their separation from the defect centre, neighbouring nuclei are classified in different shells. The symmetry of a shell is determined by symmetry elements which transform the shell's nuclei into each other. The origin of each symmetry operation is the point group symmetry of defect centre and a centre of inversion, i.e., is determined by the Laue class of the centre (site). Each nucleus of a shell leads to a certain ENDOR line and thus to an ENDOR branch in the angular dependence.

\subsubsection{Calculation of powder EPR and ENDOR spectra}

With the data known from a single crystal, the corresponding powder EPR spectrum can be calculated. For the individual EPR lines and inhomogeneous broadening, one can assume a Gaussian line shape $\Omega_{\mathrm{EPR}}$ according to

$$
\Omega_{\mathrm{EPR}}(B)=\frac{1}{\sigma_{\mathrm{EPR}} \sqrt{2 \pi}} \exp \left\{-\frac{1}{2} \frac{\left(B_{\mathrm{O}}(\vartheta, \phi)-B\right)^{2}}{\sigma_{\mathrm{EPR}}^{2}}\right\}
$$

with $\quad \sigma_{\mathrm{EPR}}=\frac{\Delta B}{2 \sqrt{2 \ln 2}}$

whereby $\Delta B$ is the full width at half maximum of the EPR line. Since the EPR line positions $B_{\mathrm{o}}$ are angular dependent, one has to integrate over all possible orientations of the magnetic field.

For the calculation of powder ENDOR spectra, one has to consider that the intensity of an ENDOR line at a certain magnetic field is proportional to the intensity of an EPR line at that field. Therefore, the intensity of the ENDOR signals at the applied magnetic field $B_{\text {ENDOR }}$ has to be weighted with the intensity of the EPR line at this field. An ENDOR frequency depends on the orientation of the magnetic field with respect to the principal axes of the interaction tensors. Therefore, in order to calculate the intensity of 
an ENDOR line for a certain frequency $v$ at a magnetic field $B_{\text {ENDOR }}$ and assuming a Gaussian line shape, one obtains

$$
\begin{aligned}
\Omega_{\mathrm{ENDOR}}(v)= & \frac{1}{\sigma_{\mathrm{EPR}} \sqrt{2 \pi}} \exp \left\{-\frac{1}{2} \frac{\left(B_{\mathrm{o}}(\vartheta, \phi)-B_{\mathrm{ENDOR}}\right)^{2}}{\sigma_{\mathrm{EPR}}^{2}}\right\} \times \\
& \frac{1}{\sigma_{\mathrm{ENDOR}} \sqrt{2 \pi}} \exp \left\{-\frac{1}{2} \frac{\left(v_{\mathrm{ENDOR}}\left(\vartheta, \phi, B_{\mathrm{ENDOR}}\right)-v\right)^{2}}{\sigma_{\mathrm{ENDOR}}^{2}}\right\}
\end{aligned}
$$

where the polar angle $\vartheta$ and the azimuthal angle $\phi$ describe the orientation of the static magnetic field $B_{\mathrm{o}}$ with respect to the crystal axes. In order to obtain the powder ENDOR spectrum as a function of the rf frequency $v$, one has to integrate equation (1.23) over all angles of $\vartheta$ and $\phi$ (see e.g., [18]). 


\section{Chapter 2}

\section{$\mathrm{X}$-ray storage phosphors}

\subsection{Performance}

To determine the performance of an X-ray storage phosphor a read-out experiment must be performed (figure 2.1). After X-irradiation at RT the sample is excited continuously with the appropriate stimulation light. A photomultiplier detects the resulting photostimulated luminescence (PSL) versus time. For detailed information see e.g. [19].

Continuous photostimulation leads to a decrease of the number of the PSL-active centres. Consequently, the PSL intensity decays under continuing stimulation. The area below the PSL curve is proportional to the absorbed X-ray dose. In a commercial system a laser beam is used to read out the information stored in the phosphor screen point by point and line by line. The information should be read-out in the shortest time possible. To describe the characteristics of an X-ray storage phosphor the quantities "conversion efficiency" (CE) and "stimulation energy" (SE) determining these requirements are introduced.

CE is defined as the released photon energy $\left(E_{\text {tot }}\right)$ per absorbed X-ray dose

$$
\mathrm{CE}=\frac{E_{\text {tot }}}{\text { absorbed } \mathrm{X}-\text { ray dose }},
$$

where $E_{\text {tot }}$ is the area below the PSL curve.

In the simplest case the time dependence of the PSL can be described by a monoexponential decay, i.e. 


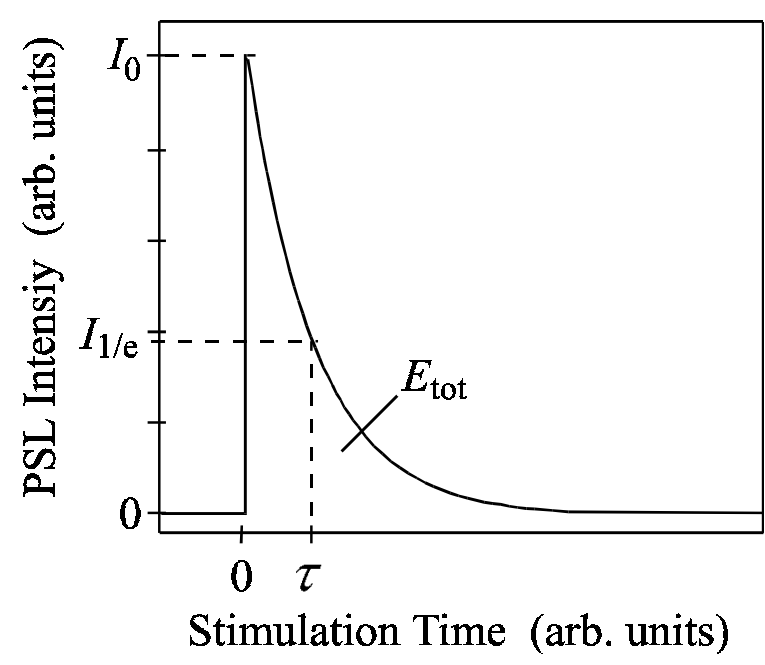

Figure 2.1 Typical PSL decay curve of an X-ray storage phosphor under continued stimulation.

$$
I(t)=I_{0} \cdot \exp (-t / \tau)
$$

$I_{\mathrm{o}}$ is the amplitude of the PSL at the beginning of the stimulation experiment, $t$ the stimulation time and $\tau$ a time constant depending on the power $P$ of the stimulation light (see definition of stimulation energy) and limited by the characteristic decay time of the activator luminescence.

Thus, $E_{\mathrm{tot}}$ is obtained by integrating $I(t)$ from $t=0$ to $t=\infty$,

$$
\begin{aligned}
E_{\mathrm{tot}} & =I_{0} \cdot \int_{0}^{\infty} \exp (-t / \tau) \mathrm{d} t \\
& =I_{0} \cdot \tau \cdot\left\{\left.\exp (-t / \tau)\right|_{0}-\left.\exp (-t / \tau)\right|_{\infty}\right\} \\
& =I_{0} \cdot \tau .
\end{aligned}
$$

Finally, CE is determined by

$$
\mathrm{CE}=\frac{I_{0} \cdot \tau}{\text { absorbed } \mathrm{X}-\text { ray dose }}
$$

In the experiment the time constant $\tau$, after which the PSL intensity is decreased to $1 / \mathrm{e}$ of its initial value, as well as the initial PSL intensity $I_{0}$ are measured. 
The stimulation energy (SE), i.e. the energy required to reduce the PSL intensity to $1 / \mathrm{e}$ of its initial value, is defined as

$$
\mathrm{SE}=\tau \cdot P,
$$

where $P$ is the power of the applied stimulation light beam.

The sensitivity of an X-ray storage phosphor is proportional to the stored energy and proportional to the inverse of energy required for the read-out. Therefore, the sensitivity is given by the ratio $\mathrm{CE} / \mathrm{SE}$.

\subsection{Spatial resolution of $\mathrm{X}$-ray storage phosphor image plates}

\subsubsection{Image sharpness}

The image of an infinitely sharp edge obtained by an X-ray imaging system based on storage phosphor screens should have a sharp step in the detected luminescence intensity from zero to a certain luminescence intensity level proportional to the absorbed Xray dose (figure 2.2a (left)). Unfortunately, this is only valid in an ideal case whereas in reality, the image does not yield such a sharp step, but a region of unsharpness in which the luminescence signal changes steadily from zero to the corresponding luminescence intensity (figure 2.2b (left)). The sharpness of such an imaging system can either be described by imaging of an infinitely sharp edge or by imaging of an infinitely narrow slit. An ideal image of such a slit would be an infinitely small square function for the luminescence intensity (figure 2.2a (right)). In reality one gets a bell-shaped curve the half width of which determines the sharpness of the system (figure $2.2 b$ (right)).

\subsubsection{Modulation transfer function}

One way to assess the image quality is to express it in terms of the resolving power of the imaging system, i.e. the smallest separation of a pair of linear objects at which the images do not merge. A very useful tool to describe the image sharpness of an X-ray imaging system is the concept of the modulation transfer function (MTF). This is based on the ideas of a Fourier analysis, for detailed information see e.g. [20]. 

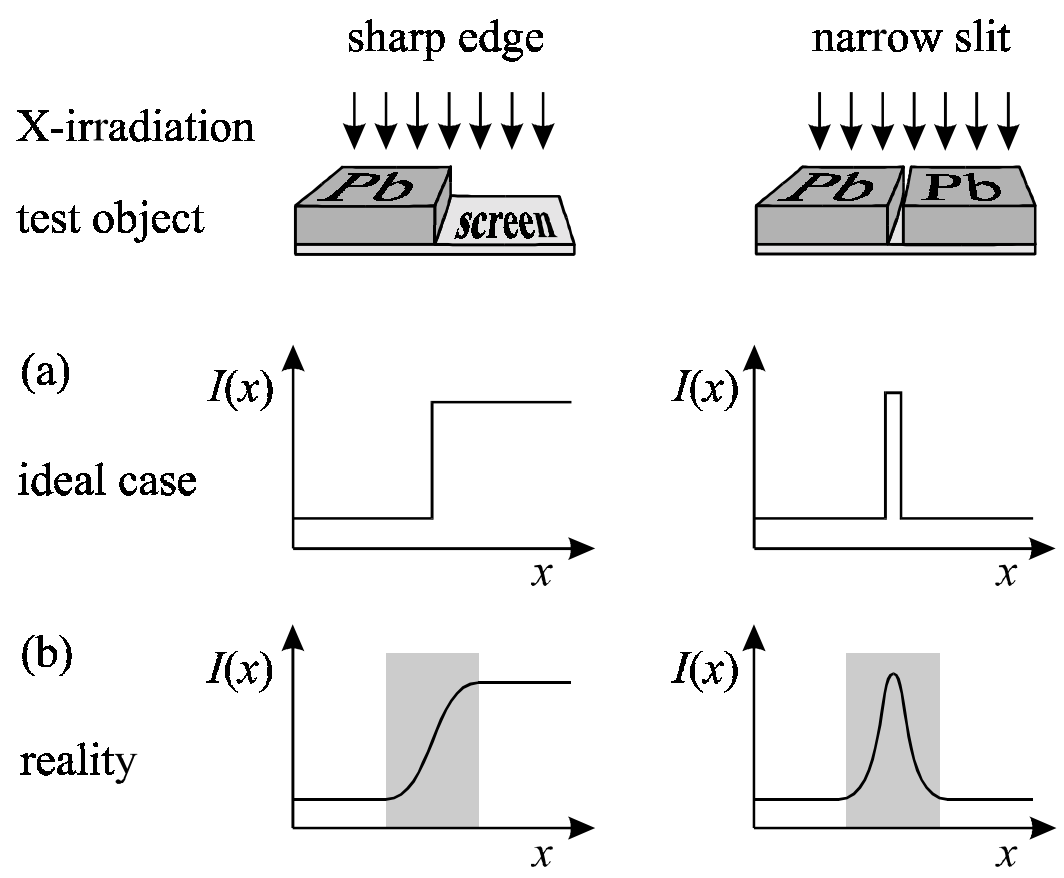

$$
I(x)=\text { luminescence intensity }
$$

Figure 2.2 Imaging of a sharp edge (left) and a narrow slit (right) by an X-ray imaging system based on X-ray storage phosphors.

Starting at the object, at any stage in the imaging process all the available information can be expressed in terms of spatial frequencies. The idea of spatial frequency can be understood by considering two ways of describing a simple object consisting of a set of equally spaced parallel lines. The usual convention would be to say the lines were equally spaced $0.2 \mathrm{~mm}$ apart. Alternatively, one could say that the lines occur with a frequency in space (spatial frequency) of five per $\mathrm{mm}$. In general, the finer the detail the greater the intensity of high spatial frequencies in the spatial frequency spectrum. Thus, fine detail, or high resolution, is associated with high spatial frequencies [21].

The imaging process converts the two-dimensional radiation image $g(x, y)$ into a twodimensional visible image $b(x, y)$. For the sake of simplicity the radiation image is taken here to change only in one dimension. The imaging process can then be described by

$$
g(x) \rightarrow b(x)
$$

A linear imaging system is characterised by the fact that a sinusoidal radiation image

$$
g(x)=A_{\text {in }}(k) \cdot \sin (k x)
$$



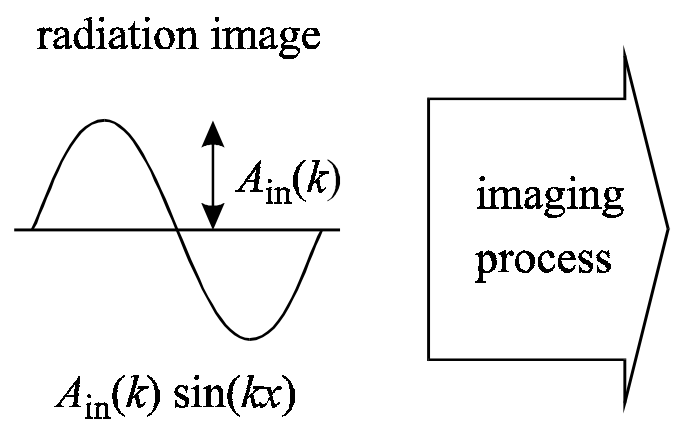

visible image

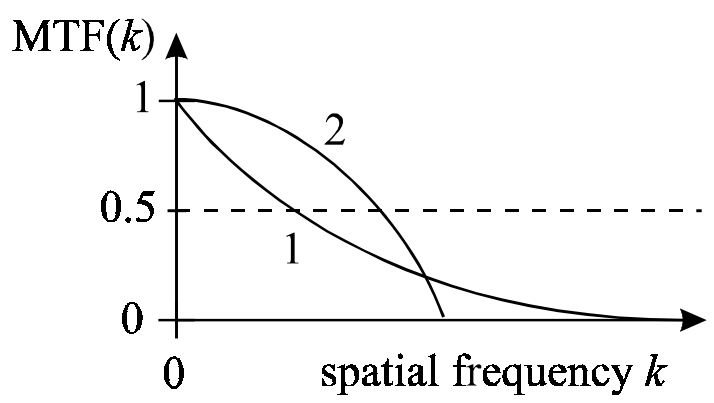

Figure 2.3 Imaging of a sinusoidal radiation image and two arbitrary modulation transfer functions (MTF).

is converted into a sinusoidal visible image

$$
b(x)=A_{\text {out }}(k) \cdot \sin (k x) .
$$

Hereby, the parameter $k$, which has the dimension of a reciprocal length, denotes the spatial frequency. The modulation transfer function (MTF) is defined as

$$
\operatorname{MTF}(k)=A_{\text {out }}(k) / A_{\text {in }}(k) .
$$

The modulation transfer function describes the transfer conditions of an imaging system. It defines how the image contrast decreases with higher spatial frequencies. The highest spatial resolution is determined by the point of intersection between the MTF and a line which represents a smallest detectable contrast. Another characteristic value often used is the spatial frequency, where the $\operatorname{MTF}(k)$ is decreased to 50\% (figure 2.3). The two MTF curves of figure 2.3 show that the spatial resolution characterises the performance of an imaging system insufficiently. The imaging system represented by curve 1 has a significantly higher spatial resolution as system 2, but for average spatial frequencies the modulation transfer and thus the image contrast for objects having these spatial frequencies is much worse than that of curve 2 . 


\subsubsection{Description of imaging processes via Fourier transformation}

The mathematical derivation of the modulation transfer function (MTF) assumes a sinusoidally varying object which is very difficult to realise practically. Thus, the relation between the MTF and the imaging of other objects has to be clarified. The imaging process of an arbitrary object function $g(x)$ via a system having a modulation transfer function $\operatorname{MTF}(k)$ can be described by the following:

The object function $g(x)$ can be Fourier transformed into its corresponding frequency spectrum $G(k)$ by

$$
G(k)=\int_{-\infty}^{+\infty} g(x) \cdot \mathrm{e}^{-\mathbf{i} 2 \pi k x} \mathrm{~d} x
$$

According to equation (2.9) the spatial frequency spectrum of the image can be obtained by a multiplication with the modulation transfer function $\operatorname{MTF}(k)$.

$$
B(k)=\operatorname{MTF}(k) \cdot G(k)
$$

Inverse Fourier transformation leads to the image function

$$
b(x)=\int_{-\infty}^{+\infty} B(k) \cdot \mathrm{e}^{\mathrm{i} 2 \pi k x} \mathrm{~d} k=\int_{-\infty}^{+\infty} \operatorname{MTF}(k) \cdot G(k) \cdot \mathrm{e}^{\mathrm{i} 2 \pi k x} \mathrm{~d} k
$$

For the Dirac delta function $\delta(x)$ as object function, that means an infinitely fine detail, one obtains with equation (2.10) a spatial frequency spectrum of $G(k)=1$. Equation (2.12) simplifies to

$$
b(x)=\int_{-\infty}^{+\infty} \operatorname{MTF}(k) \cdot \mathrm{e}^{\mathbf{i} 2 \pi k x} \mathrm{~d} k=\operatorname{LSF}(x) .
$$

The image function $b(x)$ of the Dirac delta function $\delta(x)$ is called the line spread function $\operatorname{LSF}(x)$. The integral over the line spread function $\operatorname{LSF}(x)$ yields the edge spread function $\operatorname{ESF}(x)$. The relations between $\operatorname{LSF}(x), \operatorname{ESF}(x)$ and $\operatorname{MTF}(k)$ are given by

$$
\begin{aligned}
& \operatorname{LSF}(x)=\frac{\mathrm{d}}{\mathrm{d} x} \operatorname{ESF}(x) \\
& \operatorname{MTF}(k)=\int_{-\infty}^{+\infty} \operatorname{LSF}(x) \cdot \mathrm{e}^{-\mathbf{i} 2 \pi k x} \mathrm{~d} x
\end{aligned}
$$



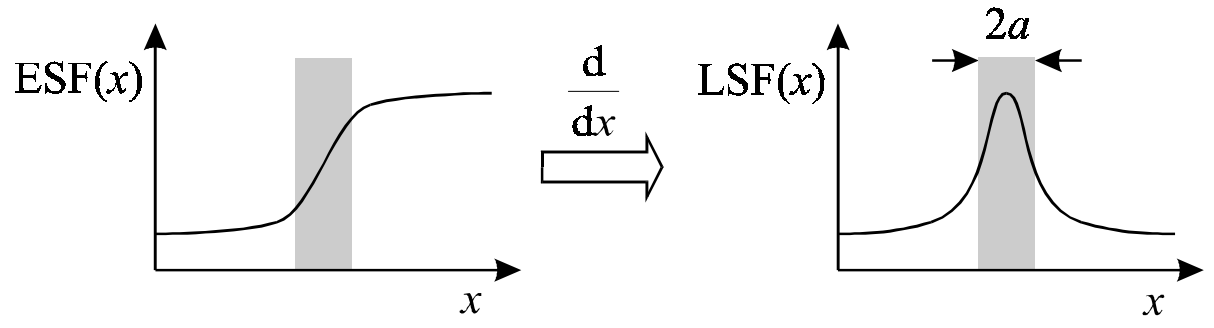

$$
\operatorname{ESF}(x)=\arctan (x / a)
$$

$$
\operatorname{LSF}(x)=a /\left(x^{2}+a^{2}\right)
$$

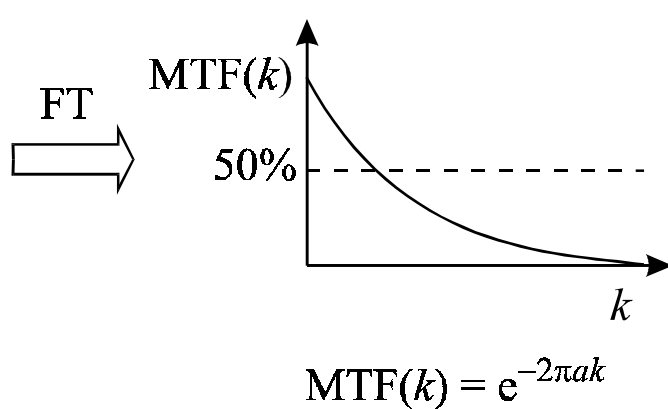

Figure 2.4 Theoretical example for the determination of the $\operatorname{MTF}(k)$ of a given $\operatorname{ESF}(x)$.

Figure 2.4 shows a theoretical example for the transformations described above. In practice one measures the $\operatorname{ESF}(x)$ of an infinitely sharp edge and determines the $\operatorname{MTF}(k)$ via numerical differentiation and subsequent fast Fourier transformation.

\subsubsection{Measurement of the spatial resolution and the modulation trans- fer function}

The assessment of image quality is obtained practically by means of special test objects. The spatial resolution is usually determined with a lead grid, where the spatial frequency (line pairs per $\mathrm{mm}$ ) changes stepwise from one line pair to the next (figure 2.5a). Here, a spatial frequency of one (two, four, five) line pair(s) per mm corresponds to a set of $500 \mu \mathrm{m}(250 \mu \mathrm{m}, 125 \mu \mathrm{m}, 100 \mu \mathrm{m})$ fine lines which are spaced $500 \mu \mathrm{m}(250 \mu \mathrm{m}$, $125 \mu \mathrm{m}, 100 \mu \mathrm{m})$ apart. The highest spatial frequency which is detectable upon imaging of such a lead grid yields the spatial resolution of the investigated imaging system. 
(a) lead grid

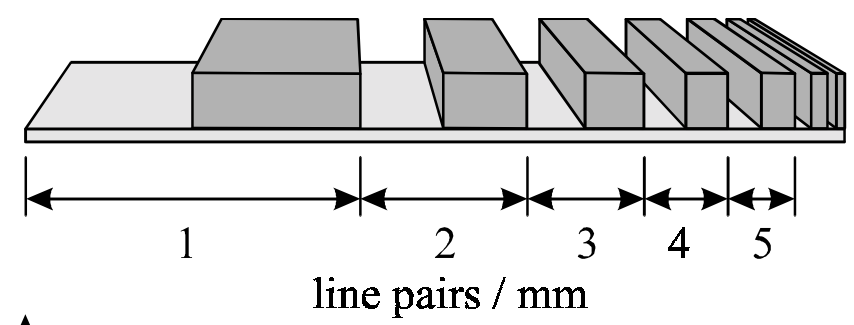

(b) ideal image

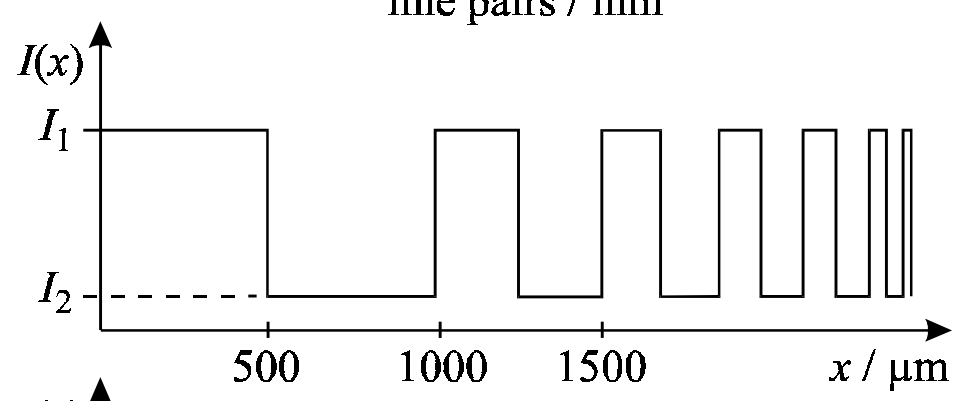

(c) real image

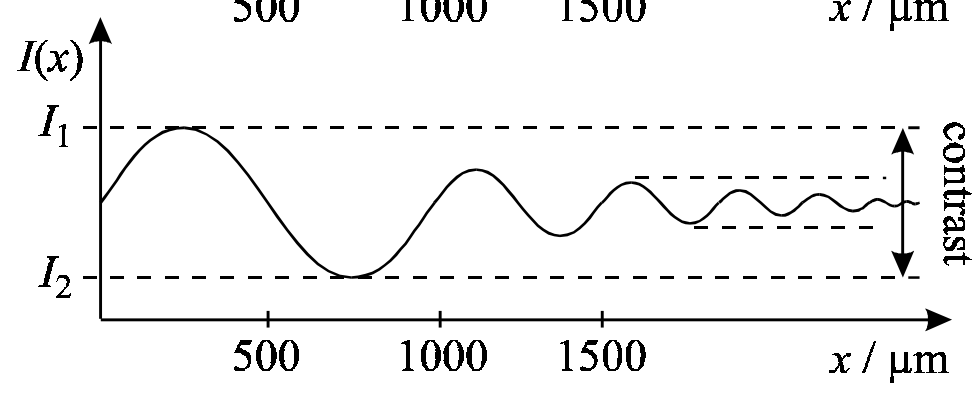

Figure 2.5 Determination of the contrast modulation and thus the contrast transfer function by imaging of a lead grid.

The spatial resolution does not characterise an imaging system sufficiently. It is often useful to determine the modulation transfer function. This requires, however, much more experimental effort. There are, in principle, two ways to determine the MTF:

One method is based on a quantitative analysis of the image of the lead grid (figure 2.5). Figure $2.5 \mathrm{c}$ shows that the measured contrast modulation depends on the spatial frequency $k$. The contrast can be described with the luminescence intensities $I_{1}$ and $I_{2}$ by

$$
C=\left(I_{1}-I_{2}\right) /\left(I_{1}+I_{2}\right)
$$

For the ideal image of the lead grid (figure 2.5b), the intensities $I_{1}$ and $I_{2}$ do not change upon increasing the spatial frequency. Thus, the resulting contrast function $C_{\text {ideal }}(k)$ is constant. For the real image (figure 2.5c), $I_{1}$ and $I_{2}$ change upon increasing the spatial frequency $k$ and the value of the contrast function $C_{\text {real }}(k)$ decreases. The analysis of this dependence yields the contrast transfer function (CTF) which is defined as

$$
\operatorname{CTF}(k)=C_{\text {real }}(k) / C_{\text {ideal }}(k)=C_{\text {real }}(k) / \text { const } .
$$



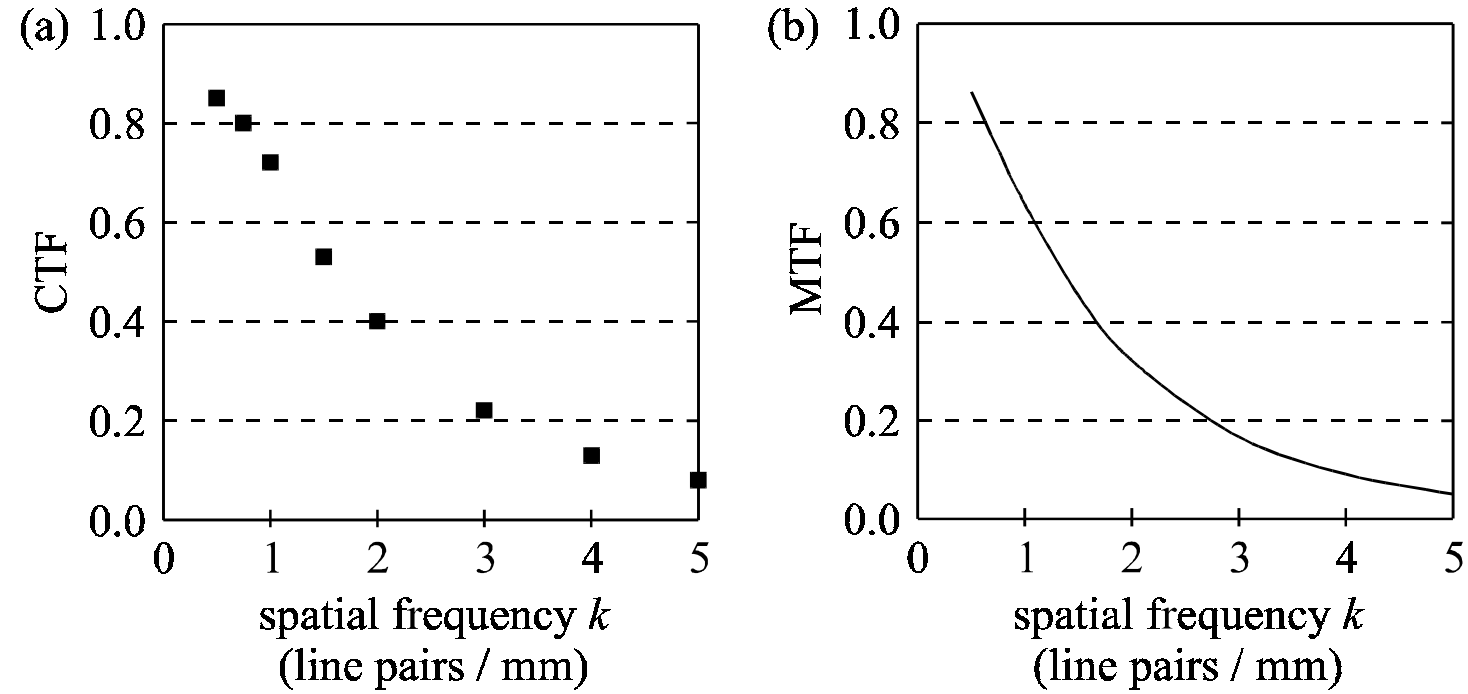

Figure 2.6 (a) Measured data of the contrast transfer function (CTF) and (b) modulation transfer function (MTF), derived from the data of (a), for a commercially-used image plate (AGFA MD 10) [22].

The CTF (figure 2.6a) can afterwards be transformed into the modulation transfer function (MTF) (figure 2.6b). Since the MTF assumes a sinusoidal varying object, the square wave function of the grid (figure $2.5 \mathrm{~b}$ ) is approximated by a series of sinusoidal functions.

The other technique is the exact analysis of a line spread function $\operatorname{LSF}(x)$ and subsequent Fourier transformation. Due to experimental reasons one measures often the edge spread function $\operatorname{ESF}(x)$ and gets the $\operatorname{LSF}(x)$ via differentiation.

\subsection{Read-out process of X-ray storage phosphor image plates}

During the read-out process the X-ray storage phosphor image plate is optically stimulated pixel by pixel and line by line by means of a laser beam, e.g. a HeNe laser $(632.8 \mathrm{~nm})$ for the commercially used $\mathrm{BaFBr}: \mathrm{Eu}^{2+}$ phosphor screen. The photostimulated luminescence light is collected globally with a waveguide and detected by a photomultiplier. The stimulation light is cut off by means of an appropriate optical filter combination which is placed between the waveguide and the photomultiplier (not indicated in figure 2.7). The detected luminescence intensity during stimulation of a pixel is 


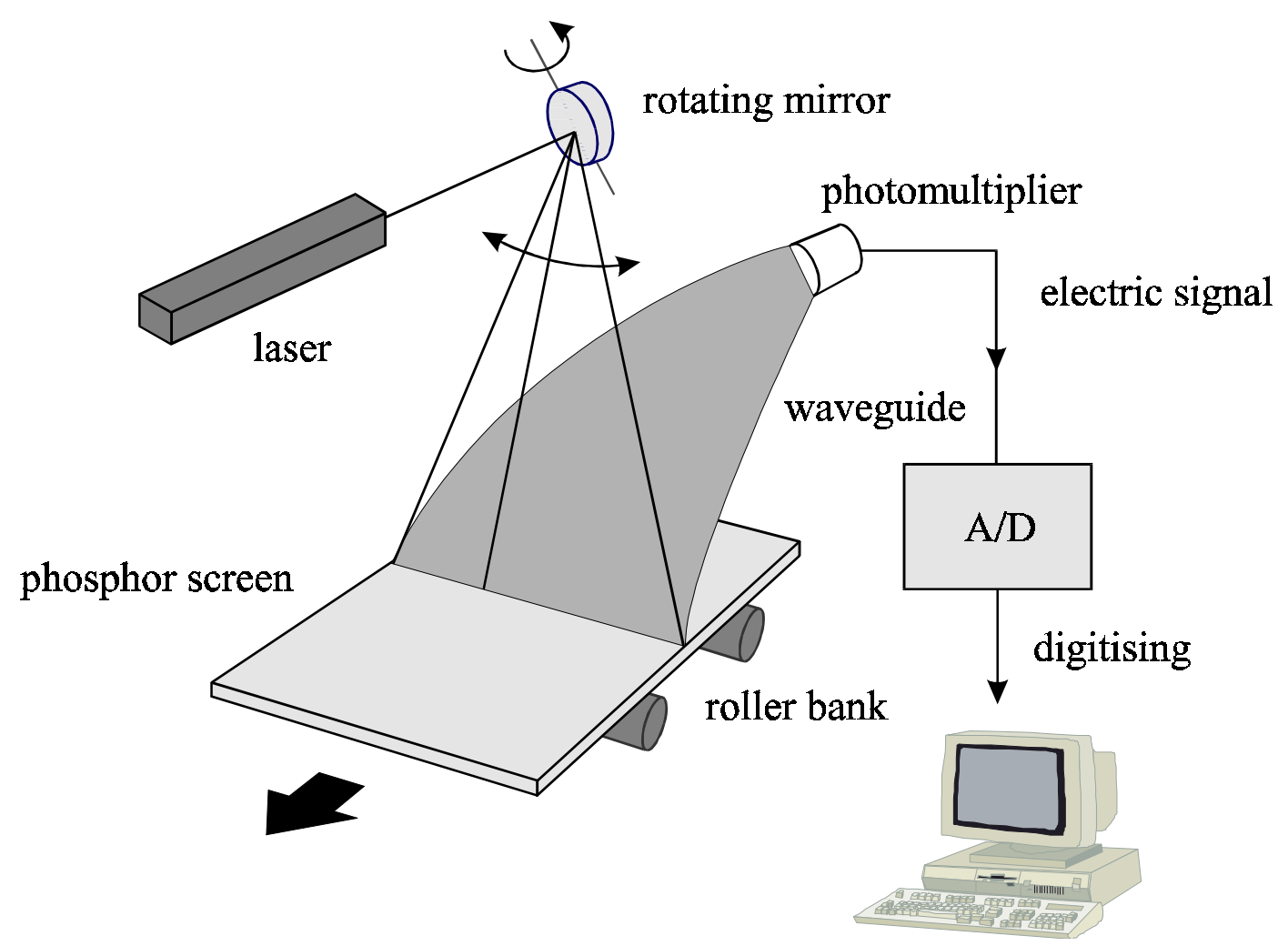

Figure 2.7 Setup for the read-out procedure of X-ray storage phosphor image plates [22].

a measure for the absorbed X-ray dose in that pixel. The analogue signal of the photomultiplier is converted by an analogue/digital (A/D) converter to a digital signal. The scanning procedure is carried out by moving the laser with a rotating mirror and/or the image plate with the roller plate (figure 2.7).

The spatial resolution of X-ray storage phosphor screens is still inferior to that of conventional X-ray films. One of the reasons for this is certainly the light scattering of the scanning laser beam which is used for the read-out. The structural reasons for this are explained in figure 2.8: The image plate consists of fine phosphor grains imbedded in an organic binder. The phosphor/binder layer is deposited on an organic substrate and protected by a thin foil. During the read-out the stimulating light of the scanning laser beam is scattered within the phosphor/binder layer due to the different refractive indices of the two components. The scattered stimulating light can then excite the electron trap centres in the X-irradiated areas and cause photostimulated luminescence (PSL) although the scanning laser beam is not in the right position yet. The luminescence light is detected globally on the side of the stimulation. The sharp edges of the X-irradiated 

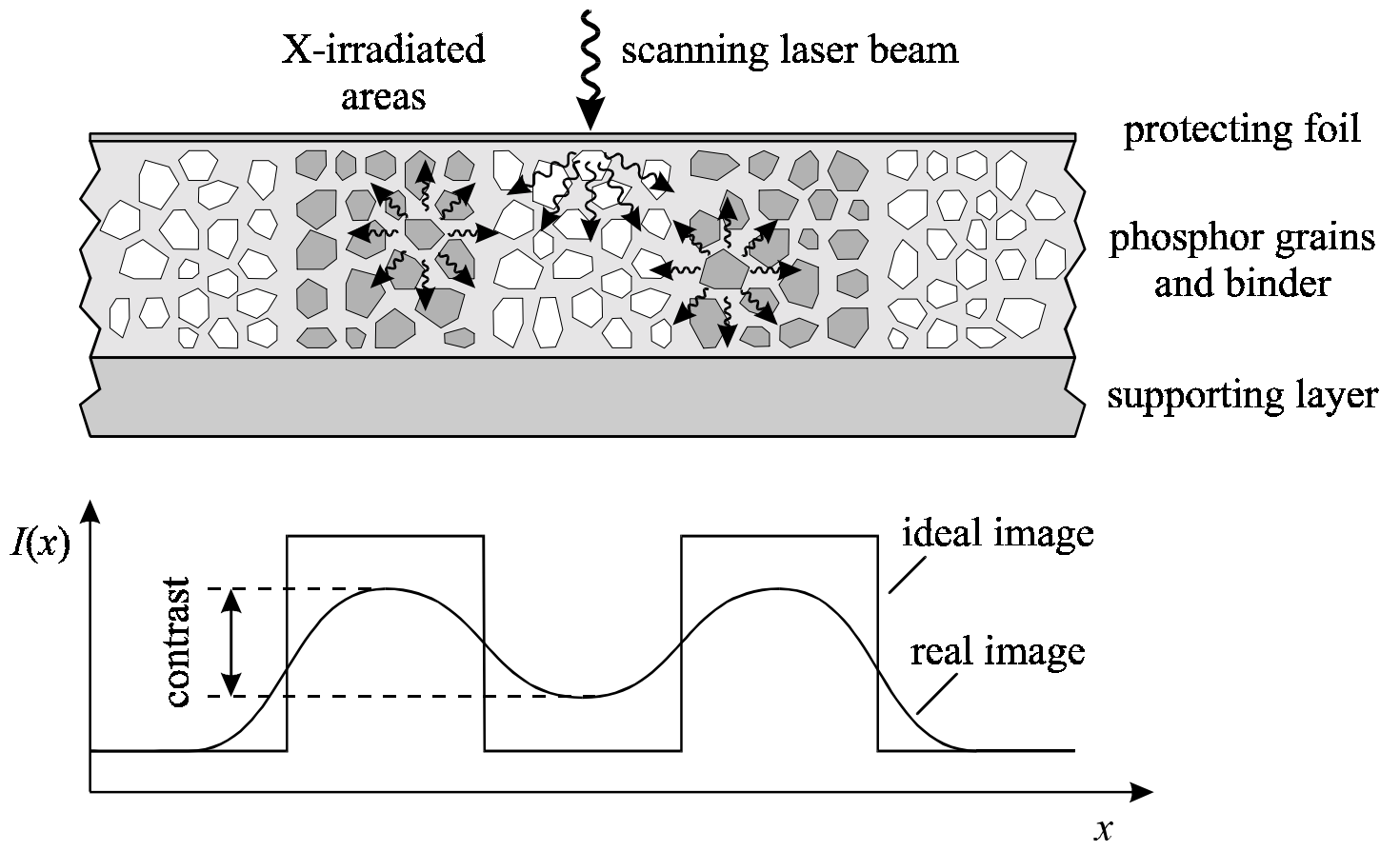

Figure 2.8 Scattering of the scanning laser beam during the read-out process of a storage phosphor image plate.

areas are spread and the contrast modulation is reduced. For a contrast modulation below the smallest detectable contrast the two X-irradiated areas in figure 2.8 cannot be resolved any more. Here, the detection of the luminescence light is done globally on the stimulation side of the phosphor screen and not focussed on the laser beam position in the layer. The spatial resolution is thus determined by the scattering region, i.e. the excitation volume of the stimulating light. 


\section{Chapter 3}

\section{The X-ray storage phosphor BaFBr:Eu ${ }^{2+}$}

The so far best and world-wide commercially used X-ray storage phosphor is $\mathrm{BaFBr}$ doped with $\mathrm{Eu}^{2+}$ as activator [1]. Upon X-irradiation, room temperature (RT) stable electron and hole trap centres are generated. The electron trap centres are photostimulable and the electron recombines upon photostimulation with the hole trap centre under light emission. Although the principle of information storage and read-out mechanism is simple, it is not clearly known how the recombination energy is transferred to the activator $\mathrm{Eu}^{2+}$ which emits at $3.18 \mathrm{eV}(390 \mathrm{~nm})$. The PSL decay time is $750 \mathrm{~ns}[1,23]$. In many years of thorough research and optimisation $\mathrm{BaFBr}: \mathrm{Eu}^{2+}$ has already reached a very high level of performance. However, there is still space for some improvements such as e.g. a better conversion to PSL-active centres [24], a higher stability of the PSL active centres, and a better erasability of the generated defects after the read-out process. The spatial resolution can probably not be improved. For recent reviews see e.g. [2, $3,4,5,25]$.

\subsection{Stoichiometric BaFBr}

\subsubsection{Generation of electron trap centres}

There is general agreement that $\mathrm{X}$-irradiation generates $\mathrm{F}$ centres as electron trap centres. In $\mathrm{BaFBr}$, which has the matlockite structure [26, 27], two $\mathrm{F}$ centres are possible, $\mathrm{F}\left(\mathrm{Br}^{-}\right)$and $\mathrm{F}\left(\mathrm{F}^{-}\right)$centres, where electrons are trapped at $\mathrm{Br}^{-}$vacancies or $\mathrm{F}^{-}$vacancies, 
respectively. Their generation mechanism, however, is controversial. In order to form an $\mathrm{F}$ centre after creating electron-hole pairs by $\mathrm{X}$-irradiation, one either needs to have a halide vacancy present in the crystal or one must generate it during the radiation damage process.

In [28] it was assumed that $\mathrm{Br}^{-}$vacancies are already present in the material. However, no experimental evidence was given for this assumption. In [29] it was shown that photostimulable centres can be created by using vacuum UV light instead of X-rays and concluded that the decay of self-trapped excitons into $\mathrm{F}$ and $\mathrm{H}$ centres $\left(\mathrm{Br}_{2}^{-}\right.$centres on a halide lattice site, see e.g. [30]), provide the necessary mechanism to create F centres.

$\mathrm{H}$ centres were not detected, though, in spite of an intense search for them at $1.5 \mathrm{~K}$ by EPR and optically detected EPR using the magneto-optical method (MCDA-EPR). Had there been $\mathrm{H}$ centres, they would have been detectable using MCDA-EPR. It was shown in [31] that $\mathrm{H}$ centres created in $\mathrm{KBr}$ can be measured in this way.

When measuring the photostimulation as a function of photon energy, two peaks are usually observed: One at $2.15 \mathrm{eV}$ and one around $2.65 \mathrm{eV}$. The two peaks are clearly resolved when using single crystals and polarised light (e.g. $\mathbf{E} \perp \mathbf{c})[32,33]$. The spectral shape of the excitation spectrum of the photostimulated luminescence (figure $3.1 \mathrm{~b}$ ) agrees very well with the optical absorption band of $\mathrm{F}\left(\mathrm{Br}^{-}\right.$) centres (peak at $2.15 \mathrm{eV}$ for $\mathbf{E} \perp \mathbf{c}$ ) and $\mathrm{F}\left(\mathrm{F}^{-}\right)$centres (peak at $2.65 \mathrm{eV}$ for $\mathbf{E} \perp \mathbf{c}$ ) (figure 3.1a). The absorption band for $\mathbf{E} \perp \mathbf{c}$ was clearly identified for each F centre by magneto-optical techniques [34]. Although it was argued that only $\mathrm{F}\left(\mathrm{Br}^{-}\right)$centres are photostimulable [24], it could be clearly shown that both F centres contribute to the PSL $[32,33]$. Yet it was interesting to observe that $\mathrm{F}\left(\mathrm{F}^{-}\right)$centres are only generated by X-irradiation above $200 \mathrm{~K}$. Their formation apparently requires a thermally activated process. When observing the generation of both centres as a function of the X-ray dose, it turns out, however, that $\mathrm{F}^{-}\left(\mathrm{F}^{-}\right)$ centres are not generated as a secondary product of $\mathrm{F}\left(\mathrm{Br}^{-}\right)$centres. $\mathrm{F}\left(\mathrm{Br}^{-}\right)$centres are generated first and then saturate, whilst $\mathrm{F}\left(\mathrm{F}^{-}\right)$centres continued to be generated, but not at the expense of the $\mathrm{F}\left(\mathrm{Br}^{-}\right)$centres. The process has not yet been understood [15]. When no F-H centre mechanism is responsible for the generation of $\mathrm{F}\left(\mathrm{Br}^{-}\right)$centres, which are found even at the lowest temperature $(1.5 \mathrm{~K})$ upon $\mathrm{X}$-irradiation together with $\mathrm{V}_{\mathrm{K}}$ centres (hole shared between two adjacent $\mathrm{Br}^{-}$[32]) as "anti-centres" (see figure 3.2a), it must indeed be assumed that $\mathrm{BaFBr}$ does contain $\mathrm{Br}^{-}$vacancies $\left(\mathrm{V}_{\mathrm{Br}^{-}}\right)$. 
(a)

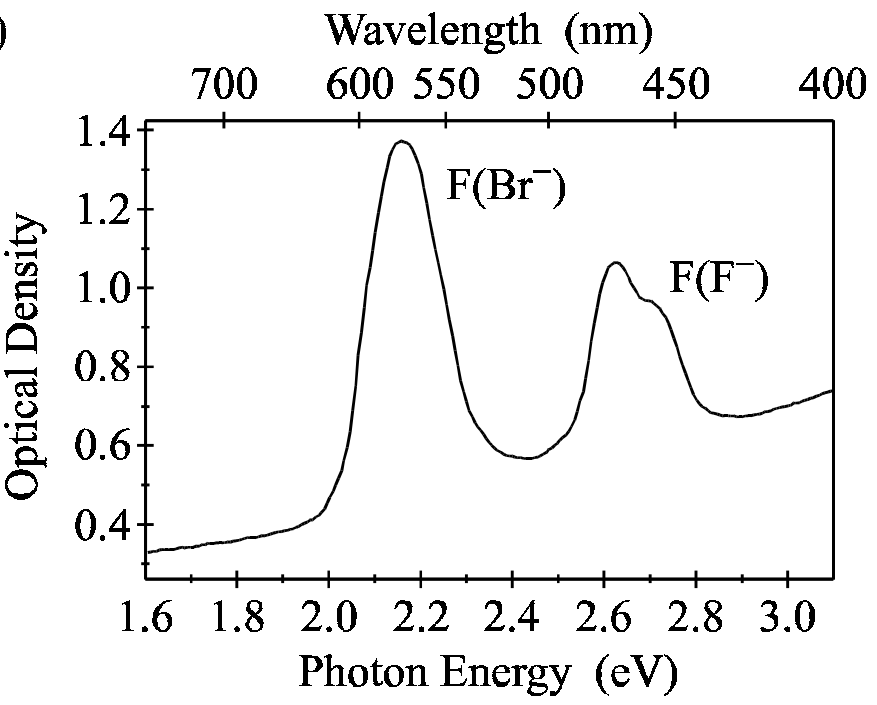

(b)

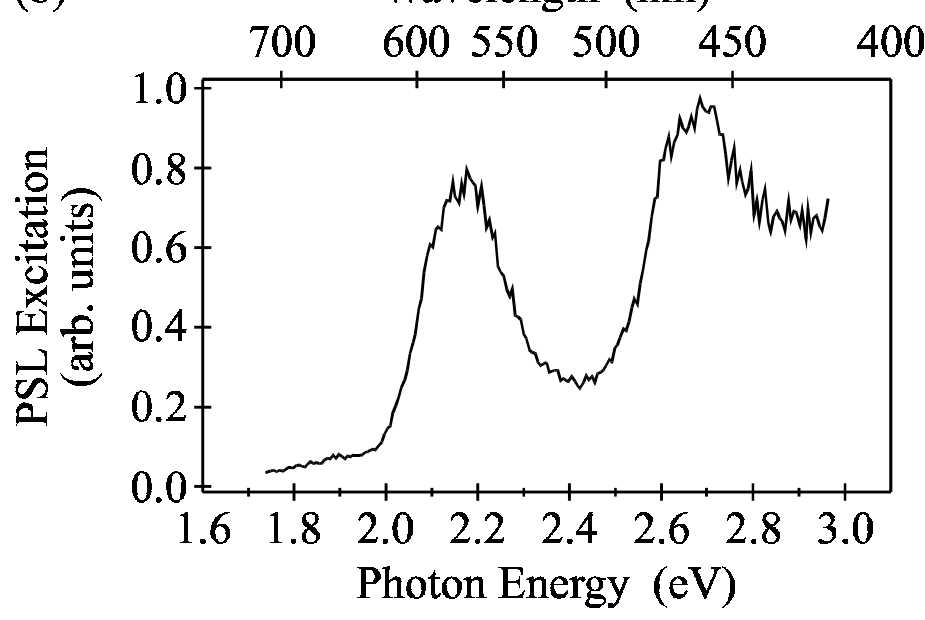

Figure 3.1 (a) Optical absorption spectrum of $\mathrm{F}\left(\mathrm{Br}^{-}\right)$and $\mathrm{F}\left(\mathrm{F}^{-}\right)$centres in $\mathrm{BaFBr}$ and (b) PSL excitation spectrum of $\mathrm{Eu}^{2+}$ in $\mathrm{BaFBr}$. Both spectra were recorded at $10 \mathrm{~K}$ for $\mathbf{E} \perp \mathbf{c}$ after $\mathrm{X}$-irradiation at RT [32].

\subsubsection{Generation of hole trap centres}

It was long overlooked that $\mathrm{BaFBr}$ produced by firing stoichiometric mixtures of $\mathrm{BaF}_{2}$ and $\mathrm{BaBr}_{2}$ or by growing single crystals from the melt of such mixtures with the Bridgman method are all contaminated with oxygen, irrespective of the manufacturer. All attempts to eliminate oxygen completely have failed. Very careful avoidance of oxygen could only reduce the oxygen contamination $[35,36]$. Oxygen can be incorpo- 
(a)

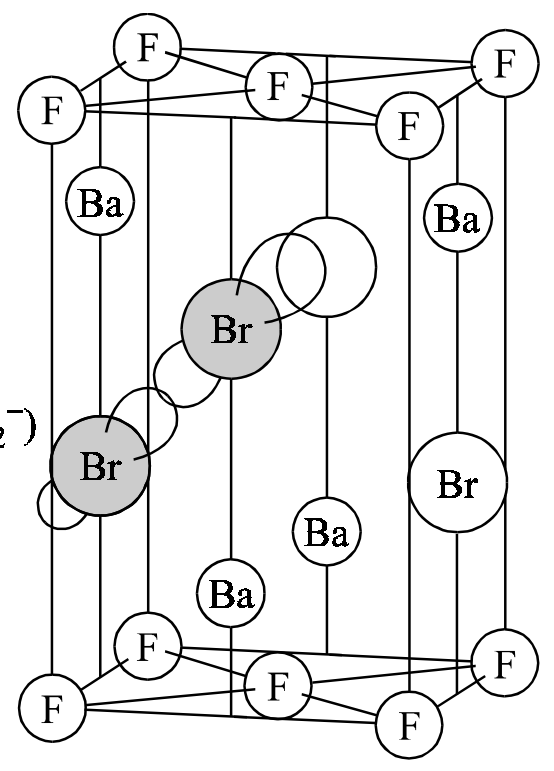

(b)

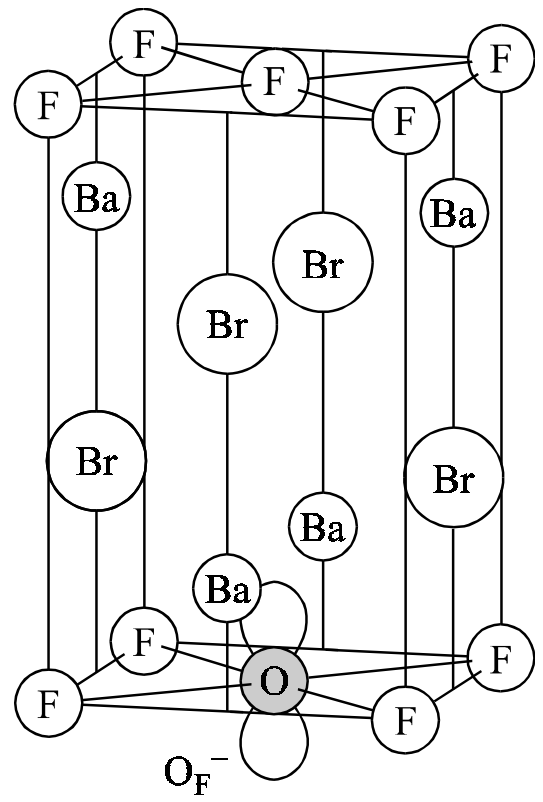

Figure 3.2 Model of (a) the $\mathrm{V}\left(\mathrm{Br}^{-}\right)$and (b) the $\mathrm{O}^{-}$centre in $\mathrm{BaFBr}$.

rated in many ways: It was found as $\mathrm{O}^{2-}$ in the fluorine $\left(\mathrm{O}_{\mathrm{F}}^{2-}\right)$ [37] as well as in the bromine sublattice $\left(\mathrm{O}_{\mathrm{Br}}^{2-}\right)[38,39]$. There was also a molecular oxygen centre $\left(\left(\mathrm{O}_{\mathrm{F}^{-}}\right.\right.$ $\left.\mathrm{O}_{\mathrm{Br}}\right)^{3-}$ ) observed where one oxygen is placed on a fluorine site and the other one on a neighbouring bromine site [39].

For charge compensation an anion vacancy is needed. It was shown by the study of the generation of $\mathrm{F}$ centres, $\mathrm{V}_{\mathrm{K}}$ centres and $\mathrm{O}^{-}$centres at low temperature using magnetooptical (MCDA) and MCDA-EPR methods that these vacancies are indeed $\mathrm{Br}^{-}$vacancies $[15,35,36]$. Upon $\mathrm{X}$-irradiation at temperatures below $120 \mathrm{~K} \mathrm{~V} \mathrm{~K}_{\mathrm{K}}\left(\mathrm{Br}_{2}^{-}\right)$centres and $\mathrm{F}\left(\mathrm{Br}^{-}\right)$centres are formed, the latter being near to the $\mathrm{O}_{\mathrm{F}}^{2-}$ centres. Above $120 \mathrm{~K}$ the $\mathrm{V}_{\mathrm{K}}\left(\mathrm{Br}_{2}^{-}\right)$centres become mobile, react with the $\mathrm{O}_{\mathrm{F}}^{2-}$ centres and form $\mathrm{O}_{\mathrm{F}}^{-}$hole trap centres. Above $200 \mathrm{~K}$ the $\mathrm{F}\left(\mathrm{Br}^{-}\right)$centres can diffuse away and become isolated [37, 40]. The microscopic structure of the $\mathrm{O}_{\mathrm{F}}^{-}$defect (figure 3.2b) was established by EPR and ENDOR. Figure 3.3 shows the EPR spectrum of ${ }^{17} \mathrm{O}_{\mathrm{F}}^{-}$centres in $\mathrm{BaFBr}$. The magnetic oxygen isotope ${ }^{17} \mathrm{O}$ has a nuclear spin of $I=5 / 2$ and hence shows a hyperfine splitting into 6 lines. The isotope substitution of ${ }^{17} \mathrm{O}$ for ${ }^{16} \mathrm{O}$ proved that the defect centre of figure 3.3, always produced upon $\mathrm{X}$-irradiation of $\mathrm{BaFBr}$, is due to an oxygen contamination [37]. 


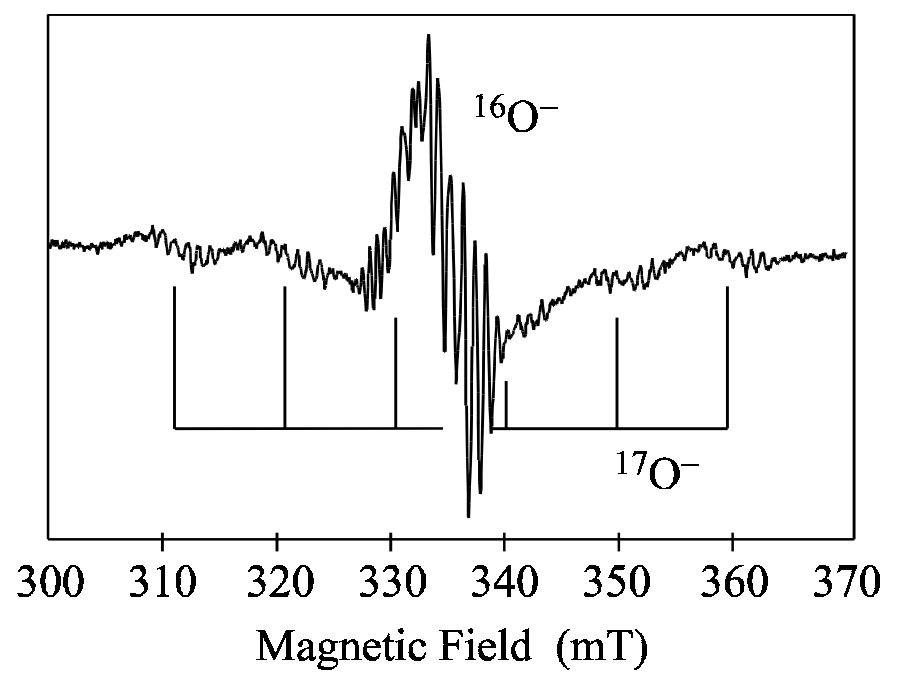

Figure 3.3 EPR spectra of the $\mathrm{O}_{\mathrm{F}}^{-}$centre in ${ }^{17} \mathrm{O}$-doped $\mathrm{BaFBr}$ after X-irradiation at $\mathrm{RT}$, recorded for $\mathbf{B} \| \mathbf{c}$ at $T=5 \mathrm{~K}$ applying a microwave frequency of $9.42 \mathrm{GHz}$. The bars indicate the ${ }^{17} \mathrm{O}$ hyperfine splittings [37].

It can be assumed that the BaFBr used by [29] also contained oxygen and thus the UV production of $\mathrm{F}\left(\mathrm{Br}^{-}\right)$centres becomes understandable by the process

$$
\begin{gathered}
\mathrm{V}_{\mathrm{Br}^{-}}+\mathrm{O}_{\mathrm{F}}^{2-} \stackrel{\mathrm{UV}, \mathrm{X} \text {-ray }}{\longrightarrow} \mathrm{F}\left(\mathrm{Br}^{-}\right)+\mathrm{V}_{\mathrm{K}}\left(\mathrm{Br}_{2}^{-}\right)+\mathrm{O}_{\mathrm{F}}^{2-} \\
\stackrel{>120 \mathrm{~K}}{\longrightarrow} \mathrm{F}\left(\mathrm{Br}^{-}\right)+\mathrm{O}_{\mathrm{F}}^{-} .
\end{gathered}
$$

Thus, the generation of $\mathrm{F}\left(\mathrm{Br}^{-}\right)$centres in oxygen-contaminated, stoichiometric $\mathrm{BaFBr}$ is understood, whereas the mechanism leading to $\mathrm{F}\left(\mathrm{F}^{-}\right)$centres remains still unclear. The microscopic structure of the two F centres was established by detailed ENDOR investigations [41].

\subsubsection{PSL active hole trap centres}

The nature of the hole trap centre taking part in the PSL process is still unclear and controversially discussed. In $[28,42]$ it was claimed that upon electron and hole creation by $\mathrm{X}$-rays holes are trapped at $\mathrm{Eu}^{2+}$ and form $\mathrm{Eu}^{3+}$. Upon photostimulation of $\mathrm{F}$ centres, the $\mathrm{F}$ electrons move through the conduction band and recombine with $\mathrm{Eu}^{3+}$, exciting $\mathrm{Eu}^{2+}$ to its excited state, from which the $390 \mathrm{~nm}$ luminescence occurs. In this model the PSL process requires thermal activation, since the excited $\mathrm{F}$ centres have re- 


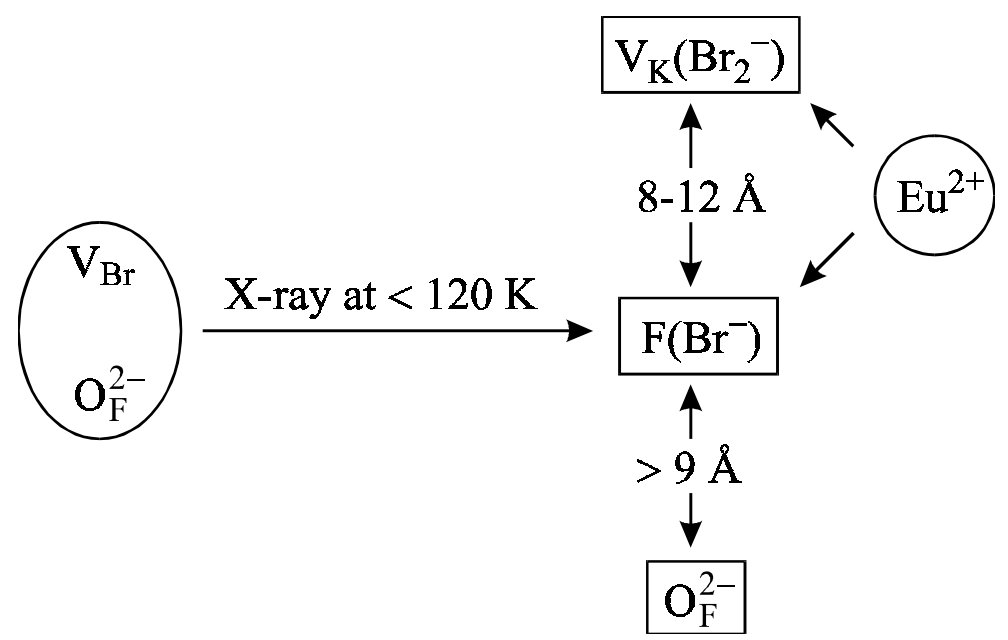

Figure 3.4 Schematic model for the spatial correlation between $\mathrm{F}\left(\mathrm{Br}^{-}\right), \mathrm{V}_{\mathrm{K}}\left(\mathrm{Br}_{2}^{-}\right)$, $\mathrm{O}^{2-}$ and $\mathrm{Eu}^{2+}$ after low temperature $\mathrm{X}$-irradiation [15].

laxed excited states below the conduction band. The thermal activation energy was determined to be $37 \mathrm{meV}$ for $\mathrm{F}\left(\mathrm{Br}^{-}\right)$and $1.3 \mathrm{meV}$ for $\mathrm{F}\left(\mathrm{F}^{-}\right)$[43].

This simple pair model for the PSL mechanism was questioned by several authors. The EPR signal of $\mathrm{Eu}^{2+}$ did not change upon prolonged X-irradiation [32], nor could a change be observed in the $\mathrm{Eu}^{2+}$ luminescence [44]. Furthermore, the observation of an almost temperature independent PSL effect by stimulating $\mathrm{F}\left(\mathrm{Br}^{-}\right)$centres from $4.2 \mathrm{~K}$ to RT [23] contradicts the model that electrons move through the conduction band upon photostimulation of $\mathrm{F}$ centres.

However, it has been proposed on the basis of several different experimental findings that the recombination between electrons and holes takes place via tunnelling and that a kind of "aggregate" between F centres, hole trap centres and the activator $\mathrm{Eu}^{2+}$ must be formed during X-irradiation (called triple aggregate centres [32]). It was found that the decay of the photostimulated luminescence under continued stimulation is temperature independent [45] and that the increase in the PSL intensity is proportional to the X-ray dose [23]. This latter result implies that retrapping of electrons after photostimulation does not occur, which makes electron-hole recombination via tunnelling more likely than via the conduction band. Tunnelling, however, requires a spatial correlation between the $\mathrm{F}$ centre and the activator. Direct evidence for a spatial correlation between $\mathrm{F}$ centres, $\mathrm{O}_{\mathrm{F}}^{-}$centres and $\mathrm{Eu}^{2+}$ was given with cross-relaxation spectroscopy using magneto-optical techniques (figure 3.4) [46]. 


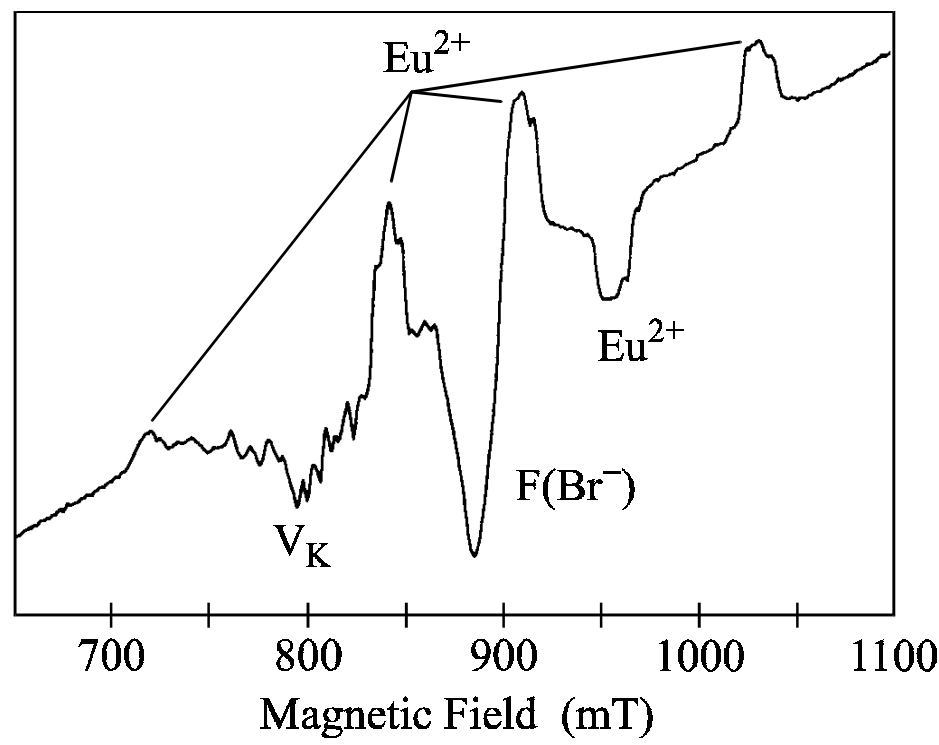

Figure 3.5 EPR spectrum detected in the MCDA band of the $\mathrm{V}_{K}\left(\mathrm{Br}_{2}^{-}\right)$centre in $\mathrm{BaFBr}$ after $\mathrm{X}$-irradiation at $4.2 \mathrm{~K}$, recorded for $\mathbf{B} \| \mathbf{c}$ at $T=1.5 \mathrm{~K}$ applying a microwave frequency of $24 \mathrm{GHz}$. The spectrum shows cross-relaxations to the $\mathrm{F}\left(\mathrm{Br}^{-}\right)$centre and to $\mathrm{Eu}^{2+}[46]$.

It could be shown by the cross-relaxation spectroscopy within the MCDA-detected EPR spectroscopy (see section 1.1.3) that there is a spatial correlation between F centres and $\mathrm{Eu}^{2+}$ as well as between $\mathrm{O}_{\mathrm{F}}^{-}$and $\mathrm{Eu}^{2+}$ after $\mathrm{X}$-irradiation at $\mathrm{RT}$. When X-irradiating at low temperature, $V_{K}$ centres also show this correlation with the other centres $[40,46]$. This leads to the speculation that an exciton decay occurs at the $\mathrm{Eu}^{2+}$ activator forming electron and hole trap centres and that there is a spatial correlation between the $\mathrm{O}_{\mathrm{F}}^{2-}$ anion vacancy pairs and the $\mathrm{Eu}^{2+}$ activators generated during the production of the material (figure 3.5).

Indirect evidence for the formation of "triple aggregate" centres was also found in the so-called replenishment effect. When the phosphor is stimulated at $4.2 \mathrm{~K}$ and the PSL exhausted, it can be replenished by annealing to temperatures above $200 \mathrm{~K}$ [32]. It seems that after exhaustion of the aggregates formed first, new aggregates can be formed by thermally activated motion of either hole trap or electron trap centres, or both. The size of the effect depends on the amount of oxygen contamination. The migration of $\mathrm{F}\left(\mathrm{Br}^{-}\right)$centres was recently investigated at RT by [47]. An investigation of the crystal size dependence on the $\mathrm{F}\left(\mathrm{Br}^{-}\right)$centre stability yielded that in small crystallites the $\mathrm{F}\left(\mathrm{Br}^{-}\right)$centres seem to migrate to be stabilised near the surface of the crystal- 
lites, whereas in larger crystals they only migrate to recombine with the hole trap centres.

The role of $\mathrm{O}_{\mathrm{F}}^{2-}$ centres is certainly that it captures holes and forms $\mathrm{O}_{\mathrm{F}}^{-}$centres. The question is, though, whether it is also the hole trap centre active in the PSL process. When bleaching into the F centre band, the number of F centres can be drastically decreased to practically zero, while that of the $\mathrm{O}_{\mathrm{F}}^{-}$centres is hardly affected: The decrease is at most by $20 \%-30 \%$ [15]. Hence, it is not very likely that the $\mathrm{O}_{\mathrm{F}}^{-}$centres are those active hole trap centres in the triple aggregates described above. On the other hand, it was found that the variation of the oxygen content influences the PSL intensity. A low oxygen content results in a low PSL intensity. Also, the stimulation energy needed for the read-out process is higher for oxygen-poor $\mathrm{BaFBr}$. Thus, it seems that oxygen is involved in two ways in the PSL mechanism: It provides vacancies for the $\mathrm{F}\left(\mathrm{Br}^{-}\right)$generation and it somehow seems to influence favourably the photostimulation of the triple aggregate centres in that less stimulation energy is needed for read-out and a high PSL intensity results after short stimulation.

\subsection{Non-stoichiometric BaFBr}

In the previous section it was shown that $\mathrm{BaFBr}$ powders which are normally formed by firing intimate mixtures of $\mathrm{BaF}_{2}$ and $\mathrm{BaBr}_{2}$ are always contaminated with oxygen. The role of the oxygen contamination is both beneficial and detrimental, and it is difficult to control its concentration such as to optimise the performance of these storage phosphors. There is a different method to produce $\mathrm{BaFBr}$ powders [22]. An intimate mixture of $\mathrm{BaF}_{2}$ and $\mathrm{NH}_{4} \mathrm{Br}$ in the ratio of $1: 1$ is fired instead of a mixture of $\mathrm{BaF}_{2}$ and $\mathrm{BaBr}_{2}$. When doped with $\mathrm{Eu}^{2+}$ the resulting material was found to be an excellent storage phosphor, although this material showed some properties significantly different from that produced by firing a mixture of $\mathrm{BaF}_{2}$ and $\mathrm{BaBr}_{2}$.

Chemical analysis of the material yielded that it is non-stoichiometric with a fluorine excess of about $10 \% \pm 2 \%$ [48]. The non-stoichiometric $\mathrm{BaF}_{1.1} \mathrm{Br}_{0.9}$ still has the matlockite structure as does the stoichiometric $\mathrm{BaFBr}$ including that no change of the lattice parameters could be detected by detailed X-ray diffraction (XRD) studies [48]. It was also shown by $\mathrm{XRD}$ that $\mathrm{BaF}_{1.1} \mathrm{Br}_{0.9}$ is a single phase compound with at most $1 \%$ of other phases present. Attempts to vary the non-stoichiometry by firing different mixtures of $\mathrm{BaF}_{2}$ and $\mathrm{NH}_{4} \mathrm{Br}$ failed to generate a single phase material. 
No oxygen luminescence $[49,50]$ could be excited in $\mathrm{BaF}_{1.1} \mathrm{Br}_{0.9}[51,52]$. Thus, this non-stoichiometric material is considered to be oxygen-free. X-irradiation at RT generates $\mathrm{F}\left(\mathrm{Br}^{-}\right)$and $\mathrm{F}\left(\mathrm{F}^{-}\right)$centres. The presence of $\mathrm{F}\left(\mathrm{Br}^{-}\right)$centres could be measured by powder-EPR, while the concentration of $\mathrm{F}\left(\mathrm{F}^{-}\right)$centres was not sufficient to be seen in the powder-EPR spectrum. The presence of $\mathrm{F}$ centres, however, can also be tested by exciting their infrared (IR) luminescence. Surprisingly, the IR luminescence peaking at $1.14 \mathrm{eV}(1088 \mathrm{~nm})$ of $\mathrm{F}\left(\mathrm{F}^{-}\right)$could be detected, while that of $\mathrm{F}\left(\mathrm{Br}^{-}\right)$centres at $0.92 \mathrm{eV}$ $(1348 \mathrm{~nm})$ could not be detected [51]. This latter result points to a possible nearby presence of another defect which may cause the excited state of the $\mathrm{F}\left(\mathrm{Br}^{-}\right)$centre to decay non-radiatively.

The question arises by what mechanism the $\mathrm{F}\left(\mathrm{Br}^{-}\right)$centres are generated. Since there is no $\mathrm{O}_{\mathrm{F}}^{2-}$ in this material, either $\mathrm{Br}^{-}$vacancies must be present or a process such as the exciton decay resulting in F-H-centre pairs as is known from the alkali halides, may be operative [30]. It could be argued that the $\mathrm{F}^{-}$excess in $\mathrm{BaF}_{1.1} \mathrm{Br}_{0.9}$ could cause the incorporation of $\mathrm{Br}^{-}$vacancies. If $18 \% \mathrm{Br}^{-}$vacancies and $9 \% \mathrm{Ba}^{2+}$ vacancies were present (the latter for charge compensation, the concentrations of $\mathrm{Br}^{-}$and $\mathrm{Ba}^{2+}$ vacancies would explain the formula $\mathrm{BaF}_{1.1} \mathrm{Br}_{0.9}$ ), then there should be a significant change of more than $10 \%$ in the density which is caused by a decrease of the molecular mass while assuming no change of volume. This was, however, not measured within experimental error of $\pm 2 \%$ [22].

Consequently, speculations arose that perhaps the $\mathrm{F}^{-}$excess was incorporated as $\mathrm{F}^{-}$on $\mathrm{Br}^{-}$sites, i.e. as $\mathrm{F}^{-}$antisites. The density change would then be as small as found within the experimental error of $\pm 2 \%$. The presence of $\mathrm{F}^{-}$antisites could be established by NMR experiments. In order to obtain NMR lines narrow enough to resolve a possibly small chemical shift between ${ }^{19} \mathrm{~F}$ on a regular lattice site and an $\mathrm{F}^{-}$on a $\mathrm{Br}^{-}$lattice site, magic angle spinning nuclear magnetic resonance (MAS-NMR) spectroscopy [13] was applied. It was shown (see section 3.2.2) that indeed $\mathrm{F}^{-}$antisites are present in nonstoichiometric $\mathrm{BaF}_{1.1} \mathrm{Br}_{0.9}$ [52].

The question still remained whether the $\mathrm{F}^{-}$antisites provide a mechanism whereby $\mathrm{F}\left(\mathrm{Br}^{-}\right)$centres can be created or whether, in addition to the $\mathrm{F}^{-}$antisites, $\mathrm{Br}^{-}$vacancies are present in the material. This question is answered in the following section on EPR experiments after X-irradiation at low temperature and at RT. Both assumptions are correct: There are $\mathrm{Br}^{-}$vacancies in the material, and there is a mechanism generating $\mathrm{F}\left(\mathrm{Br}^{-}\right)$centres which originates in the $\mathrm{F}^{-}$antisites. 


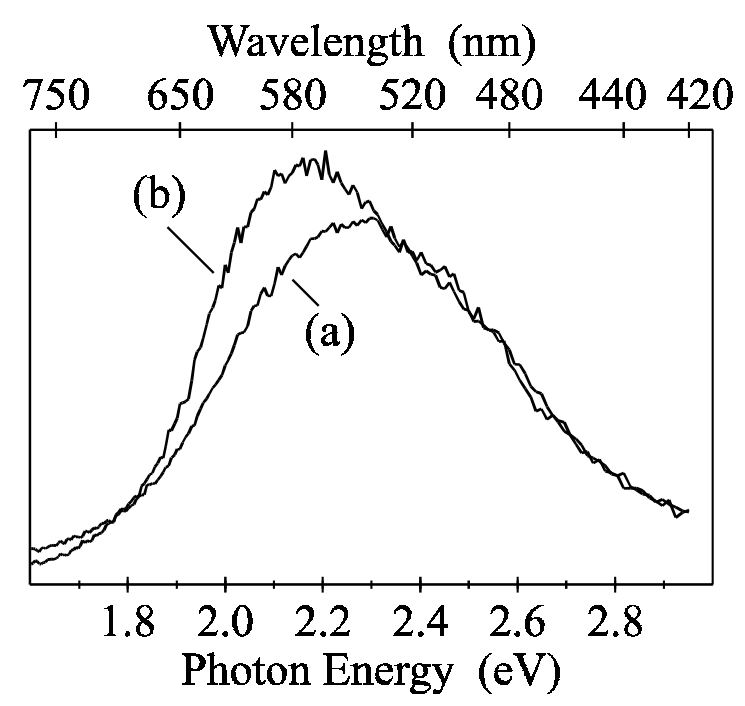

Figure 3.6 PSL excitation spectra measured at RT of (a) stoichiometric BaFBr:Eu ${ }^{2+}$ powder and (b) non-stoichiometric $\mathrm{BaF}_{1.1} \mathrm{Br}_{0.9}: \mathrm{Eu}^{2+}$ powder after $\mathrm{X}$ irradiation at RT [52].

\subsubsection{Photostimulated luminescence}

The PSL excitation spectra of stoichiometric BaFBr:Eu and of non-stoichiometric $\mathrm{BaF}_{1.1} \mathrm{Br}_{0.9}: \mathrm{Eu}$ powder yielded that the peak of the stoichiometric sample is at $540 \mathrm{~nm}$ (figure 3.6a) while that of the non-stoichiometric one is at $580 \mathrm{~nm}$, i.e. at lower photon energy, and there is an additional shoulder at $510 \mathrm{~nm}$ (figure 3.6b). The intensity ratio between the $580 \mathrm{~nm}$ peak and the high-energy shoulder at $510 \mathrm{~nm}$ is approximately 2:1. In both materials the luminescence is due to the stimulation of $\mathrm{F}\left(\mathrm{Br}^{-}\right)$and $\mathrm{F}\left(\mathrm{F}^{-}\right)$centres. The absorption peak of $\mathrm{F}\left(\mathrm{Br}^{-}\right)$centres is at $580 \mathrm{~nm}$ for the electrical light vector perpendicular to the crystal $c$-axis, while it is at $510 \mathrm{~nm}$ for $\mathbf{E} \| \mathbf{c}$. For $\mathrm{F}\left(\mathrm{F}^{-}\right)$centres the absorption peaks are at $470 \mathrm{~nm}$ for $\mathbf{E} \perp \mathbf{c}$ and at $520 \mathrm{~nm}$ for $\mathbf{E} \| \mathbf{c}$ [34]. It is seen qualitatively in figure 3.6, that fluorine excess leads to an enhanced concentration of $\mathrm{F}\left(\mathrm{Br}^{-}\right)$ centres [51]. The absorption peaks of $\mathrm{F}\left(\mathrm{Br}^{-}\right)$centres agree well with the peak and shoulder of figure $3.6 \mathrm{~b}$. The intensity ratio of $2: 1$ is caused by the statistical distribution of the parallel and perpendicular crystallite orientations with respect to the electrical light vector. Apparently in the non-stoichiometric $\mathrm{BaFBr}$ very few $\mathrm{F}\left(\mathrm{F}^{-}\right)$centres are generated in comparison to $\mathrm{F}\left(\mathrm{Br}^{-}\right)$centres. 


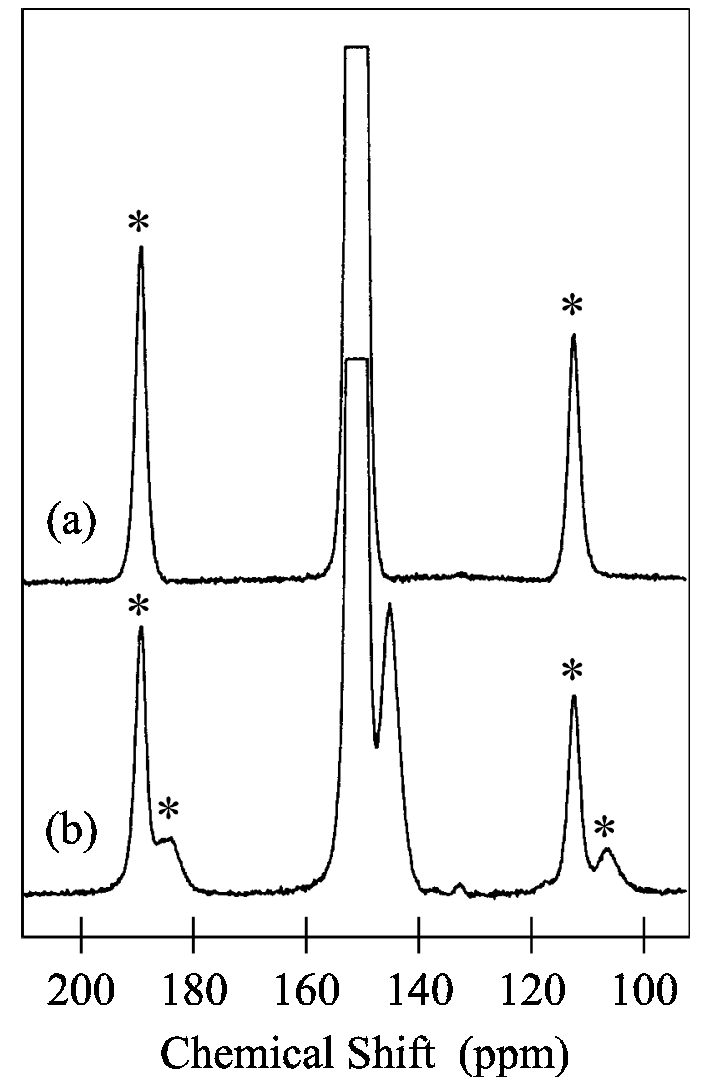

Figure 3.7 ${ }^{19} \mathrm{~F}$ MAS-NMR spectra of (a) a crushed stoichiometric $\mathrm{BaFBr}$ single crystal and (b) non-stoichiometric $\mathrm{BaF}_{1.1} \mathrm{Br}_{0.9}$ powder. The spinning side bands are marked with asterisks [52].

\subsubsection{Identification of fluorine antisites with MAS-NMR}

Figure 3.7 shows the MAS-NMR spectra of ${ }^{19} \mathrm{~F}$ of a pulverised stoichiometric single crystal of $\mathrm{BaFBr}$ and of non-stoichiometric $\mathrm{BaF}_{1.1} \mathrm{Br}_{0.9}$ powder. The peaks due to the lattice ${ }^{19} \mathrm{~F}$ nuclei of both spectra coincide within experimental error at $150.9 \mathrm{ppm}$. A new line appears in $\mathrm{BaF}_{1.1} \mathrm{Br}_{0.9}$ powder at lower frequency, at $145.3 \mathrm{ppm}$, which also shows up in the spinning side bands (marked with asterisks in figure 3.7). The intensity of the new line as measured by the area in comparison to that of the lattice ${ }^{19} \mathrm{~F}$ is $7.3 \%$. The addition of the contributions of the spinning side bands yields in total $8.6 \%$ intensity. Thus, the new line shifted by almost $6 \mathrm{ppm}$ to lower frequencies is due to approximately $9 \%$ of ${ }^{19} \mathrm{~F}$ nuclei with a different site compared to the lattice nuclei. This is close to the $10 \%$ excess of $\mathrm{F}$ in the lattice determined by chemical analysis [48]. Since for 


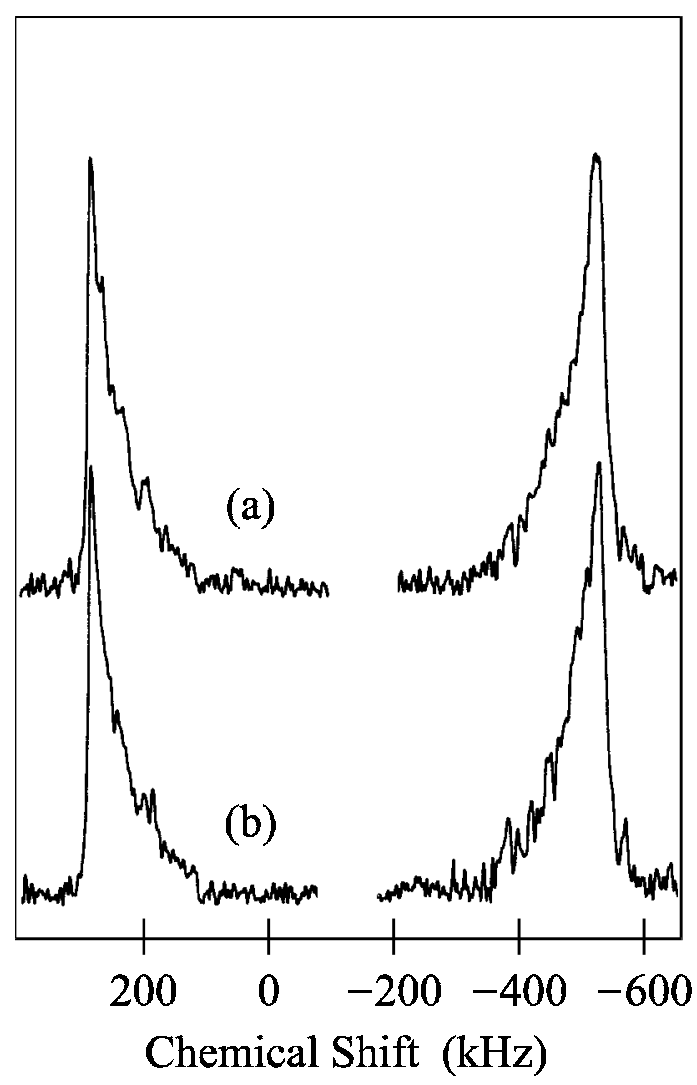

Figure 3.8 Edge singularities for ${ }^{137} \mathrm{Ba}$ of (a) a crushed stoichiometric $\mathrm{BaFBr}$ single crystal and (b) non-stoichiometric $\mathrm{BaF} \mathrm{Br}$ powder [52].

electrostatic reasons it is very unlikely that the new site is an interstitial site, the new line was assigned to $\mathrm{F}^{-}$on $\mathrm{Br}^{-}$vacant sites, i.e. to $\mathrm{F}^{-}$antisites [52].

Figure 3.8 shows the high and low frequency edge singularities of the ${ }^{137} \mathrm{Ba}$ static powder spectrum having second order quadrupole interaction [53]. The edge singularities of $\mathrm{Ba}$ as well as those of $\mathrm{Br}$ (which are not shown here) are identical for both the stoichiometric and the non-stoichiometric BaFBr. Thus, the $\mathrm{F}^{-}$excess does not change the crystal structure, i.e. the geometry must be practically identical for both crystals.

The MAS-NMR spectra confirm an earlier suggestion that the $\mathrm{F}^{-}$to $\mathrm{Br}^{-}$ratio of about 1.1 to 0.9 is achieved by $10 \%$ enhanced fluorine incorporation and a simultaneous $10 \%$ bromine reduction [51]. In this case a charge compensation on the cationic sublattice is not necessary. The change in density is approximately $2 \%$ which could not be observed experimentally within experimental error of $\pm 2 \%$ [22]. 
The two chemical shifts found for ${ }^{19} \mathrm{~F}$ for the regular $\mathrm{F}$ lattice site and the antisite ${ }^{19} \mathrm{~F}$ are not very different: $150.9 \mathrm{ppm}$ for the regular sites, $145.3 \mathrm{ppm}$ for the antisites. The difference of $5.6 \mathrm{ppm}$ is smaller than that found for ${ }^{19} \mathrm{~F}$ in the divalent fluorides $\mathrm{CaF}_{2}$, $\mathrm{SrF}_{2}$ and $\mathrm{BaF}_{2}$ (see e.g. [54, 55]) which vary between $58 \mathrm{ppm}$ and $152 \mathrm{ppm}$, respectively. It is interesting to note that the $\mathrm{Ba}^{2+}-\mathrm{F}^{-}$distance in $\mathrm{BaF}_{2}(2.68 \AA)$ is almost identical to that in $\mathrm{BaFBr}(2.66 \AA)$. In [54] it was argued that the chemical shift is determined by the metal- $\mathrm{F}^{-}$distance. The $150.9 \mathrm{ppm}$ found for the regular ${ }^{19} \mathrm{~F}$ lattice nuclei tie in well with this rule. Not so the ${ }^{19} \mathrm{~F}$ antisites having a distance of $3.36 \AA$ to the nearest $\mathrm{Ba}^{2+}$ neighbour (along the $c$-axis) and $3.42 \AA$ to the four next nearest $\mathrm{Ba}^{2+}$ neighbours, respectively. Perhaps the larger screening is the result of a larger site for $\mathrm{F}^{-}$and the more expanded electron core.

\subsubsection{Identification of electron and hole trap centres with EPR}

After X-irradiation at RT the EPR spectrum of non-stoichiometric $\mathrm{BaF}_{1.1} \mathrm{Br}_{0.9}$ powder shows the lines of $\mathrm{F}\left(\mathrm{Br}^{-}\right)$centres and a powder-EPR line the $g$ factor of which indicates that it is caused by a hole trap centre (figure $3.9 \mathrm{~b}$ ). The spectrum can be simulated well by assuming an axial centre with the $g$ values of $g_{\perp}=2.02$ and $g_{\|}=2.002$ [52]. In figure 3.9a the powder-EPR spectrum of stoichiometric $\mathrm{BaFBr}$ is shown which contains oxygen and where the resonances of $\mathrm{O}_{\mathrm{F}}^{-}$centres as well as of $\mathrm{F}\left(\mathrm{Br}^{-}\right)$centres are seen. The positive shift of the $g$ values of the new centre indicates that it is indeed a hole trap centre.

Its nature as a hole trap centre is further supported by the observation that its intensity increases proportional to the $\mathrm{X}$-ray dose as does that of the $\mathrm{F}\left(\mathrm{Br}^{-}\right)$centres. The simultaneous growth of the hole trap centre and that of the $\mathrm{F}\left(\mathrm{Br}^{-}\right)$centre suggests that the hole trap centre is the "anticentre" of the $\mathrm{F}\left(\mathrm{Br}^{-}\right)$centre, i.e. electron-hole separation results in the $\mathrm{F}\left(\mathrm{Br}^{-}\right)$-hole trap centre pairs. When exciting the $\mathrm{F}\left(\mathrm{Br}^{-}\right)$band with light, a simultaneous destruction of $\mathrm{F}\left(\mathrm{Br}^{-}\right)$and the hole trap centres is observed. All F centres disappear, while $30 \%$ of the hole trap centres remain. These observations support the view that $\mathrm{F}$ centres and hole trap centres are generated as pairs. The fact that not all hole trap centres are recombined with the electrons of the F centres can be explained by the formation of RT-stable F aggregate centres which occurs simultaneously when exciting in the F band at RT. 


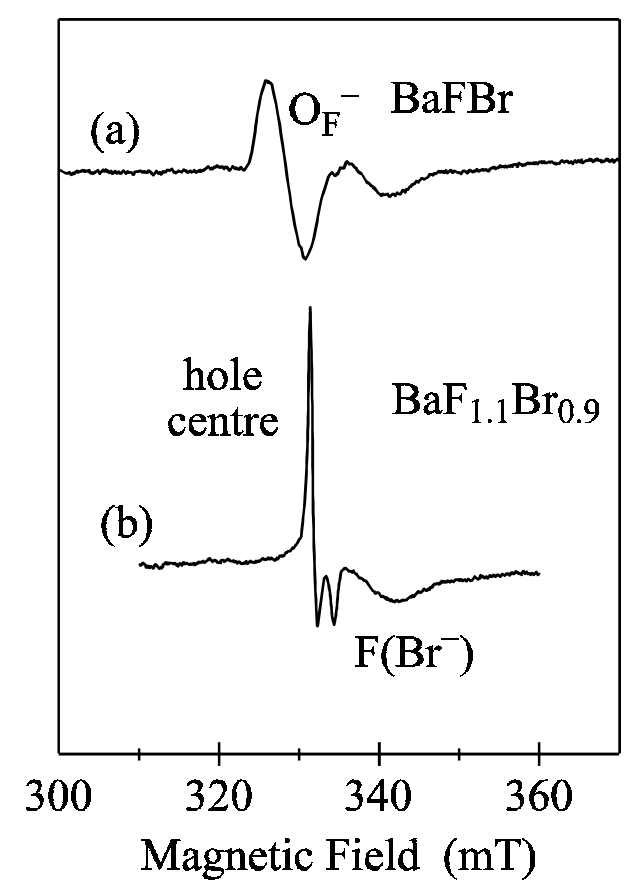

Figure 3.9 Powder EPR spectra of (a) stoichiometric and (b) non-stoichiometric $\mathrm{BaFBr}$ powder after X-irradiation at $\mathrm{RT}$, recorded at $10 \mathrm{~K}$ applying a microwave frequency of $9.335 \mathrm{GHz}$ [52].

After $\mathrm{X}$-irradiation of stoichiometric $\mathrm{BaFBr}$ powder at temperatures below $77 \mathrm{~K}$ intense resonances lines of the $\mathrm{V}_{\mathrm{K}}\left(\mathrm{Br}_{2}^{-}\right)$centres and a weak EPR signal of the $\mathrm{F}\left(\mathrm{Br}^{-}\right)$centres were observed [52]. After annealing up to $300 \mathrm{~K}$, the $\mathrm{V}_{\mathrm{K}}\left(\mathrm{Br}_{2}^{-}\right)$centre lines disappear whereas the $\mathrm{O}_{\mathrm{F}}^{-}$centre line appears. The $\mathrm{V}_{\mathrm{K}}\left(\mathrm{Br}_{2}^{-}\right)$centre decays at about $120 \mathrm{~K}$ [32]. The moving hole is trapped by an $\mathrm{O}_{\mathrm{F}}^{2-}$ impurity to form the $\mathrm{O}_{\mathrm{F}}^{-}$centre [56].

After X-irradiation at temperatures below $77 \mathrm{~K}$ the EPR spectrum of the non-stoichiometric $\mathrm{BaFBr}$ powder showed again intense resonance lines of the $\mathrm{V}_{\mathrm{K}}\left(\mathrm{Br}_{2}^{-}\right)$centres and a weak signal of the $\mathrm{F}\left(\mathrm{Br}^{-}\right)$centres as well as the powder EPR line of the new hole trap centre described above. When using a low X-ray dose a rather strong signal of the $\mathrm{V}_{\mathrm{K}}$ centres appears relative to that of the new hole trap centre. Upon increasing the X-ray dose the signal of the new hole trap centre increases rapidly while that of the $V_{K}$ centre grows at a slower rate. The experiments were not carried as far as reaching a saturation of the $\mathrm{V}_{\mathrm{K}}$ centre signal, but it appears that such a saturation can be reached while no sign of an incipient saturation was observed for the new hole trap centre [52].

After annealing up to $300 \mathrm{~K}$ the $\mathrm{V}_{\mathrm{K}}\left(\mathrm{Br}_{2}^{-}\right)$centre EPR lines have disappeared. This thermal decay of the $\mathrm{V}_{\mathrm{K}}\left(\mathrm{Br}_{2}^{-}\right)$centre did not cause a change in the EPR line intensity 
of the new hole trap centre, but part of the F centre signal was destroyed. Unfortunately, the $\mathrm{S} / \mathrm{N}$ ratio of the $\mathrm{F}$ centre was not good enough, in order to check whether as many $\mathrm{F}$ centres were destroyed as $\mathrm{V}_{\mathrm{K}}$ centres have disappeared.

\subsubsection{Generation of electron and hole trap centres}

The generation of $\mathrm{F}$ centres in non-stoichiometric $\mathrm{BaF}_{1.1} \mathrm{Br}_{0.9}$ powders seems to occur via two mechanisms. At $77 \mathrm{~K}$ two kinds of hole trap centres were observed: $\mathrm{V}_{\mathrm{K}}\left(\mathrm{Br}_{2}^{-}\right)$ centres and the new hole centres, which are considered to be $\mathrm{H}$ centres in the $\mathrm{F}^{-}$sublattice (see below). The $\mathrm{V}_{\mathrm{K}}\left(\mathrm{Br}_{2}^{-}\right)$centre generation at $77 \mathrm{~K}$ seems to indicate that in spite of no oxygen contamination the non-stoichiometric $\mathrm{BaFBr}$ contains also $\mathrm{Br}^{-}$vacancies. Upon annealing to RT the $\mathrm{V}_{\mathrm{K}}\left(\mathrm{Br}_{2}^{-}\right)$centres and part of the $\mathrm{F}\left(\mathrm{Br}^{-}\right)$centres disappear: Mobile $\mathrm{V}_{\mathrm{K}}\left(\mathrm{Br}_{2}^{-}\right)$centres recombine with $\mathrm{F}\left(\mathrm{Br}^{-}\right)$centres. However, some $\mathrm{F}\left(\mathrm{Br}^{-}\right)$centres remain and so does the EPR signal of the new hole trap centre, which is not changed at all upon the availability of mobile $\mathrm{V}_{\mathrm{K}}\left(\mathrm{Br}_{2}^{-}\right)$centres.

Since $\mathrm{F}\left(\mathrm{Br}^{-}\right)$centres and the new hole trap centre are electron and hole trap centres created simultaneously and proportional to each other, it is suggested that $\mathrm{F}^{-}$antisites $\left(\mathrm{F}_{\mathrm{Br}}^{-}\right)$are the origin of the $\mathrm{F}\left(\mathrm{Br}^{-}\right)$centres and the new hole trap centre according to the reaction

$$
\mathrm{F}_{\mathrm{Br}}^{-} \stackrel{\text { X-ray }}{\longrightarrow} \mathrm{F}\left(\mathrm{Br}^{-}\right)+\mathrm{F}_{2, \mathrm{~F}}^{-}
$$

i.e. an $\mathrm{F}\left(\mathrm{Br}^{-}\right)$and an $\mathrm{F}_{2}^{-}$molecular centre in the $\mathrm{F}^{-}$sublattice $\left(\mathrm{F}_{2, \mathrm{~F}}^{-}\right)$are created in an $\mathrm{F}$ $\mathrm{H}$-process where the electron trap centre ( $\mathrm{F}$ centre) is formed in the $\mathrm{Br}^{-}$sublattice and the $\mathrm{H}$ centre is formed in the $\mathrm{F}^{-}$sublattice. To support this suggestion, the powder EPR spectra of the new $\mathrm{H}$ centre was analysed in more detail. It is known that $\mathrm{F}_{2}^{-}$molecular centres on $\mathrm{F}^{-}$sites can be produced in alkali earth fluorides by X-irradiation below $77 \mathrm{~K}$ [57]. There, the two fluorine nuclei of the H-type centre are not equivalent, i.e. one fluorine nucleus is placed on an interstitial site ("fluorine interstitial") whereas the second one is on a regular lattice site ("fluorine substitutional"). The hyperfine (hf) interactions of the fluorine interstitial and the fluorine substitutional are different. 


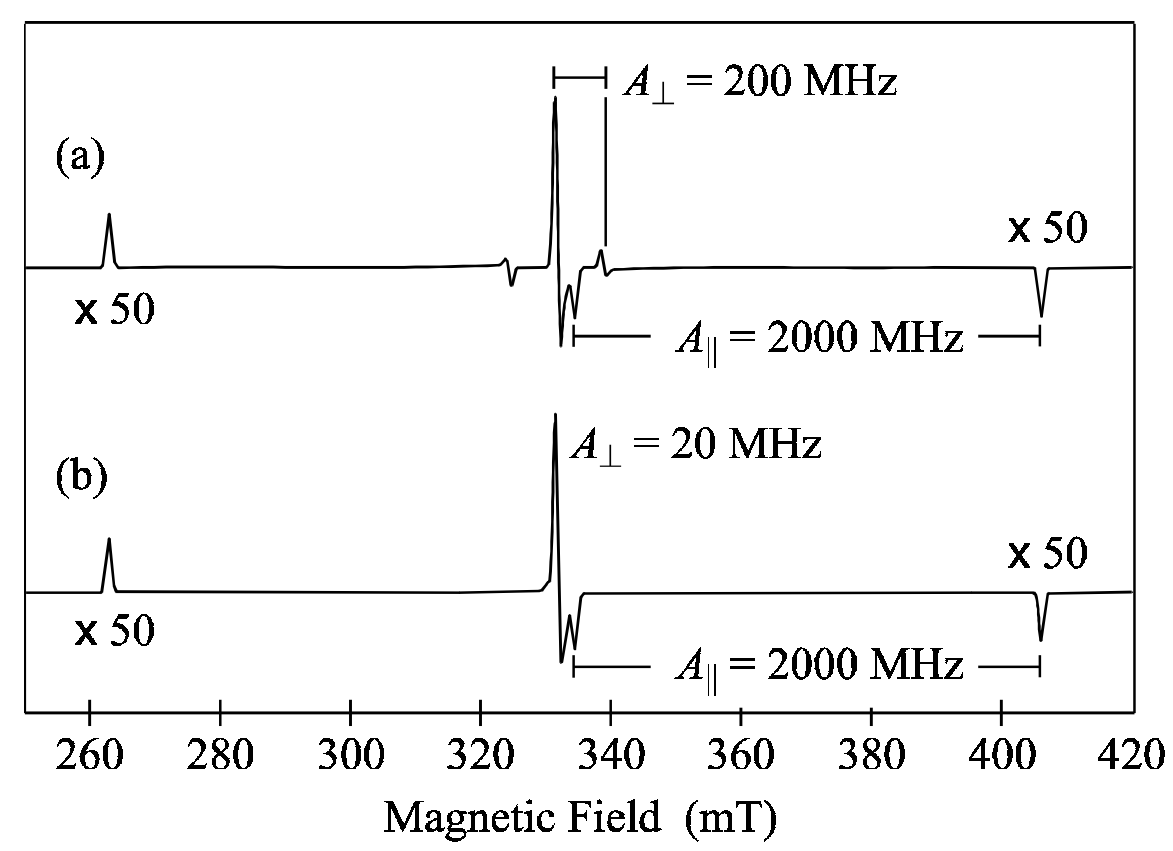

Figure 3.10 Calculated powder EPR spectra of a $\mathrm{F}_{2}^{-}$centre with two equivalent fluorine nuclei. The $g$ tensors with $g_{\perp}=2.02$ and $g_{\|}=2.002$ are axial as well as the ${ }^{19} \mathrm{~F}$ hyperfine tensors. The bars indicate the corresponding hyperfine splittings. The microwave frequency is $9.335 \mathrm{GHz}$ [52].

Figure 3.10 shows two calculated powder EPR spectra of an $\mathrm{F}_{2}^{-}$centre with two equivalent fluorine nuclei. Hereby typical fluorine hf interaction values [57] of $A_{\perp}=$ $200 \mathrm{MHz}$ and $A_{\|}=2000 \mathrm{MHz}$ or $A_{\perp}=20 \mathrm{MHz}$ and $A_{\|}=2000 \mathrm{MHz}$, respectively, were assumed. In both cases the powder EPR lines indicating the hf interaction for an orientation parallel to the molecular axis are very weak. In figure 3.10 the lines are scaled up by a factor of 50. The powder EPR lines indicating the hf interaction perpendicular to the molecular axis are clearly visible in figure 3.10a. Assuming a small value for $A_{\perp}$ (= $20 \mathrm{MHz}$ ), the hf lines are superimposed by the central lines (figure 3.10b). Thus, by comparison with figure $3.9 \mathrm{~b}$, it was proposed that the hole trap centre has $A_{\perp} \leq 20 \mathrm{MHz}$ [52].

Figure 3.11 shows a model of the $\mathrm{F}_{2}^{-}$centre in $\mathrm{BaFBr}$ with two equivalent fluorine nuclei. The molecular axis of the $\mathrm{F}_{2}^{-}$centre with the two equivalent fluorine nuclei is parallel to the $a$-axis ( $b$-axis) of the crystal as calculated in [58]. Since a powder EPR spectrum is a summation over all possible orientations of the magnetic field vector, the information about the orientation of the interaction tensors to the crystal axes is lost. 


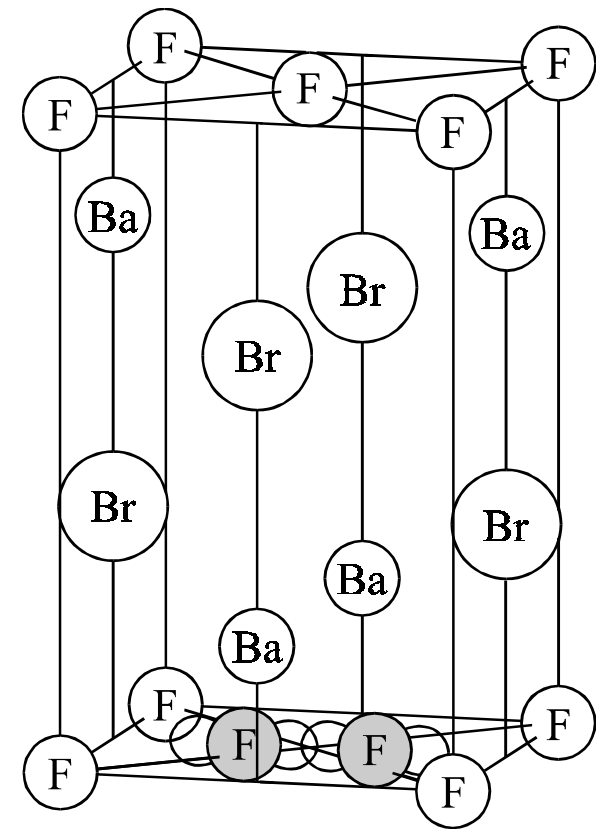

Figure 3.11 Model of an $\mathrm{H}$-type $\mathrm{F}_{2}^{-}$centre in $\mathrm{BaFBr}$ with two equivalent fluorine nuclei after [58].

Therefore, the measured powder EPR spectrum of the new hole trap centre does not allow to decide on the position of the molecular axis.

A qualitative view of the F-H process would be that the valence electron of the $\mathrm{F}^{-}$antisite is excited upon an exciton decay at the $\mathrm{F}_{\mathrm{Br}}^{-}$antisite into a diffuse excited state and that the $\mathrm{F}^{0}$ becomes mobile and moves to the $\mathrm{F}^{-}$sublattice, where it associates itself with a lattice $\mathrm{F}^{-}$to form the $\mathrm{H}\left(\mathrm{F}_{2}^{-}\right)$centre on a fluorine site (figure 3.12). It was calculated by Baetzold [58] that such an $\mathrm{H}$ centre is stable and also that the formation of $\mathrm{F}_{\mathrm{Br}}^{-}$ antisites is exothermic in $\mathrm{BaFBr}$ [59]. It was not possible to say whether the $\mathrm{F}\left(\mathrm{Br}^{-}\right)$and $\mathrm{H}$ centres are nearest neighbours or further apart. Judging from the results obtained in the alkali halides, they will be further apart, otherwise they would probably recombine [60]. 

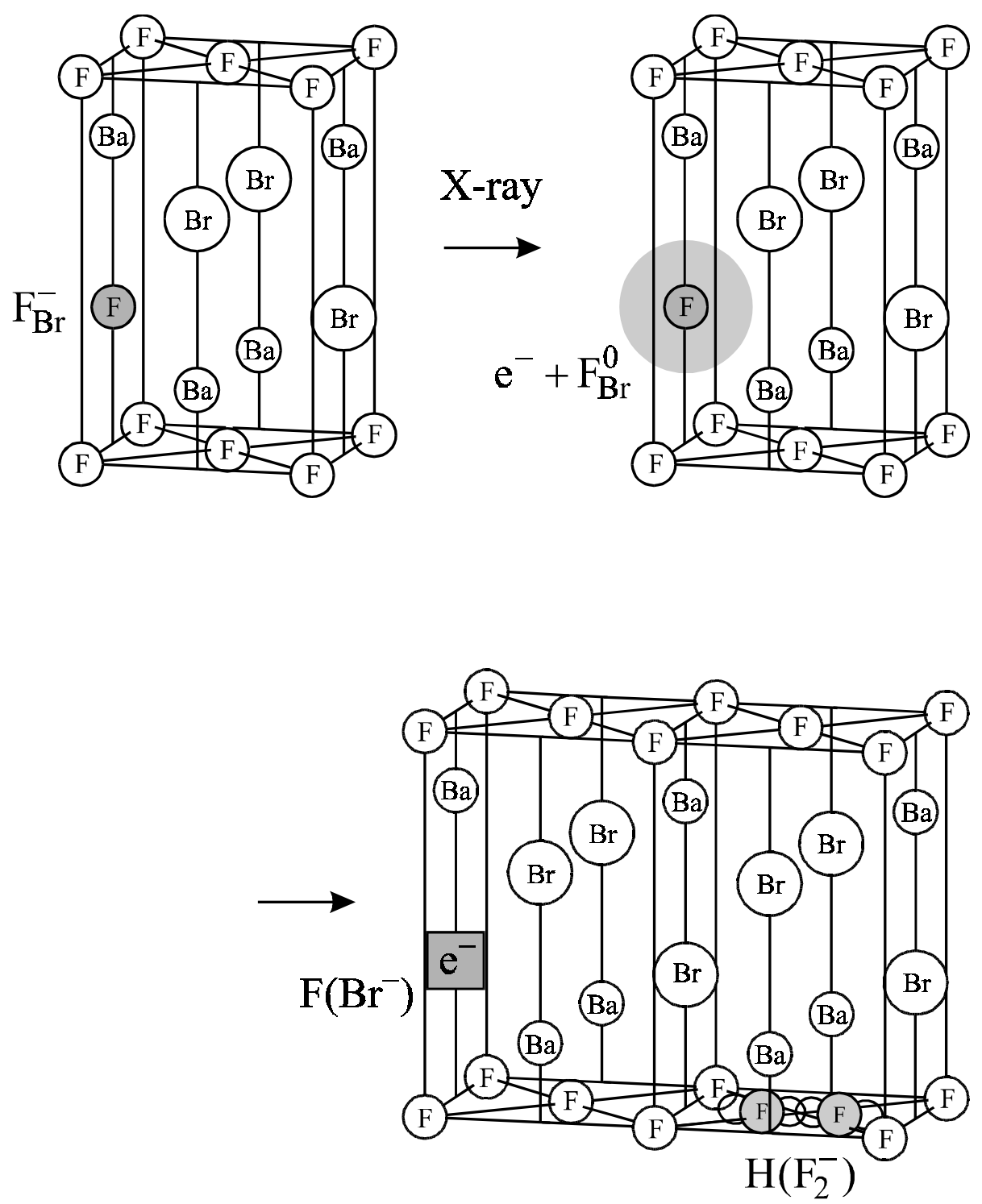

Figure 3.12 Schematic presentation for the F-H centre generation process in nonstoichiometric BaFBr [5].

To be stable at RT it is important for the hole trap centre to avoid recombination with the $\mathrm{F}$ centre. It seems reasonable to argue that the hole can move away more easily from the $\mathrm{F}$ centre in the $\mathrm{F}^{-}$sublattice than in the $\mathrm{Br}^{-}$sublattice. This is because the $\mathrm{F}^{-}-\mathrm{F}^{-}$ distance is much shorter $(3.18 \AA)$ than the $\mathrm{Br}^{-}-\mathrm{Br}^{-}$distance, either in plane $(4.50 \AA)$ or out of plane (3.72 $\AA$ ). Also there are linear [110] or [100] chains of equivalent $\mathrm{F}^{-}$ions, whereas the hole motion within the $\mathrm{Br}^{-}$double layer would need to proceed in a zigzag motion to separate from the $\mathrm{F}$ centre. The former pathway resembles more the situation 
in the alkali halides, where the hole motion is known to proceed along the [110] halogen chain.

The experiments have shown that the $\mathrm{V}_{\mathrm{K}}$ centre production seems to saturate upon increasing the X-ray dose, while that of the $\mathrm{H}$ centre production showed no sign of saturation [52]. The maximum number of $\mathrm{V}_{\mathrm{K}}$ centres depends on the number of $\mathrm{Br}^{-}$vacancies present, which cannot be excessively large, as otherwise a significant change of the density would have been observed. Although it was not possible to determine the number of $\mathrm{V}_{\mathrm{K}}$ centres quantitatively from the powder spectra, it will be of the order of $10^{16} \mathrm{~cm}^{-3}$ and that should be the order of magnitude of the $\mathrm{Br}^{-}$vacancies present. On the other hand, $\mathrm{F}^{-}$antisite defects are "abundant" (10\%) in comparison. Thus, no saturation in $\mathrm{H}$ centre production is expected in line with this model. The decay of the $\mathrm{V}_{\mathrm{K}}\left(\mathrm{Br}_{2}^{-}\right)$centres did not influence the EPR line intensity of the new hole trap centre. Had the moving holes of the decaying $\mathrm{V}_{\mathrm{K}}\left(\mathrm{Br}_{2}^{-}\right)$centres been trapped by $\mathrm{F}^{-}$interstitials, the EPR signal of $\mathrm{H}\left(\mathrm{F}_{2}^{-}\right)$hole trap centres would have been enhanced. This was not the case. Therefore, it was suggested that the $\mathrm{F}\left(\mathrm{Br}^{-}\right)$centre production in non-stoichiometric $\mathrm{BaFBr}$ and the simultaneous generation of the $\mathrm{F}_{2}^{-}$hole trap centre is caused by $\mathrm{F}^{-}$antisites and not by $\mathrm{F}^{-}$interstitials.

\subsection{Red-shift of the PSL excitation upon $\mathrm{Ca}^{2+}$ or $\mathrm{Sr}^{2+}$ doping}

For practical use, apart from a high sensitivity, i.e. a high conversion efficiency of Xrays into photostimulable defects, it is desirable that the phosphors can be stimulated with low laser light intensity, particularly in the infrared spectral region. It was shown that the PSL excitation of $\mathrm{BaFBr}$ doped with $\mathrm{Eu}^{2+}$ can be made sensitive to stimulation further into the infrared by additional $\mathrm{Ca}^{2+}$ or $\mathrm{Sr}^{2+}$ doping [51, 61]. 


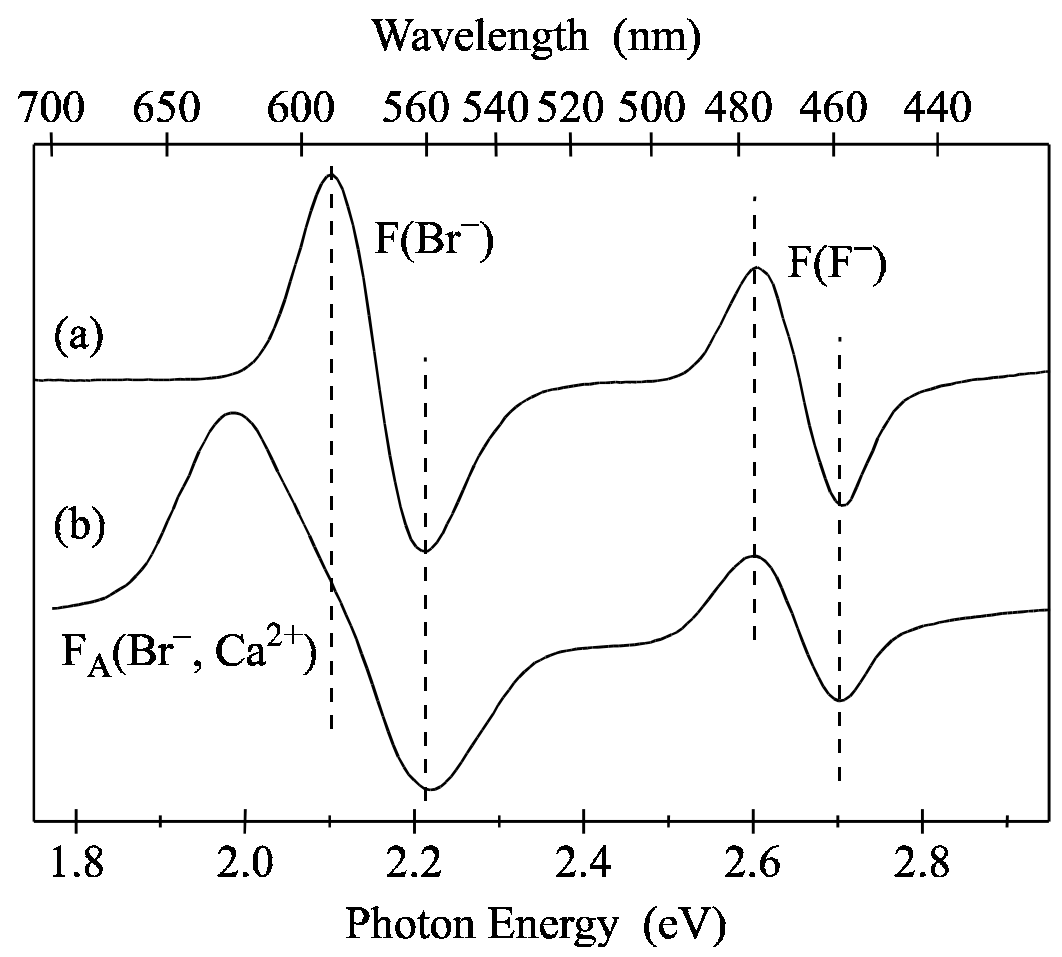

Figure 3.13 MCDA spectra of $\mathrm{F}\left(\mathrm{Br}^{-}\right), \mathrm{F}\left(\mathrm{F}^{-}\right)$, and $\mathrm{F}_{\mathrm{A}}\left(\mathrm{Br}^{-}, \mathrm{Ca}^{2+}\right)$ centres in (a) undoped $\mathrm{BaFBr}$ and (b) $\mathrm{Ba}_{0.98} \mathrm{Ca}_{0.02} \mathrm{FBr}$ after $\mathrm{X}$-irradiation at $\mathrm{RT}$, recorded for $\mathbf{B} \| \mathbf{c}$ at $1.5 \mathrm{~K}[61]$.

After X-irradiation at RT the MCDA of $\mathrm{BaFBr}$, recorded for $\mathbf{B} \| \mathbf{c}$, shows two derivative-like structured bands due to the two possible $\mathrm{F}$ centres $\left(\mathrm{F}\left(\mathrm{Br}^{-}\right)\right.$and $\mathrm{F}\left(\mathrm{F}^{-}\right)$centre) (figure 3.13a) [34]. The centres of these bands, where the MCDA changes sign, are at $2.15 \mathrm{eV}$ and $2.65 \mathrm{eV}$, respectively. In $\mathrm{Ca}^{2+}$ doped $\mathrm{BaFBr}$ these two $\mathrm{F}$ centres are also observed after X-irradiation at RT (figure 3.13b). The shape and spectral position of the MCDA band of the $\mathrm{F}\left(\mathrm{F}^{-}\right)$centre remain the same as in undoped $\mathrm{BaFBr}$, whereas in the case of the $\mathrm{F}\left(\mathrm{Br}^{-}\right)$centre the spectrum shows a superposition of at least two bands. The minimum of the perturbed $\mathrm{F}\left(\mathrm{Br}^{-}\right)$centre band keeps its position while the maximum shifts to lower energies. The perturbed $\mathrm{F}\left(\mathrm{Br}^{-}\right)$centre is supposed to be a $\mathrm{F}$ centre where $\mathrm{a} \mathrm{Ba}^{2+}$ ion in a nearest-neighbour position is replaced by a $\mathrm{Ca}^{2+}$ ion, in analogy to what was observed for $\mathrm{F}$ centres in alkali halides [62]. The MCDA bands observed in $\mathrm{Ca}^{2+}$ doped $\mathrm{BaFBr}$ are thus a superposition of the MCDA band of the unperturbed $\mathrm{F}\left(\mathrm{Br}^{-}\right)$ centre and of that of the perturbed $\mathrm{F}_{\mathrm{A}}\left(\mathrm{Br}^{-}, \mathrm{Ca}^{2+}\right)$ centre. 


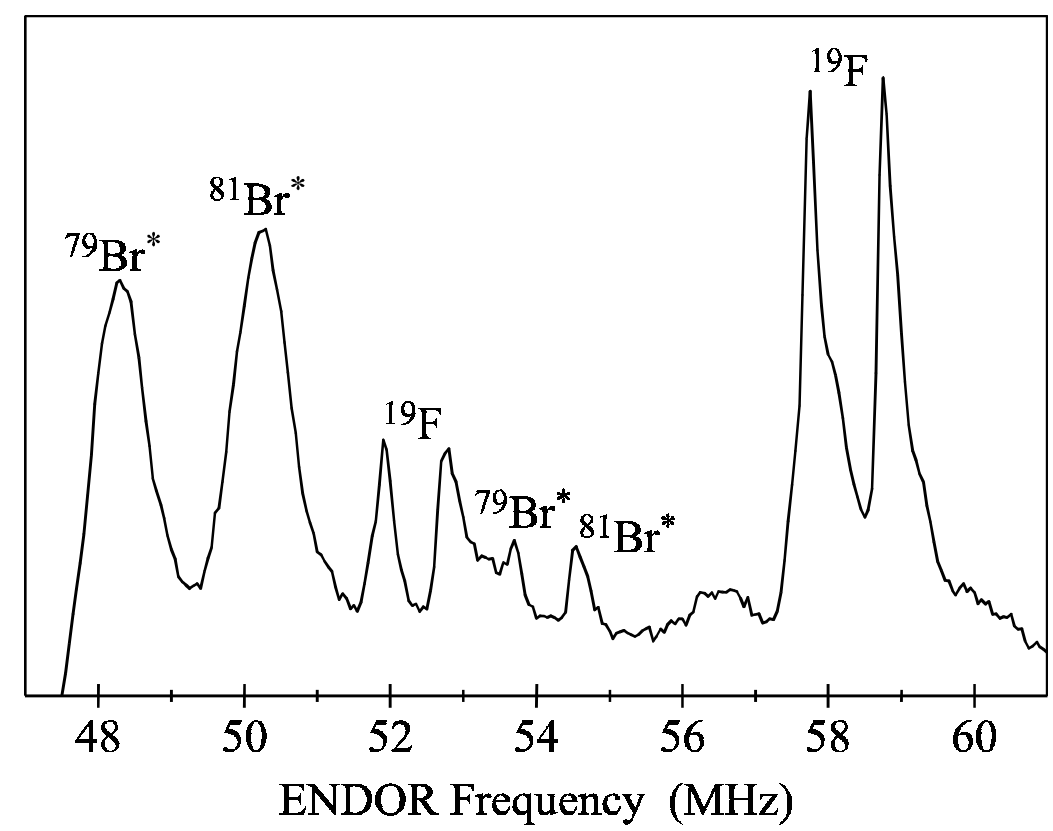

Figure 3.14 MCDA-detected ENDOR spectra of $\mathrm{F}\left(\mathrm{Br}^{-}\right)$and $\mathrm{F}_{\mathrm{A}}\left(\mathrm{Br}^{-}, \mathrm{Ca}^{2+}\right)$ centres in $\mathrm{Ca}^{2+}$ doped $\mathrm{BaFBr}$ after $\mathrm{X}$-irradiation at $\mathrm{RT}, \mathbf{B} \| \mathbf{c}, B=871 \mathrm{mT}$, recorded at a photon energy of $1.984 \mathrm{eV}$ and at $1.5 \mathrm{~K}$ applying a microwave frequency of $24 \mathrm{GHz}$. The lines marked by asterisks are from $\mathrm{F}_{\mathrm{A}}\left(\mathrm{Br}^{-}, \mathrm{Ca}^{2+}\right)$ centres [61].

MCDA-detected ENDOR measurements performed on the perturbed $\mathrm{F}\left(\mathrm{Br}^{-}\right)$centre band yielded that there are resonances due to the unperturbed $\mathrm{F}\left(\mathrm{Br}^{-}\right)$centre as well as those of the $\mathrm{F}_{\mathrm{A}}\left(\mathrm{Br}^{-}, \mathrm{Ca}^{2+}\right)$ centre (figure 3.14). The two ENDOR lines marked with ${ }^{19} \mathrm{~F}$ at about $52 \mathrm{MHz}$ are due to the nearest-neighbouring fluorine nuclei of the unperturbed $\mathrm{F}\left(\mathrm{Br}^{-}\right)$centre in $\mathrm{BaFBr}$ [34]. The two peaks marked with ${ }^{19} \mathrm{~F}^{*}$ at about $58 \mathrm{MHz}$ cannot be explained with the shf interactions of neighbouring nuclei of the unperturbed $\mathrm{F}\left(\mathrm{Br}^{-}\right)$ centre. Thus, they must be due to the $\mathrm{F}_{\mathrm{A}}\left(\mathrm{Br}^{-}, \mathrm{Ca}^{2+}\right)$ centre. A field shift experiment where the shift in the frequency of the ENDOR lines due to the nuclear Zeeman interaction was measured with respect to the variation of the external magnetic field, showed that the lines at $58 \mathrm{MHz}$ originate from fluorine nuclei (for details of the field shift method see e.g. [10]). In analogy with the ENDOR lines of the unperturbed $\mathrm{F}\left(\mathrm{Br}^{-}\right)$centre these signals were assigned to the nearest fluorine neighbours of the $\mathrm{F}_{\mathrm{A}}\left(\mathrm{Br}^{-}, \mathrm{Ca}^{2+}\right)$ centre. This assignment was confirmed by the ENDOR analysis of the conventional ENDOR measurements. The splitting of the ${ }^{19} \mathrm{~F}$ and the ${ }^{19} \mathrm{~F}^{*}$ lines for the magnetic field parallel to the $c$-axis is caused by a slight misorientation of the crystal. The other four ENDOR lines are caused by the nearest-neighbouring bromine nuclei of the $\mathrm{F}_{\mathrm{A}}\left(\mathrm{Br}^{-}\right.$, 


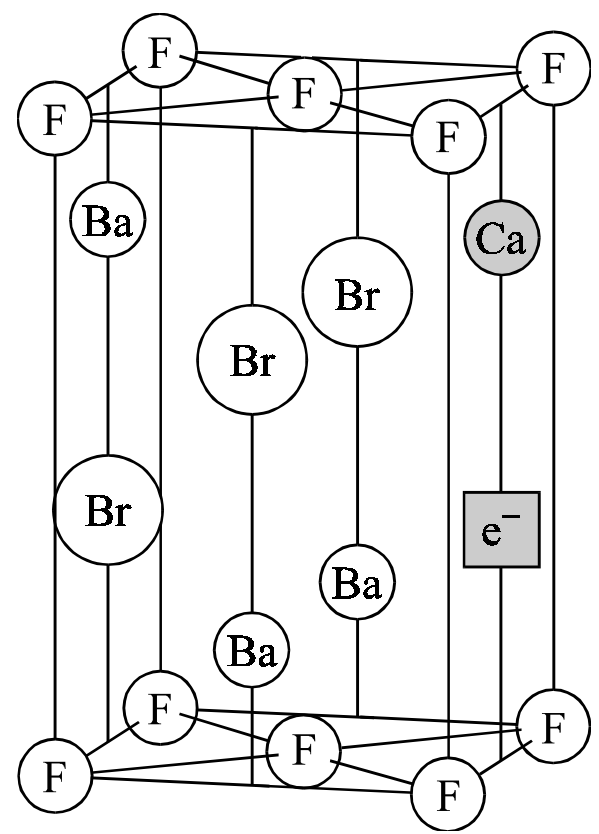

Figure 3.15 Defect model of the $\mathrm{F}_{\mathrm{A}}\left(\mathrm{Br}^{-}, \mathrm{Ca}^{2+}\right)$ centre in $\mathrm{Ca}^{2+}$ doped $\mathrm{BaFBr}$. One $\mathrm{Ca}^{2+}$ replaces either the upper or the lower $\mathrm{Ba}^{2+}$ along the $c$-axis [61].

$\left.\mathrm{Ca}^{2+}\right)$ centre. For the magnetic field exactly parallel to the $c$-axis the ${ }^{19} \mathrm{~F}$ ENDOR lines of the $\mathrm{F}\left(\mathrm{Br}^{-}\right)$centre coincide, so do the ${ }^{19} \mathrm{~F}^{*}$ lines for the $\mathrm{F}_{\mathrm{A}}\left(\mathrm{Br}^{-}, \mathrm{Ca}^{2+}\right)$ centre which shows that the four ions of the first fluorine shell are magnetically equivalent. Therefore, the perturbing $\mathrm{Ca}^{2+}$ ion must be located on the fourfold axis of the $\mathrm{F}_{\mathrm{A}}\left(\mathrm{Br}^{-}, \mathrm{Ca}^{2+}\right)$ centre (figure 3.15). A more detailed investigation of the symmetry of the $\mathrm{Ca}^{2+}$ perturbed $\mathrm{F}\left(\mathrm{Br}^{-}\right)$centre was made with conventional ENDOR measurements [61].

A rough estimate of the relative concentrations of the $\mathrm{F}_{\mathrm{A}}\left(\mathrm{Br}^{-}, \mathrm{Ca}^{2+}\right)$ and the $\mathrm{F}\left(\mathrm{Br}^{-}\right)$ centre created with X-irradiation at RT can be made, assuming that the ENDOR effect of the nearest fluorine lines is not much different for both defects. The ratio of the $\mathrm{F}_{\mathrm{A}}\left(\mathrm{Br}^{-}, \mathrm{Ca}^{2+}\right)$ centre to $\mathrm{F}\left(\mathrm{Br}^{-}\right)$centre is approximately $3: 1$, i.e. $75 \%$ of $\mathrm{F}$ centres are $\mathrm{F}_{\mathrm{A}}$ centres. It seems that the exciton decay mechanism producing $\mathrm{F}$ centres upon $\mathrm{X}$ irradiation occurs preferentially at the $\mathrm{Ca}^{2+}$ perturbed sites. Otherwise it would not have been possible to observe such a large ratio between $F_{A}$ and $F$ centres which deviates from pure statistical probability according to the doping by almost two orders of magnitude.

The observed red-shift of the $\mathrm{F}_{\mathrm{A}}$ centre absorption band can be explained by a shallower Madelung potential well binding the electron of the $\mathrm{F}$ centre. The smaller $\mathrm{Ca}^{2+}$ ion (ionic radius $0.99 \AA$ ) replacing the larger $\mathrm{Ba}^{2+}$ ion (ionic radius $1.34 \AA$ ) along the $c$-axis 
may be relaxed away from the $\mathrm{Br}^{-}$vacancy leaving a larger space for the $\mathrm{F}$ centre electron. According to the Mollwo-Ivey relation the peak energy of the F centre absorption band is proportional to $1 / d^{2}$ where $d$ is the lattice constant [62]. The lattice constant will be increased along the $c$-axis resulting in a red-shift of the optical absorption band. However, it is not possible to decide which of the two $\mathrm{Ba}^{2+}$ ions along the $c$-axis is replaced by $\mathrm{Ca}^{2+}$. It seems highly improbable that both are substituted by $\mathrm{Ca}^{2+}$.

\subsection{Surrounding of the activator $\mathrm{Eu}^{2+}$}

It is reasonable to assume that $\mathrm{Eu}^{2+}$ substitutes for $\mathrm{Ba}^{2+}$ in $\mathrm{BaFBr}$. An EPR investigation [63] yielded an axial centre with the $z$-axes of the fine structure and hf tensors of $\mathrm{Eu}^{2+}$ along the $c$-axis as expected for such a site [63]. What could not be inferred from EPR was whether or not there are lattice relaxations about the $\mathrm{Eu}^{2+}$. The ionic radius of the replaced $\mathrm{Ba}^{2+}$ is $0.134 \mathrm{~nm}$, that of $\mathrm{Eu}^{2+} 0.109 \mathrm{~nm}$, i.e. about $20 \%$ smaller. Therefore, a substantial lattice relaxation about $\mathrm{Eu}^{2+}$, or a non-central position of $\mathrm{Eu}^{2+}$, can be anticipated. This is of interest since a lattice relaxation could in principle be an explanation for the observation that upon X-irradiation, electron and hole trap centres are created with a spatial correlation to the activator $\mathrm{Eu}^{2+}$, an important feature for the functioning of $\mathrm{BaFBr}: \mathrm{Eu}^{2+}$ as a storage phosphor. Information about this question could be obtained from an ENDOR investigation, in which the shf interaction tensors with the lattice neighbours are determined [64].

\subsubsection{EPR and ENDOR of crystalline BaFBr: $\mathrm{Eu}^{2+}$}

The EPR spectrum of $\mathrm{Eu}^{2+}$ in $\mathrm{BaFBr}$ consists of seven fine-structure groups each having a hf splitting of 12 lines. $\mathrm{Eu}^{2+}$ has an $S=7 / 2$ ground state and two stable isotopes: ${ }^{151} \mathrm{Eu}$ with $I=5 / 2$ and $47.82 \%$ abundance and ${ }^{153} \mathrm{Eu}$ with $I=5 / 2$ and $52.18 \%$ abundance. Each Eu isotope thus has a hf structure of 6 lines; since the two nuclear $g$ factors differ significantly so do the hf interactions $\left(g_{\mathrm{n}}\left({ }^{151} \mathrm{Eu}\right)=1.389, g_{\mathrm{n}}\left({ }^{153} \mathrm{Eu}\right)=0.6134\right)$, and consequently the two sextets are clearly resolved [63].

Figure 3.16 shows a ENDOR spectrum of ${ }^{151} \mathrm{Eu}^{2+}$ measured in the $m_{S}$ transition -1/2 $\leftrightarrow+1 / 2$ for a orientation of the magnetic field parallel to the crystal $c$-axis. Besides the two lines of ${ }^{151} \mathrm{Eu}$ at 4.1 and $20.3 \mathrm{MHz}$ there are several intense lines due to ${ }^{19} \mathrm{~F}$. Around the Larmor frequency of ${ }^{19} \mathrm{~F}$ at $13.2 \mathrm{MHz}$ there are lines at $11.8 \mathrm{MHz}$ and 


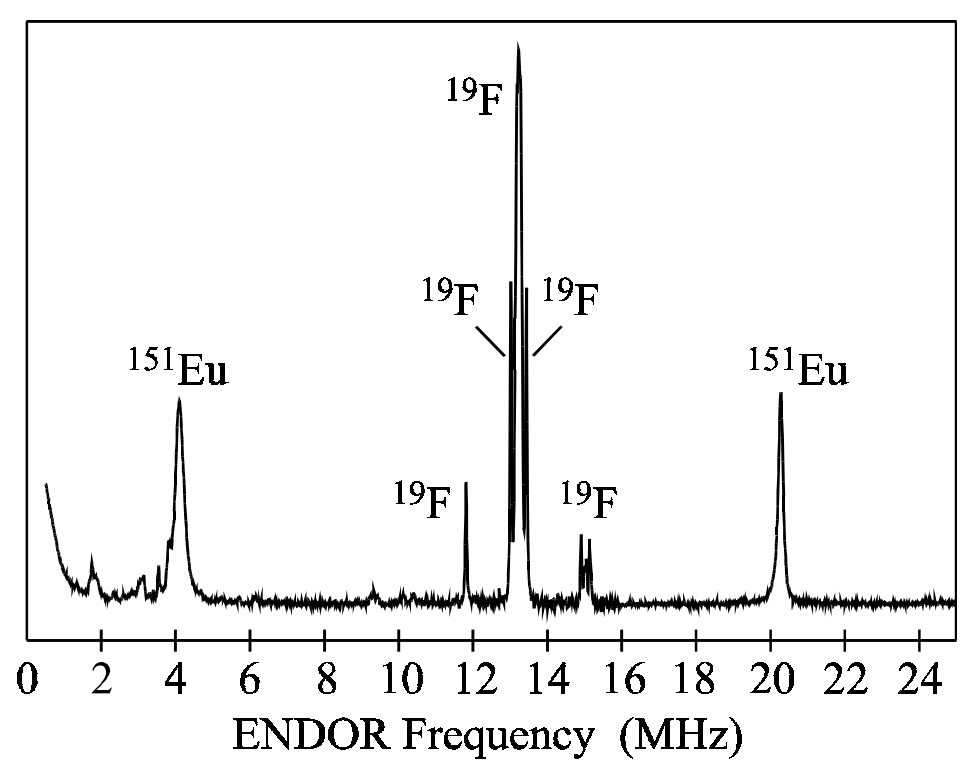

Figure 3.16 ENDOR spectrum of $\mathrm{Eu}^{2+}$ in crystalline $\mathrm{BaFBr}$ for $\mathbf{B} \| \mathbf{c}, B=331.1 \mathrm{mT}$ $\left(m_{S}\right.$ transition $\left.-1 / 2 \leftrightarrow+1 / 2\right), T=20 \mathrm{~K}$ and a microwave frequency of 9.345 GHz [64].

15.0 MHz from the nearest and at $13.0 \mathrm{MHz}$ and $13.4 \mathrm{MHz}$ from the next-nearest fluorine nuclei as was determined from their angular dependence. The low intensity lines at low frequency are probably due to ${ }^{79} \mathrm{Br}$ and ${ }^{81} \mathrm{Br}$. They were not analysed. Ba lines were not seen, most likely due to their low abundance of magnetic isotopes ${ }^{135} \mathrm{Ba}(6.6 \%)$ and ${ }^{137} \mathrm{Ba}(11.3 \%)$ [64].

In figure 3.17 the fluorine nuclei the shf interaction of which with the $\mathrm{Eu}^{2+}$ activator were determined are shaded grey. The analysis of these fluorine shf interactions yielded that no significant shift of $\mathrm{Eu}^{2+}$ away from the regular $\mathrm{Ba}^{2+}$ position occurs [64].

\subsubsection{EPR and ENDOR of powdered BaFBr: $\mathrm{Eu}^{2+}$}

EPR on powdered $\mathrm{BaFBr}$ doped with $\mathrm{Eu}^{2+}$ yielded resonances in a magnetic field range from 200-500 $\mathrm{mT}$ in X-band $(9.235 \mathrm{GHz})$ [64]. The strongest lines are seen between 300 and $370 \mathrm{mT}$ in agreement with the EPR angular dependence of a single crystal, where the intense line groups of the $m_{S}$ transitions $-3 / 2 \leftrightarrow-1 / 2,-1 / 2 \leftrightarrow+1 / 2$ and $+1 / 2 \leftrightarrow+3 / 2$ occur. The spectrum is asymmetric with respect to its transition through zero at $340 \mathrm{mT}$. This is a consequence of the rather high fine structure interaction. 


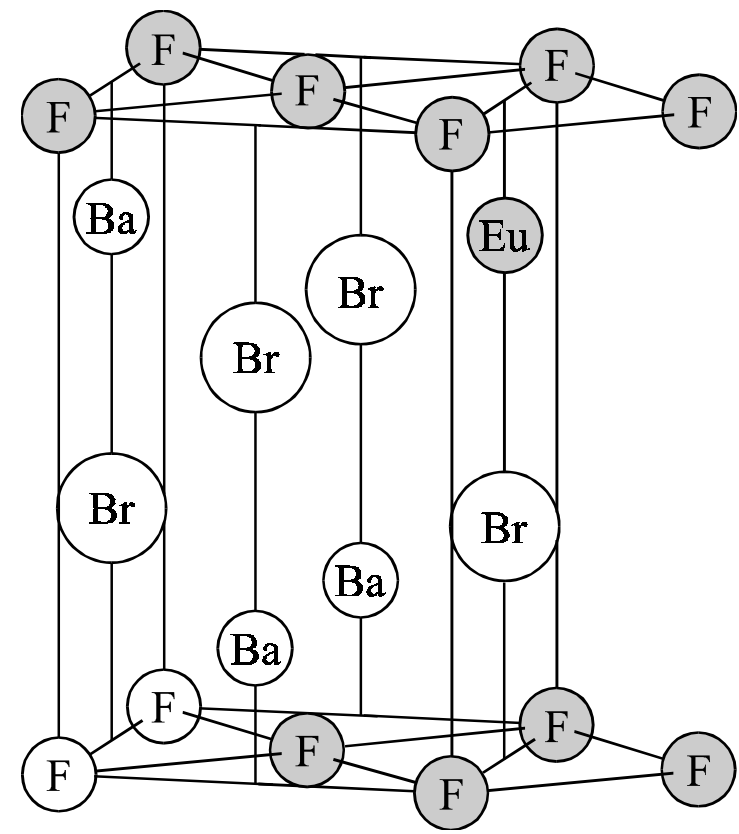

Figure 3.17 Centre model of the $\mathrm{Eu}^{2+}$ centre in $\mathrm{BaFBr}$. The defect and its nearest fluorine neighbours the shf interactions of which were determined are shaded grey.

The powder-ENDOR spectrum measured at $331 \mathrm{mT}$ is shown in figure 3.18. In order to identify the lines, magnetic field shift measurements were performed (see e.g., [10]). The powder spectrum is a superposition of many single spectra due to the different orientations of the crystalline axes with respect to the magnetic field. If the magnitude of the magnetic field is changed, the ENDOR lines are measured in single crystal EPR lines which belong to different magnetic field orientations, i.e. upon shifting the magnetic field the field orientation is changed indirectly. Here, because of the possibility of comparison with the single crystal spectra and their angular dependencies, the assignment of other lines can be made.

The broad intense line between 12.5 and $14 \mathrm{MHz}$ is centred around the Larmor frequency of ${ }^{19} \mathrm{~F}$. The assignment of the ENDOR lines at 10.4 and $16.5 \mathrm{MHz}$, which belong to the nearest fluorine neighbours, was achieved by magnetic field shift measurements in the field range between 320 and $350 \mathrm{mT}$. Between 325 and $345 \mathrm{mT}$ the lines are intense. Choosing magnetic field values outside this range, e.g. 320 or $350 \mathrm{mT}$, the lines decrease to about a third of the former intensity. The angular dependence of the single crystal EPR lines yielded that the EPR $m_{S}$ transition $-1 / 2 \leftrightarrow+1 / 2$ is within the range of 325 to $345 \mathrm{mT}$ for all orientations of the magnetic field. The angular depend- 


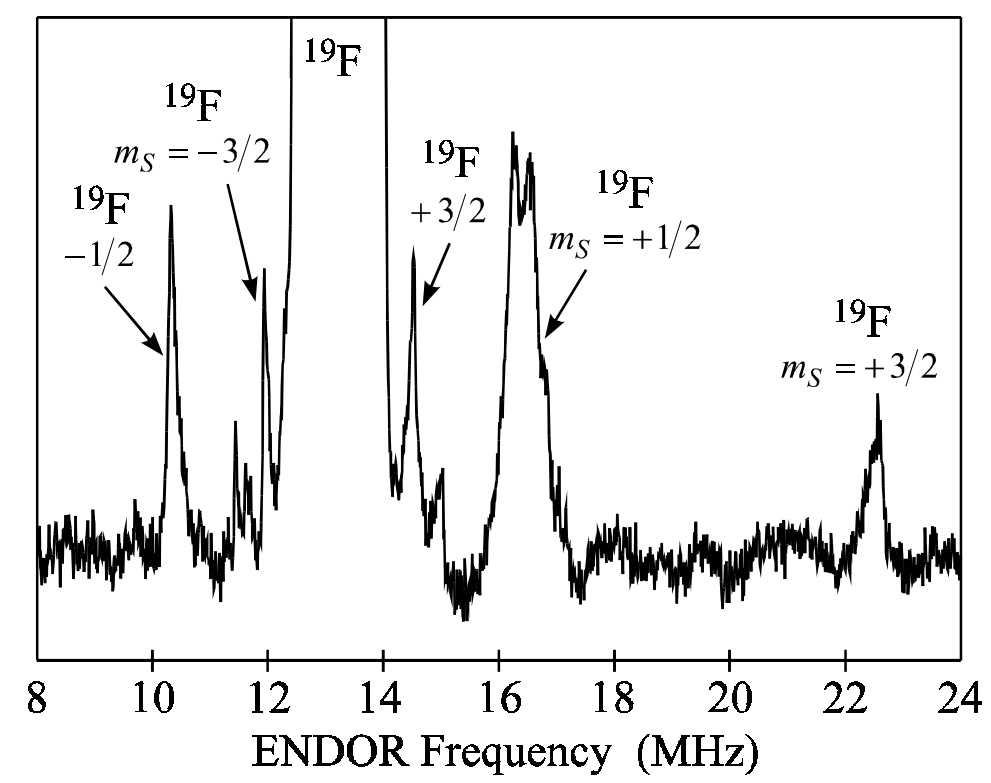

Figure 3.18 Powder ENDOR spectrum of $\mathrm{Eu}^{2+}$ in $\mathrm{BaFBr}$ for $B=331 \mathrm{mT}, T=20 \mathrm{~K}$ and a microwave frequency of $9.233 \mathrm{GHz}$. The ${ }^{19} \mathrm{~F}$ lines of the nearest and the next-nearest fluorine neighbours as well as their $m_{S}$ quantum numbers are identified. The frequency dependent background is subtracted [64].

ence of the ENDOR lines of the nearest fluorine neighbours belonging to this EPR transition have many lines per angle in the range of 10.4-16.5 MHz. Therefore, choosing the magnetic field within the range of 325 to $345 \mathrm{mT}$ one induces the EPR $m_{S}$ transition $-1 / 2 \leftrightarrow+1 / 2$ and thus the corresponding fluorine ENDOR lines. If the magnetic field is $320 \mathrm{mT}$ or $350 \mathrm{mT}$, this EPR transition is not saturated, the corresponding fluorine lines do not contribute to the ENDOR spectrum. One can only see ENDOR lines belonging to the weaker contributions of the neighbouring fine-structure groups $-3 / 2 \leftrightarrow$ $-1 / 2$ and $+1 / 2 \leftrightarrow+3 / 2$. In this way the assignment of the ENDOR lines presented in figure 3.18 was made. Even a small change in the local structure of $\mathrm{Eu}^{2+}$, i.e. a change in the shf interaction parameters by only $10 \%$, would have been seen in the corresponding powder ENDOR spectra by a significant shift of the powder ENDOR lines [64].

\subsubsection{Influence of the production process}

Another question is whether the local environment of $\mathrm{Eu}^{2+}$ is changed, depending on how the phosphor is produced. Stoichiometric or non-stoichiometric BaFBr powders 
could, in principle, differ from the single crystal environment around $\mathrm{Eu}^{2+}$ due to the different production processes [52]. Since, in particular, it was interesting to study details about the local structure of $\mathrm{Eu}^{2+}$ in non-stoichiometric $\mathrm{BaFBr}$, which can only be made as a powder, the above described investigations were performed: First, EPR and ENDOR of $\mathrm{Eu}^{2+}$ in crystalline BaFBr were measured and analysed. The single crystal was afterwards crushed to a powder, and the powder EPR as well as the powderENDOR spectrum were recorded and analysed using the single crystal data. Then, the powder-ENDOR spectra of $\mathrm{Eu}^{2+}$ in stoichiometric and in non-stoichiometric $\mathrm{BaFBr}$ powders, generated by means of a solid state reaction firing appropriate mixtures of fluorides and bromides [52], were measured. It turned out that no significant shift of $\mathrm{Eu}^{2+}$ away from the regular $\mathrm{Ba}^{2+}$ position occurs, and that the local properties of $\mathrm{Eu}^{2+}$ are identical within experimental error in all investigated samples. 


\section{Chapter 4}

\section{Alkali halides and elpasolites}

One of the disadvantages of present X-ray storage phosphors is still the unsatisfactory spatial resolution of the $\mathrm{X}$-ray images. The light scattering of the scanning laser beam during the read-out process is certainly one of the reasons for that. The BaFBr crystallites in the X-ray storage phosphor image plates are birefringent, a consequence of the matlockite structure. With respect to the light scattering it would be advantageous to replace the optically anisotropic $\mathrm{BaFBr}$ crystallites by optically isotropic crystals, e.g. cubic crystals. It is, therefore, a challenge to find cubic X-ray storage phosphors systems which have a similarly high performance as a standard $\mathrm{BaFBr}: \mathrm{Eu}^{2+}$ phosphor

\begin{tabular}{ccccc}
\hline \hline Storage phosphor & $\begin{array}{c}\text { stimulation } \\
(\mathrm{nm})\end{array}$ & $\begin{array}{c}\mathrm{CE} \\
\left(\mathrm{pJ} / \mathrm{mm}^{2} / \mathrm{mR}\right)\end{array}$ & $\begin{array}{c}\mathrm{SE} \\
\left(\mu \mathrm{J} / \mathrm{mm}^{2}\right)\end{array}$ & $\begin{array}{c}\mathrm{CE} / \mathrm{SE} \\
(\text { arb. units })\end{array}$ \\
\hline $\mathrm{BaFBr}: \mathrm{Eu}^{2+}$ & $633^{1)}$ & 20.4 & 15.7 & 1300 \\
& $680^{2)}$ & 14.4 & 28 & 510 \\
$\mathrm{RbBr}: \mathrm{In}^{+}$ & $680^{2)}$ & 1.9 & 25.0 & 77 \\
$\mathrm{RbBr}: \mathrm{Ga}^{+}$ & $680^{2)}$ & 5.6 & 3.9 & 1470 \\
$\mathrm{CsBr}: \mathrm{In}^{+}$ & $680^{2)}$ & 3.0 & 23.0 & 140 \\
$\mathrm{CsBr}: \mathrm{Ga}^{+}$ & $680^{2)}$ & 5.4 & 4.3 & 1370 \\
\hline \hline
\end{tabular}

Table 4.1 Performance of some $\mathrm{In}^{+}$and $\mathrm{Ga}^{+}$doped alkali halide X-ray storage phosphors in comparison with a standard $\mathrm{BaFBr}: \mathrm{Eu}^{2+} \mathrm{X}$-ray storage phosphor screen after [8]. ${ }^{1)}$ HeNe-laser, ${ }^{2)}$ laser diode. 
screen. For special applications, in particular for non-destructive testing, systems can also be used where e.g. a longer radiative life time of the activator luminescence is not a hindrance, because the read-out time can be longer or the screen is smaller, i.e. less pixels have to be read out.

There are two cubic systems which have proved to have storage properties and which have been investigated very intensely (mostly by luminescence spectroscopy): Alkali halides doped with $\mathrm{Ga}^{+}, \mathrm{In}^{+}$or $\mathrm{Tl}^{+}$(e.g. [65, 66]) and $\mathrm{Ce}^{3+}$ or $\mathrm{Pr}^{3+}$ doped elpasolites (e.g. [9]). In table 4.1 some of the best alternative systems to $\mathrm{BaFBr}: \mathrm{Eu}^{2+}$ are listed for which the conversion efficiency (CE) and the stimulation energy (SE) as well as the quantity $\mathrm{CE} / \mathrm{SE}$ are given in comparison to a standard $\mathrm{BaFBr} \mathrm{Eu}^{2+}$ screen. It is seen that the two alkali halides $\mathrm{RbBr}: \mathrm{Ga}^{+}$and $\mathrm{CsBr}: \mathrm{Ga}^{+}$have excellent figures of merit. In the following a short characterisation is presented for the $\mathrm{X}$-ray storage phosphors $\mathrm{KBr}: \mathrm{In}^{+}$and $\mathrm{RbI}: \mathrm{Tl}^{+}$, whereas $\mathrm{RbBr}: \mathrm{Ga}^{+}$and $\mathrm{CsBr}: \mathrm{Ga}^{+}$are described in more detail because of their importance. After that first results on $\mathrm{Eu}^{2+}$-doped $\mathrm{RbBr}$ and $\mathrm{CsBr}$ are presented. Finally, the elpasolites $\mathrm{Cs}_{2} \mathrm{NaYF}_{6}: \mathrm{Ce}^{3+}$ and $\mathrm{Cs}_{2} \mathrm{NaYF}_{6}: \mathrm{Pr}^{3+}$ are briefly characterised.

\subsection{KBr:In ${ }^{+}$}

$\mathrm{KBr}: \mathrm{In}^{+}$has been shown to have storage and PSL properties [6]. Although from the practical point of view it will not be a very important system, since $\mathrm{K}$ is not heavy enough to guarantee a sufficient stopping power. It was, however, interesting to study

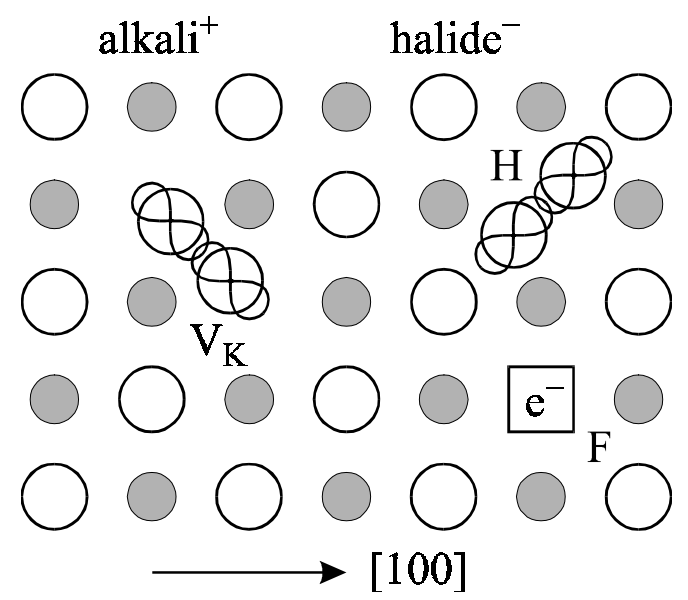

Figure 4.1 Models of $\mathrm{F}, \mathrm{V}$ and $\mathrm{H}$ centres in cubic alkali halides. 


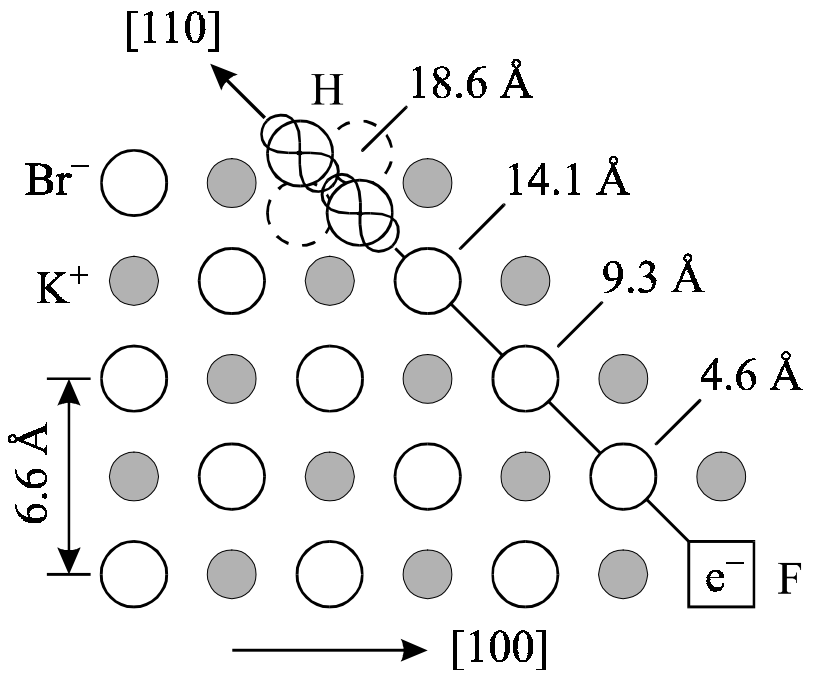

Figure 4.2 Schematic representation of the spatial correlation between $\mathrm{F}$ and $\mathrm{H}$ centre pairs in $\mathrm{KBr}$ as estimated from cross relaxation spectroscopy. The orientation of the $\mathrm{H}$ centre cannot be inferred from the experiments [60].

the mechanism in order to see whether in this case the activator plays the role of the hole trap centre.

It was shown with MCDA and MCDA-EPR that the radiation damage centres formed after X-irradiation at RT are $\operatorname{In}^{2+}, \operatorname{In}^{0}(1)$ ( $\mathrm{In}^{0}$ next to an anion vacancy [67]) and $\mathrm{F}$ centres [68]. Upon photostimulation into the $\mathrm{F}$ band at $2.06 \mathrm{eV}(602 \mathrm{~nm})$, two luminescence bands of $\mathrm{In}^{+}$are observed around $2.9 \mathrm{eV}(428 \mathrm{~nm})$ and $2.4 \mathrm{eV}(517 \mathrm{~nm})$ [6, 69, 70, 71]. In [68] it was shown, that there is, as in $\mathrm{BaFBr}: \mathrm{Eu}^{2+}$, a replenishment effect, but only for a low (100 ppm) $\mathrm{In}^{+}$doping level. For a high (1000 ppm) $\mathrm{In}^{+}$doping level, no replenishment effect was observed [8]. The PSL active centres in $\mathrm{KBr}: \mathrm{In}^{+}$are F centres and $\operatorname{In}^{2+}$ hole trap centres. The role of $\operatorname{In}^{0}(1)$ centres is not clear.

The PSL efficiency of $\mathrm{KBr}: \mathrm{In}^{+}$depends clearly on the activator concentration. It was largest for an $\mathrm{In}^{+}$concentration between $8 \cdot 10^{16}$ and $2 \cdot 10^{17} \mathrm{~cm}^{-3}$ [72]. Investigations of the stability of the PSL active centres showed that after X-irradiation at RT $20 \%-30 \%$ of the initially generated $\mathrm{F}$ centres decay within 20-30 min [68]. 


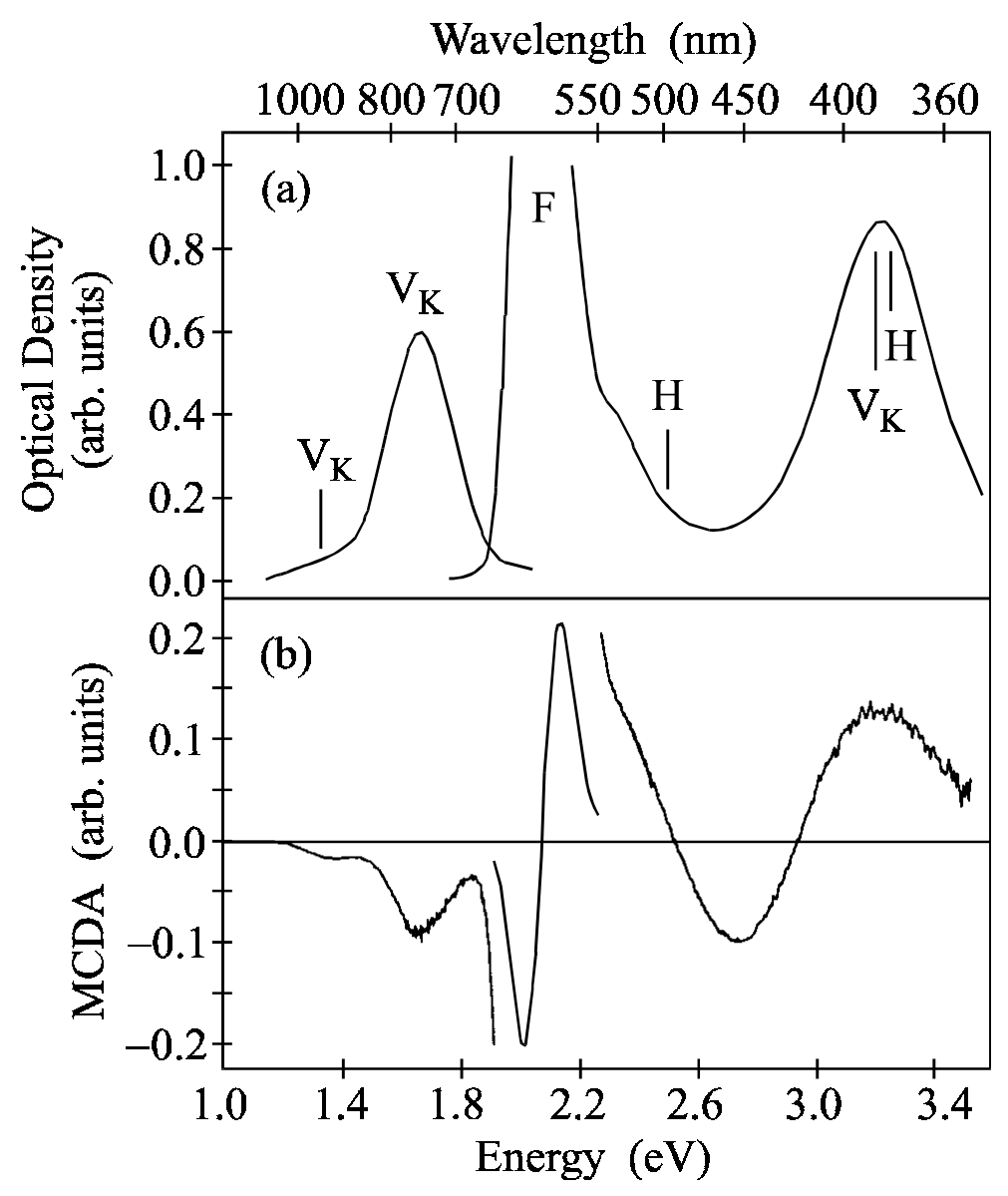

Figure 4.3 (a) Absorption of $\mathrm{F}, \mathrm{V}_{\mathrm{K}}$ and $\mathrm{H}$ centres in $\mathrm{KBr}$ after $\mathrm{X}$-irradiation below $20 \mathrm{~K}$. (b) MCDA spectrum of $\mathrm{KBr}$ after $\mathrm{X}$-irradiation at $4.2 \mathrm{~K}$, recorded at $1.5 \mathrm{~K}[60]$.

\subsubsection{Generation of electron and hole trap centres}

After X-irradiation of $\mathrm{KBr}: \mathrm{In}^{+}$at $4.2 \mathrm{~K}$ the MCDA spectra of $\mathrm{F}, \mathrm{V}_{\mathrm{K}}$ and $\mathrm{H}$ centres have been detected [68]. For a high $(1000 \mathrm{ppm}) \mathrm{In}^{+}$doping level also $\mathrm{In}^{2+}$ hole trap centres were found [8]. $\mathrm{H}$ centres are found as result of the decay of self-trapped excitons, whereby $\mathrm{F}$ centres are formed simultaneously [30]. For the creation of $\mathrm{V}_{\mathrm{K}}$ centres electron traps have to be present in the crystal. However, $\mathrm{V}_{\mathrm{K}}$ centres could also be generated in particularly pure $\mathrm{KBr}$ [60], i.e. there are most probably $\mathrm{Br}^{-}$vacancies present which capture the electrons. A schematic representation of these centres in cubic alkali halides is shown in figure 4.1. No $\operatorname{In}^{0}(1)$ centres could be observed when X-irradiating at $4.2 \mathrm{~K}$ in contrast to what was found after X-irradiation at RT. It was shown by cross- 


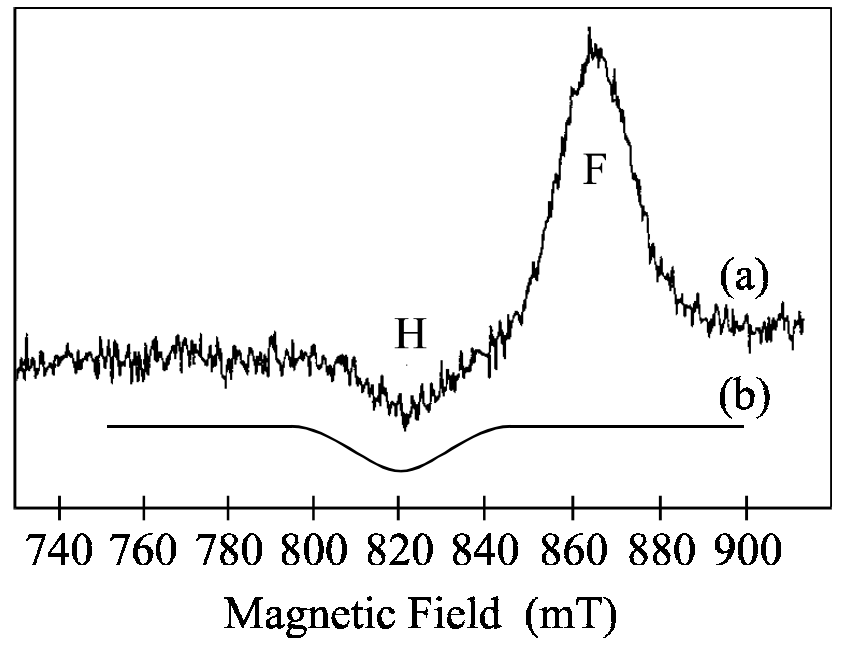

Figure 4.4 (a) MCDA-EPR spectrum of $\mathrm{KBr} X$-irradiated at $4.2 \mathrm{~K}$, recorded at $1.5 \mathrm{~K}$ for $\mathbf{B} \|$ [100]. (b) EPR simulation of $\mathrm{H}$ centres in $\mathrm{KBr}$ with their axes perpendicular to $\mathbf{B}$ using $g_{\perp}=2.074, A_{\perp}=5 \mathrm{mT}$ and a halfwidth of $5 \mathrm{mT}$ for the hyperfine lines [60].

relaxation (CR) spectroscopy in undoped $\mathrm{KBr}$ that after $\mathrm{X}$-irradiation at $4.2 \mathrm{~K}$ all $\mathrm{F}$ and $\mathrm{H}$ centres are spatially correlated. A quantitative analysis of the $\mathrm{CR}$ effects yielded a F$\mathrm{H}$ pair separation of four lattice spacings along the [110] directions as shown in figure $4.2[60]$.

The dominant band in the optical absorption spectrum (figure 4.3a) as well as in the corresponding MCDA spectrum (figure 4.3b) is that of the F centre at $2.06 \mathrm{eV}(602 \mathrm{~nm})$ $[60,62,68]$. The three extrema in the MCDA at $3.2 \mathrm{eV}, 1.65 \mathrm{eV}$ and $1.4 \mathrm{eV}$ correlate with the peaks of the $\mathrm{V}_{\mathrm{K}}$ absorption bands [73]. The extremum at $2.8 \mathrm{eV}$ cannot be correlated with any known absorption band. It is caused by forbidden transitions of the $V_{K}$ centre, which become dipole allowed due to the loss of the inversion symmetry by slow oscillations [74]. Since the known $\mathrm{H}$ centre bands at $3.26 \mathrm{eV}$ and $2.50 \mathrm{eV}$ [75] are superimposed by the intense bands of the $\mathrm{F}$ and $\mathrm{V}_{\mathrm{K}}$ centre, respectively, no MCDA band can be clearly assigned to the $\mathrm{H}$ centre. Due to the strong overlap of the $\mathrm{H}$ centre bands with those of the $\mathrm{F}$ and the $\mathrm{V}_{\mathrm{K}}$ centre, respectively, the identification of $\mathrm{H}$ centres by MCDA-EPR turned out to be difficult. This superposition is clearly seen in the MCDAEPR spectrum of figure 4.4a which shows not only the EPR line of $\mathrm{H}$ centres with their axes perpendicular to the magnetic field, but also that of the F centre. The fact that only those $\mathrm{H}$ centres can be observed was explained in [31]. Figure 4.4b shows a calculated 
EPR spectrum of $\mathrm{H}$ centres with their axes perpendicular to the magnetic field. Upon annealing to $70 \mathrm{~K}$, the $\mathrm{H}$ centres decay thermally.

The failure to detect $\mathrm{In}^{2+}$ centres after X-irradiation at $4.2 \mathrm{~K}$ demonstrates that $\mathrm{F}$ - $\mathrm{In}^{2+}$ pairs are not produced as primary radiation defects. The doped $\mathrm{In}^{+}$impurities do not act as primary hole traps. However, the fact that $\mathrm{In}^{2+}$ are observable at RT shows that the formation of $\mathrm{In}^{2+}$ centres is thermally activated. From mobile hole trap centres the $\mathrm{In}^{+}$ must capture the hole to form $\mathrm{In}^{2+}$. The analysis of the MCDA-EPR measurements of $\mathrm{In}^{2+}$ yielded that there is no other defect such as a nearest-neighbour vacancy associated with the $\mathrm{In}^{2+}$ centre. It was proposed that $\mathrm{V}_{\mathrm{K}}$ centres decay at an $\mathrm{In}^{+}$site to form $\mathrm{In}^{2+}$ [68].

\subsection{RbI:Tl ${ }^{+}$}

The X-ray induced defects in $\mathrm{RbI}: \mathrm{X}\left(\mathrm{X}=\mathrm{Tl}^{+}, \mathrm{In}^{+}, \mathrm{Eu}^{2+}, \mathrm{Pb}^{2+}\right)$ and their role in the PSL process were investigated in detail in [7]. The following section is focussed on $\mathrm{RbI}: \mathrm{Tl}^{+}$ which has, in principle, very good storage and PSL properties. However, the stored image fades away within minutes at RT. Therefore, unless a very fast read-out process is initiated immediately after taking the image, the system is less adequate for practical use. As to the mechanism, RbI: $\mathrm{Tl}^{+}$is well understood. After X-irradiation the generated electron trap centre (F centre) can be photostimulated. The $\mathrm{F}$ centre electron recombines with the complementarily generated $\mathrm{Tl}^{2+}$ hole trap centre leading to the $\mathrm{Tl}^{+}$emission at $2.86 \mathrm{eV}(433 \mathrm{~nm})$. The maximum of the PSL excitation spectrum is at $1.69 \mathrm{eV}$ $(735 \mathrm{~nm})$.

\subsubsection{Generation of electron and hole trap centres}

$\mathrm{X}$-irradiation of $\mathrm{RbI}: \mathrm{Tl}^{+}$at liquid nitrogen temperature (LNT) generates mainly $\mathrm{F}$ and $\mathrm{V}_{\mathrm{K}}$ centres, only very few $\mathrm{Tl}^{2+}$ centres are directly formed (figure $4.5 \mathrm{a}$ ). This was shown by MCDA and MCDA-EPR experiments [76]. Additionally $\mathrm{Tl}^{0}$ centres can be detected by their optical absorption bands at $0.87 \mathrm{eV}, 1.32 \mathrm{eV}$ and $2.27 \mathrm{eV}$ [7]. Upon annealing to $150 \mathrm{~K}$ the $\mathrm{V}_{\mathrm{K}}$ centre decays and the MCDA bands of the $\mathrm{Tl}^{2+}$ centre increase (figure 4.5b). Note, that the $\mathrm{V}_{\mathrm{K}}$ centres become mobile at $125 \mathrm{~K}$ [77]. This is in agreement with the thermoluminescence glow curve of $\mathrm{RbI}: \mathrm{Tl}^{+}$after X-irradiation at 4.2 $\mathrm{K}$ which shows two characteristic peaks, at $125 \mathrm{~K}$ and at $175 \mathrm{~K}$ [7]. No $\mathrm{Tl}^{+}$dis- 


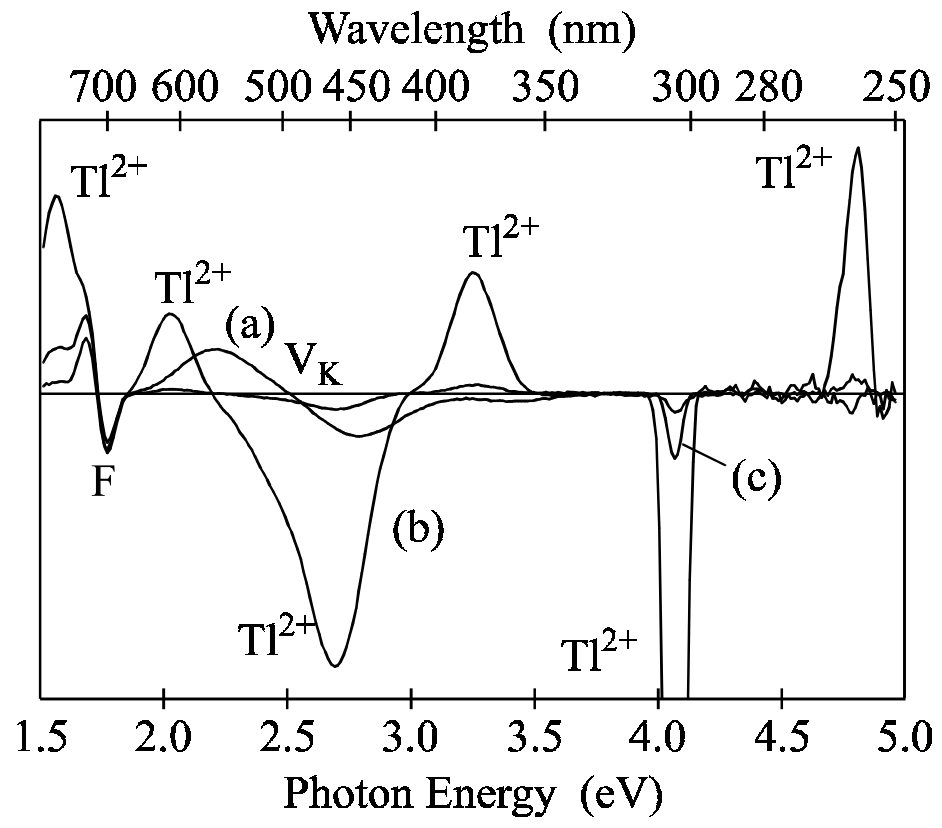

Figure 4.5 MCDA spectra of $\mathrm{RbI}^{+} \mathrm{Tl}^{+}$, recorded at $4.2 \mathrm{~K}$ (a) immediately after Xirradiation at $80 \mathrm{~K}$, (b) after subsequent annealing to $150 \mathrm{~K}$ and (c) after subsequent annealing to $220 \mathrm{~K}$ [76].

turbed $\mathrm{V}_{\mathrm{K}}$ centres [76] could be detected. At $180 \mathrm{~K}$ the $\mathrm{Tl}^{0}$ centres become mobile and recombine with $\mathrm{Tl}^{2+}$ centres. Consequently, after an additional annealing step to $220 \mathrm{~K}$ almost $95 \%$ of the $\mathrm{Tl}^{2+}$ have disappeared (figure $4.5 \mathrm{c}$ ).

$\mathrm{Tl}^{2+}$ is paramagnetic and has seven absorption bands which could be identified by "tagged" MCDA experiments [78]. Theoretical calculations [79] showed that the unpaired $6 s$-electron of $\mathrm{Tl}^{2+}$ is mainly located at the $\mathrm{I}^{-}$ligands of a $\left[\mathrm{TlI}_{6}\right]^{4-}$ complex. The two UV absorption bands (4.07 eV and $4.82 \mathrm{eV}$ ) belong to the spin-orbit split ${ }^{2} P_{1 / 2}$ and ${ }^{2} P_{3 / 2}$ components of the $\mathrm{a}_{1 g}^{*} \rightarrow \mathrm{t}_{1 u}^{*}$ transition, whereas the five additional transitions $(1.57 \mathrm{eV}, 2.03 \mathrm{eV}, 2.35 \mathrm{eV}, 2.7 \mathrm{eV}$ and $3.25 \mathrm{eV})$ can be explained by the components of the $\mathrm{t}_{1 u}(\pi) \rightarrow \mathrm{a}_{1 g}^{*}, \mathrm{t}_{1 u}(\sigma) \rightarrow \mathrm{a}_{1 g}^{*}$, and $\mathrm{t}_{2 u}(\pi) \rightarrow \mathrm{a}_{1 g}^{*}$ charge transfer transitions. Bleaching into any of the seven identified $\mathrm{Tl}^{2+}$ absorption bands at LNT destroys the $\mathrm{Tl}^{2+}$ centres and leads to the $\mathrm{Tl}^{+}$emission as well as to the formation of $\mathrm{V}_{\mathrm{K}}$ centres (figure 4.6, from left to right). Upon annealing above the stability temperature of the $\mathrm{V}_{\mathrm{K}}$ centres, $95 \%$ of the $\mathrm{Tl}^{2+}$ centres are restored (figure 4.6, from right to left). Thus, the $\mathrm{V}_{\mathrm{K}}$ centres generated in this way are spatially correlated to $\mathrm{Tl}^{+}$. 


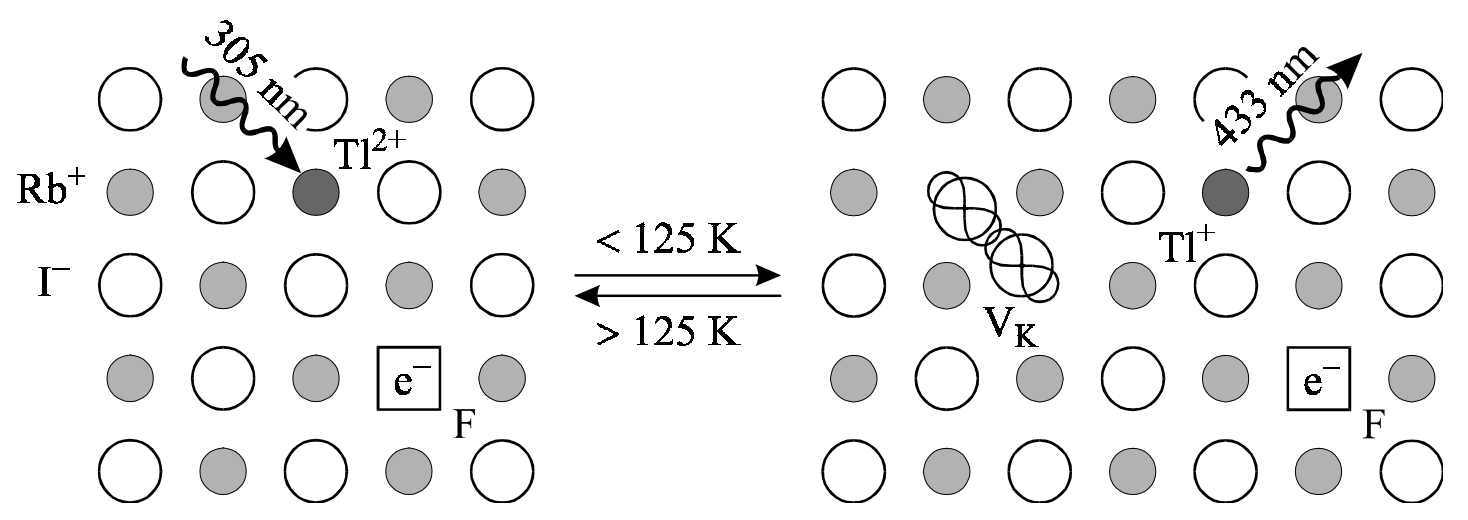

Figure 4.6 Model for the charge transfer character of $\mathrm{Tl}^{2+}$ in $\mathrm{RbI}: \mathrm{Tl}^{+}$.

Photostimulation into the $\mathrm{F}$ centre absorption band at temperatures above $150 \mathrm{~K}$ leads to a recombination between $\mathrm{Tl}^{2+}$ and $\mathrm{F}$ centres giving rise to the $\mathrm{Tl}^{+}$luminescence, i.e. the PSL effect.

\subsection{RbBr: $\mathrm{Ga}^{+}$and $\mathrm{CsBr}: \mathrm{Ga}^{+}$}

Before X-irradiation the excitation of $\mathrm{RbBr}: \mathrm{Ga}^{+}$or $\mathrm{CsBr}: \mathrm{Ga}^{+}$with UV light leads to a single luminescence band peaking at $2.25 \mathrm{eV}(550 \mathrm{~nm})$ and at $2.41 \mathrm{eV}(515 \mathrm{~nm})$, respectively $[80,81]$. The corresponding excitation spectra revealed a broad band peaking at $4.8 \mathrm{eV}\left(260 \mathrm{~nm}, \mathrm{RbBr}: \mathrm{Ga}^{+}\right)$and at $5.0 \mathrm{eV}\left(250 \mathrm{~nm}, \mathrm{CsBr}: \mathrm{Ga}^{+}\right)$, respectively. No luminescence can be detected by exciting $\mathrm{RbBr}: \mathrm{Ga}^{+}$or $\mathrm{CsBr}: \mathrm{Ga}^{+}$with light in the range between $600 \mathrm{~nm}$ and $800 \mathrm{~nm}$. After X-irradiation at RT the $\mathrm{Ga}^{+}$luminescence can be excited in the F centre absorption band at $1.85 \mathrm{eV}\left(670 \mathrm{~nm}, \mathrm{RbBr}: \mathrm{Ga}^{+}\right)$and at $1.94 \mathrm{eV}$ $\left(640 \mathrm{~nm}, \mathrm{CsBr}: \mathrm{Ga}^{+}\right)$, respectively. The PSL decay time is $26.4 \mu \mathrm{s}$ for $\mathrm{RbBr}: \mathrm{Ga}^{+}$and $18.6 \mu$ s for $\mathrm{CsBr}: \mathrm{Ga}^{+}$, respectively [82].

\subsubsection{Sample preparation}

$\mathrm{RbBr}$ and $\mathrm{CsBr}$ were doped with 200-10000 ppm $\mathrm{Ga}^{+}$in the melt and single crystals were grown by the Bridgman method under inert gas. By using appropriate amounts of $\mathrm{GaBr}_{3}$ and elementary gallium it was attempted to avoid the incorporation of trivalent gallium [80, 81]. Due to the crystal growth method the single crystal part grown first contains only a small $\mathrm{Ga}^{+}$concentration. The $\mathrm{Ga}^{+}$concentration in the melt increases with the crystal growth. Therefore, the crystal's end part is doped with a much larger 
amount of $\mathrm{Ga}^{+}$. In addition, the end part of the single crystal also contains more other unavoidable impurities than the first part. Samples from the first part and from the end part have been investigated. Henceforth, the samples are referred to as "L" (low $\mathrm{Ga}^{+}$ concentration) and " $\mathrm{H}$ " (high $\mathrm{Ga}^{+}$concentration). The absolute $\mathrm{Ga}^{+}$concentration incorporated into the crystal could not be determined. The maximum concentration is probably one order of magnitude less than the doping level. From optical absorption measurements the $\mathrm{Ga}^{+}$concentration ratio between the $\mathrm{L}$ and $\mathrm{H}$ samples was found to be about 5:1.

\subsubsection{Generation of electron and hole trap centres}

After X-irradiation of RbBr: $\mathrm{Ga}^{+}$at $4.2 \mathrm{~K} \mathrm{~F}, \mathrm{~V}_{\mathrm{K}}, \mathrm{H}$ and I (interstitial halide) centres are formed. The latter two are not stable above $40 \mathrm{~K}[80,83]$. The F centre remains stable up to RT, whereas the $\mathrm{V}_{\mathrm{K}}$ centre becomes mobile at temperatures above $180 \mathrm{~K}$ [80]. Note, that the $\mathrm{V}_{\mathrm{K}}$ centre in undoped $\mathrm{RbBr}$ is stable only to about $170 \mathrm{~K}$ [77]. In undoped $\mathrm{CsBr}$ the $\mathrm{V}_{\mathrm{K}}$ centres has two critical temperatures for migration, namely $106 \mathrm{~K}$ for $0^{\circ}$ jumps and $130 \mathrm{~K}$ for $90^{\circ}$ jumps, respectively [84]. The maxima at $110 \mathrm{~K}$ and $145 \mathrm{~K}$ in the thermoluminescence glow curve of $\mathrm{CsBr}: \mathrm{Ga}^{+}$were thus assigned to the $\mathrm{V}_{\mathrm{K}}$ decay [81].

After X-irradiation at RT the MCDA spectra of $\mathrm{RbBr}: \mathrm{Ga}^{+}$and $\mathrm{CsBr}: \mathrm{Ga}^{+}$, respectively, show a derivative-like structured band at $1.85 \mathrm{eV}\left(670 \mathrm{~nm}, \mathrm{RbBr}: \mathrm{Ga}^{+}\right)$and at $1.94 \mathrm{eV}$ (640 nm, CsBr: $\mathrm{Ga}^{+}$), respectively, which belong to the corresponding F centres. Besides the F centre bands, several MCDA bands were detected in the UV spectral range.

MCDA-EPR experiments showed that the UV bands belong to two different $\mathrm{Ga}^{2+}$ hole trap centres which are henceforth labelled with $\left(\mathrm{Ga}^{2+}\right)^{\mathrm{I}}$ and $\left(\mathrm{Ga}^{2+}\right)^{\mathrm{II}}$ (figure 4.7). The EPR lines of each $\mathrm{Ga}^{2+}$ centre are split by a hyperfine (hf) interaction between the unpaired $4 s$-electron and the two magnetic isotopes ${ }^{69} \mathrm{Ga}(60.4 \%$ natural abundance) and ${ }^{71} \mathrm{Ga}$ (39.6\% natural abundance), both having a nuclear spin of $I=3 / 2$. The hf interaction leads to four "allowed" $\Delta m_{I}=0$ transitions marked by bars in figure 4.7. The transitions labelled with asterisks are due to "forbidden" $\Delta m_{I}= \pm 1, \pm 2$ transitions. The forbidden transitions are nearly as intense as the allowed ones. This can occur in the MCDA detection scheme when the allowed transitions are strongly saturated due to long spin-lattice relaxation times [85]. The allowed quartet lines have the same intensity, but since they are superimposed to forbidden transitions, the intensity pattern is 


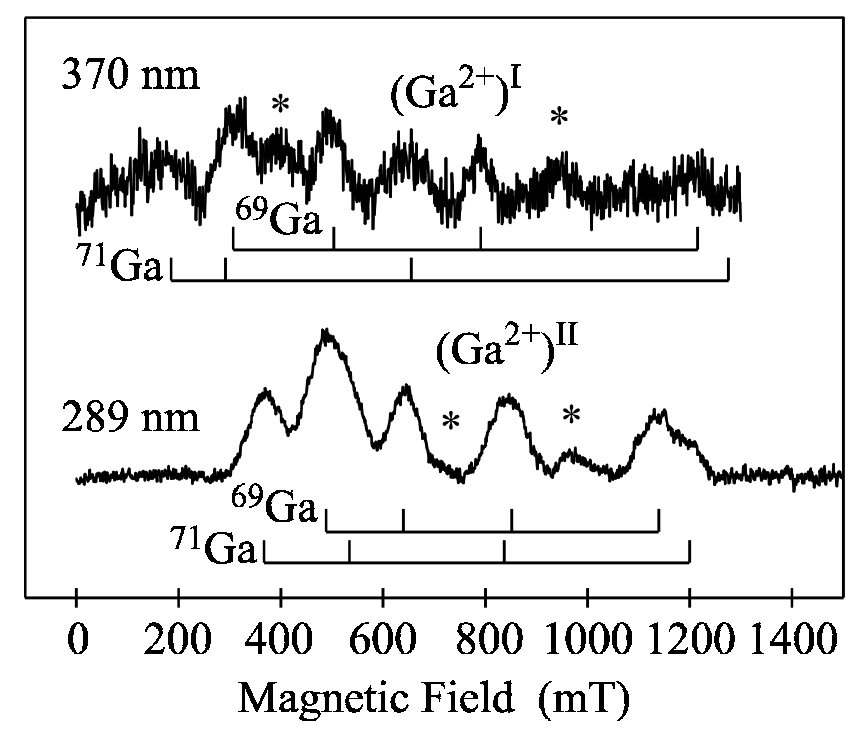

Figure 4.7 MCDA-detected EPR of $\left(\mathrm{Ga}^{2+}\right)^{\mathrm{I}}$ and $\left(\mathrm{Ga}^{2+}\right)^{\mathrm{II}}$ centres in $\mathrm{RbBr}^{\mathrm{G}} \mathrm{Ga}^{+}$ (200 ppm, sample L) after X-irradiation at RT, recorded at $1.5 \mathrm{~K}$ applying a microwave frequency of $23.9 \mathrm{GHz}$. The detection wavelength was $3.35 \mathrm{eV}(370 \mathrm{~nm})$ and $4.28 \mathrm{eV}(289 \mathrm{~nm})$, respectively [80].

different from that expected for allowed transitions only. Unfortunately, it was not possible to resolve structural differences between these two centres by EPR.

The assignment of the UV bands to their corresponding $\mathrm{Ga}^{2+}$ hole trap centre was done by "tagged" MCDA measurements (figure 4.8), where an energy of $3.35 \mathrm{eV}(370 \mathrm{~nm})$ is very suitable for measuring the MCDA-detected EPR of the $\left(\mathrm{Ga}^{2+}\right)^{\mathrm{I}}$ centres and $4.29 \mathrm{eV}$ $(289 \mathrm{~nm})$ for the $\left(\mathrm{Ga}^{2+}\right)^{\mathrm{II}}$ centres $[80,81]$.

\subsubsection{Generation of $\left(\mathrm{Ga}^{2+}\right)^{\mathrm{I}}$ and $\left(\mathrm{Ga}^{2+}\right)^{\mathrm{II}}$ centres in $\mathrm{RbBr}: \mathrm{Ga}^{+}$}

When X-irradiating at $4.2 \mathrm{~K}$ only $\mathrm{F}$ and $\mathrm{V}_{\mathrm{K}}$ centres are observed in MCDA experiments. No $\mathrm{Ga}^{2+}$ centres could be found. After annealing to about $180 \mathrm{~K}$, where the $\mathrm{V}_{\mathrm{K}}$ centres have begun to disappear, $\mathrm{Ga}^{2+}$ centres start to appear. For $\mathrm{RbBr}: \mathrm{Ga}^{+}(200 \mathrm{ppm}$, sample $\mathrm{L})$, the MCDA band of $\left(\mathrm{Ga}^{2+}\right)^{\mathrm{I}}$ centres appears at $180 \mathrm{~K}$ and reaches its maximum value at $220 \mathrm{~K}$. A weak MCDA band of the $\left(\mathrm{Ga}^{2+}\right)^{\mathrm{II}}$ centres also appears at $180 \mathrm{~K}$, reaches its maximum value when annealing further to $250 \mathrm{~K}$ and then remains unchanged to $\mathrm{RT}$ (figure 4.9). Corresponding to the increase of the MCDA band of the $\left(\mathrm{Ga}^{2+}\right)^{\mathrm{II}}$ centres the MCDA band of the $\left(\mathrm{Ga}^{2+}\right)^{\mathrm{I}}$ centres decreases between $220 \mathrm{~K}$ and $250 \mathrm{~K}$. At $250 \mathrm{~K}$ about half of $\left(\mathrm{Ga}^{2+}\right)^{\mathrm{I}}$ centres are destroyed. For sample $\mathrm{H}$, the MCDA band of $\left(\mathrm{Ga}^{2+}\right)^{\mathrm{I}}$ 


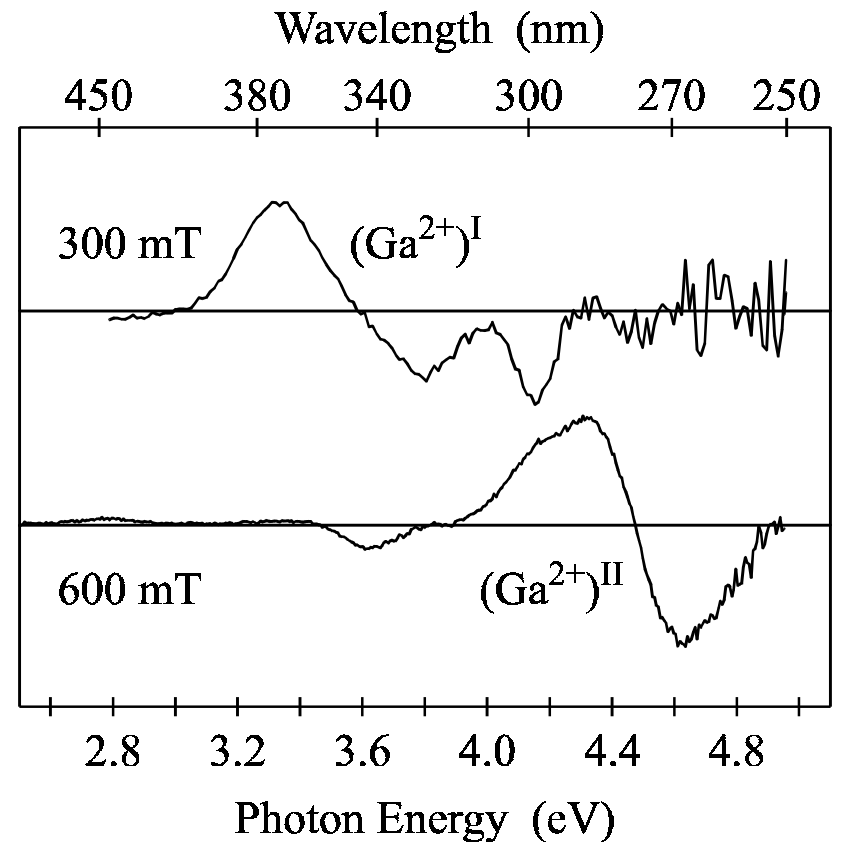

Figure 4.8 "Tagged" MCDA of $\left(\mathrm{Ga}^{2+}\right)^{\mathrm{I}}(200 \mathrm{ppm}$, sample $\mathrm{H})$ and $\left(\mathrm{Ga}^{2+}\right)^{\mathrm{II}}$ centres (200 ppm, sample L) in $\mathrm{RbBr}: \mathrm{Ga}^{+}$, after X-irradiation at $\mathrm{RT}$, recorded at $1.5 \mathrm{~K}[80]$.

centres appears at $180 \mathrm{~K}$ with a further increase to its maximum value at about $220 \mathrm{~K}$. No MCDA of $\left(\mathrm{Ga}^{2+}\right)^{\mathrm{II}}$ centres is observed, even after annealing up to RT (figure 4.9). In general, the MCDA of $\left(\mathrm{Ga}^{2+}\right)^{\mathrm{I}}$ centres reaches its maximum value at about $220 \mathrm{~K}$, i.e. by an annealing step above the decay temperature of the $\mathrm{V}_{\mathrm{K}}$ centres, while the MCDA of $\left(\mathrm{Ga}^{2+}\right)^{\mathrm{II}}$ centres reaches its maximum at $250 \mathrm{~K}$.

It is obvious that the $\left(\mathrm{Ga}^{2+}\right)^{\mathrm{I}}$ centres are formed from a mobile $\mathrm{V}_{\mathrm{K}}$ centre upon hole capture by $\mathrm{Ga}^{+}$, while the formation of $\left(\mathrm{Ga}^{2+}\right)^{\mathrm{II}}$ centres needs as well the mobility of another species, thought to be cation vacancies $\left(\mathrm{v}_{\mathrm{c}}\right)$. The $\left(\mathrm{Ga}^{2+}\right)^{\mathrm{I}}$ centre is probably an isolated $\mathrm{Ga}^{2+}$, whereas the $\left(\mathrm{Ga}^{2+}\right)^{\mathrm{II}}$ centre is proposed to be a $\mathrm{Ga}^{2+}$-cation vacancy complex (figure 4.10), similarly to what was proposed in [86] to occur upon X-irradiation in $\mathrm{KCl}$ and $\mathrm{NaCl}$ doped with $\mathrm{Ga}^{+}$. The observation that the $\mathrm{V}_{\mathrm{K}}$ centre does not recombine with the $\mathrm{F}$ centre electron, but that it is captured by $\mathrm{Ga}^{+}$could be explained by the fact that the ionic radius of the $\mathrm{Ga}^{+}$activator $(0.81 \AA)$ is almost twice smaller than that of $\mathrm{Rb}^{+}\left(1.47 \AA\right.$ ). Thus, a relaxation of the bromine neighbours towards the $\mathrm{Ga}^{+}$could occur which causes an attractive potential for the $\mathrm{V}_{\mathrm{K}}$ centres.

The formation process of the $\left(\mathrm{Ga}^{2+}\right)^{\mathrm{II}}$ centres is more complex than that proposed for $\left(\mathrm{Ga}^{2+}\right)^{\mathrm{I}}$ centres. In $\mathrm{KCl}$ and $\mathrm{RbCl}$ cation vacancies become mobile at about $220 \mathrm{~K}$ [87, 


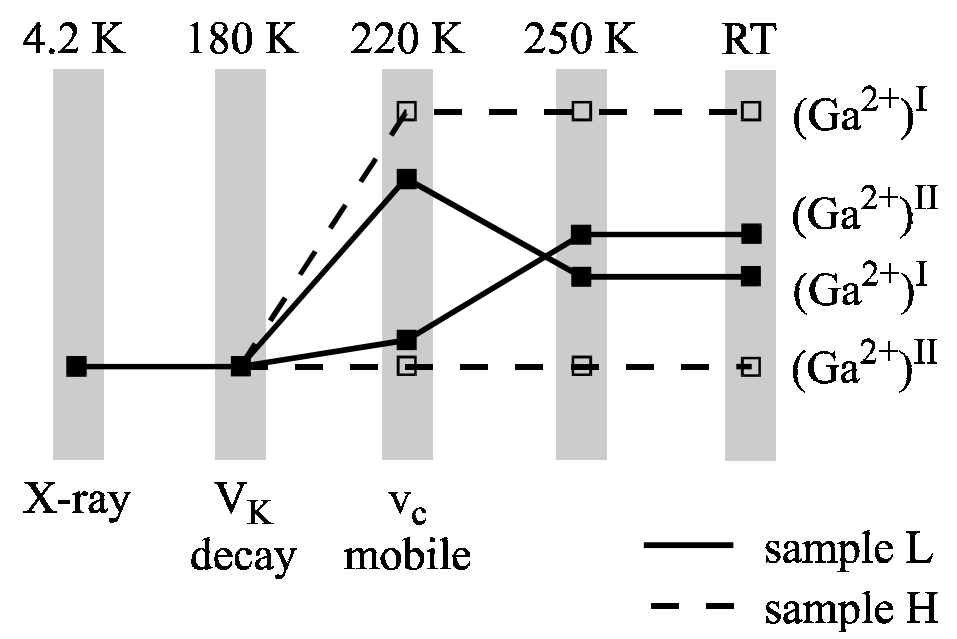

Figure 4.9 Generation of $\left(\mathrm{Ga}^{2+}\right)^{\mathrm{I}}$ and $\left(\mathrm{Ga}^{2+}\right)^{\mathrm{II}}$ centres in $\mathrm{RbBr}: \mathrm{Ga}^{+}(200 \mathrm{ppm}$, sample $\mathrm{L}$ and sample $\mathrm{H}$ ) after $\mathrm{X}$-irradiation at $4.2 \mathrm{~K}$ and subsequent annealing steps to RT [92].

88, 89]. A similar mobility temperature is also expected for $\mathrm{RbBr}$ since the migration energy of cation vacancies in $\operatorname{RbBr}(0.81 \mathrm{eV})$ is very close to that of $\mathrm{KCl}(0.84 \mathrm{eV})$ and $\mathrm{RbCl}(0.80 \mathrm{eV})$ [90]. The mobile cation vacancies can be captured by a $\mathrm{Ga}^{2+}$, which attracts the negative cation vacancies due to its positive charge. The resulting complex is electrically neutral and stable. Apparently, the investigated $\mathrm{RbBr}$ samples with low $\mathrm{Ga}^{+}$concentration contain cation vacancies in a considerable concentration, i.e. in the same order of magnitude as the concentration of $\mathrm{Ga}^{+}$in those samples which is probably due to the doping method [80]. When following the formation of $\mathrm{Ga}^{2+}$ centres above $220 \mathrm{~K}$, the initial concentration of $\left(\mathrm{Ga}^{2+}\right)^{\mathrm{I}}$ centres is found to decrease from $220 \mathrm{~K}$ to $250 \mathrm{~K}$ at the expense of the formation of more $\left(\mathrm{Ga}^{2+}\right)^{\mathrm{II}}$ centres. Thus, cation vacancies are attracted by the positive $\left(\mathrm{Ga}^{2+}\right)^{\mathrm{I}}$ centres and form $\left(\mathrm{Ga}^{2+}\right)^{\mathrm{II}}$ centres.

After X-irradiation at $\mathrm{RT}$ in $\mathrm{RbBr}$ with low $\mathrm{Ga}^{+}$concentration the MCDA shows a significant band of $\left(\mathrm{Ga}^{2+}\right)^{\mathrm{II}}$ centres, but only a small band of $\left(\mathrm{Ga}^{2+}\right)^{\mathrm{I}}$ centres. This is in agreement with the $\mathrm{X}$-irradiation at $4.2 \mathrm{~K}$ and subsequent annealing procedure (figure 4.9). In $\mathrm{RbBr}$ with high $\mathrm{Ga}^{+}$concentration the intensities of both MCDA bands are of the same order of magnitude with a smaller MCDA band of $\left(\mathrm{Ga}^{2+}\right)^{\mathrm{II}}$ centres. This is contrary to the fact that after X-irradiation at $4.2 \mathrm{~K}$ and subsequent annealing to RT very few $\left(\mathrm{Ga}^{2+}\right)^{\mathrm{II}}$ centres were found (figure 4.9). A very high mobility of the cation vacancies during the RT X-irradiation seems to favour the creation of the $\left(\mathrm{Ga}^{2+}\right)^{\mathrm{II}}$ centres, while after low temperature $\mathrm{X}$-irradiation and annealing to $220 \mathrm{~K}$ the $\mathrm{V}_{\mathrm{K}}$ centres 


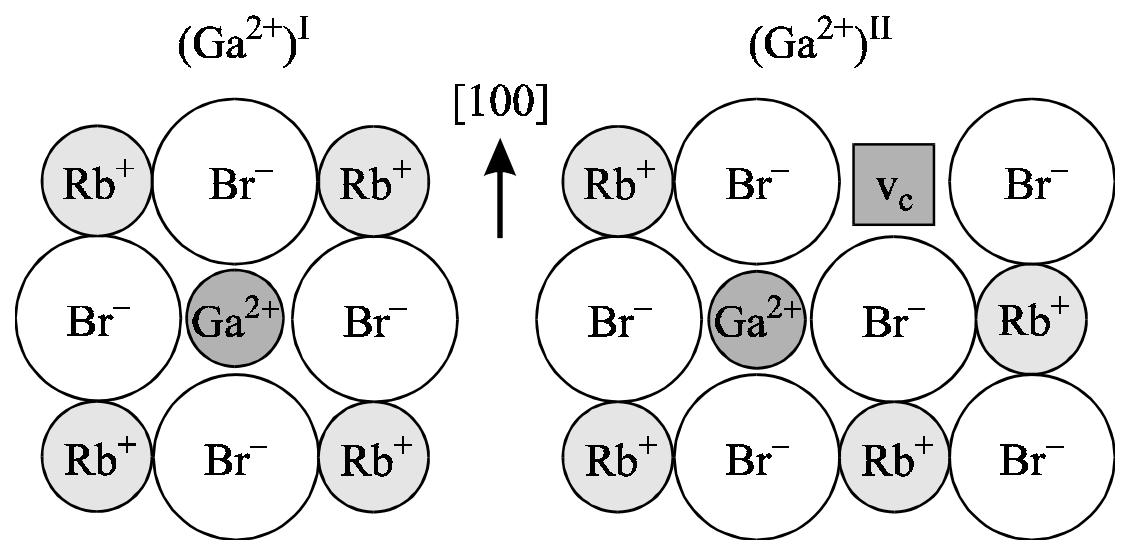

Figure 4.10 Models for the $\left(\mathrm{Ga}^{2+}\right)^{\mathrm{I}}$ and the $\left(\mathrm{Ga}^{2+}\right)^{\mathrm{II}}$ centre in $\mathrm{RbBr}: \mathrm{Ga}^{+}$.

are preferentially trapped at $\mathrm{Ga}^{+}$to form $\left(\mathrm{Ga}^{2+}\right)^{\mathrm{I}}$ centres and are not converted to $\left(\mathrm{Ga}^{2+}\right)^{\mathrm{II}}$ centres. It is assumed that $\mathrm{RbBr}$ with high $\mathrm{Ga}^{+}$concentration contains less cation vacancies than $\mathrm{RbBr}$ with low $\mathrm{Ga}^{+}$concentration. This together with an enhanced vacancy mobility under RT X-irradiation may be the reason for the different ratio between $\left(\mathrm{Ga}^{2+}\right)^{\mathrm{I}}$ and $\left(\mathrm{Ga}^{2+}\right)^{\mathrm{II}}$ centres when produced by low temperature $\mathrm{X}$-irradiation and annealing or by RT X-irradiation.

\subsubsection{PSL experiments with $\mathrm{RbBr}: \mathrm{Ga}^{+}$and $\mathrm{CsBr}: \mathrm{Ga}^{+}$}

Stimulation of the F centre absorption band of X-irradiated $\mathrm{RbBr}: \mathrm{Ga}^{+}$to excite the $\mathrm{Ga}^{+}$ luminescence could not destroy the $\left(\mathrm{Ga}^{2+}\right)^{\mathrm{II}} \mathrm{MCDA}$ signal, neither at RT nor at $4.2 \mathrm{~K}$, but it decreases the $\left(\mathrm{Ga}^{2+}\right)^{\mathrm{I}} \mathrm{MCDA}$ band. Thus, only the $\left(\mathrm{Ga}^{2+}\right)^{\mathrm{I}}$ centres are participating in the read-out process upon photostimulation of the $\mathrm{F}$ centre electron. From the proposed centre models for the two $\mathrm{Ga}^{2+}$ centres this is understandable, since $\left(\mathrm{Ga}^{2+}\right)^{\mathrm{I}}$ centres are positively charged and attract mobile electrons, while the neutral $\left(\mathrm{Ga}^{2+}\right)^{\mathrm{II}}$ centres do not. For the use of $\mathrm{RbBr}: \mathrm{Ga}^{+}$as a storage phosphor, the generation of $\left(\mathrm{Ga}^{2+}\right)^{\mathrm{II}}$ centres must be avoided, since they may compete for primary holes.

After stimulation at $4.2 \mathrm{~K}$ it was possible to restore part of the $\left(\mathrm{Ga}^{2+}\right)^{\mathrm{I}}$ centres by subsequent annealing to $\mathrm{RT}$ in $\mathrm{RbBr}$ with low $\mathrm{Ga}^{+}$concentration, but not in $\mathrm{RbBr}$ with high $\mathrm{Ga}^{+}$concentration. This "replenishment" effect $[32,33]$ of the $\left(\mathrm{Ga}^{2+}\right)^{\mathrm{I}}$ centres starts to appear after annealing the sample to about $200 \mathrm{~K}$ and reaches its maximum after annealing to RT (figure 4.11). For a tentative explanation of this observation it is suggested [80] that the $\mathrm{Ga}^{+}$concentration does not suffice to capture all holes from the 


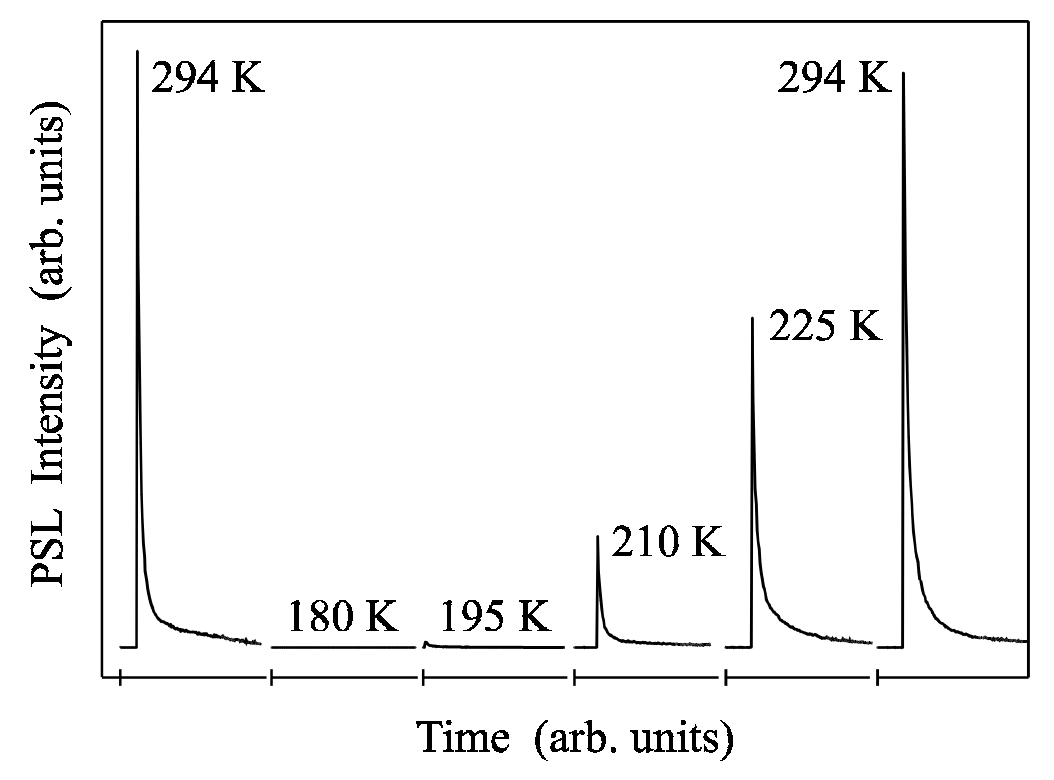

Figure 4.11 Temperature dependence of the replenishment effect in $\mathrm{RbBr}_{\mathrm{Ga}}{ }^{+}$ (200 ppm, sample L). The PSL decay curves were detected at $2.21 \mathrm{eV}$ $(560 \mathrm{~nm})$ under continuous excitation with $1.85 \mathrm{eV}(670 \mathrm{~nm})$ light. The sample was X-irradiated at RT, read out at $80 \mathrm{~K}$, annealed up to the respective temperature and afterwards again read out at $80 \mathrm{~K}$ [92].

generated $V_{K}$ centres. Some holes are trapped elsewhere. Above $200 \mathrm{~K}$ they become mobile and can be trapped by $\mathrm{Ga}^{+}$centres having become available again after the readout process, i.e. after $\left(\mathrm{Ga}^{2+}\right)^{\mathrm{I}}$ centres have recombined with the photostimulated electrons of the F centres. When the dose is lower, the replenishment effect decreases, since relative to the number of $\mathrm{V}_{\mathrm{K}}$ centres there are more $\mathrm{Ga}^{+}$centres available to form $\left(\mathrm{Ga}^{2+}\right)^{\mathrm{I}}$ centres. In $\mathrm{RbBr}$ with high $\mathrm{Ga}^{+}$concentration practically all $\mathrm{V}_{\mathrm{K}}$ hole trap centres are trapped at $\mathrm{Ga}^{+}$and no replenishment effect could be observed.

In CsBr:Ga the PSL active $\left(\mathrm{Ga}^{2+}\right)^{\mathrm{I}}$ centres clearly dominate over the PSL inactive $\left(\mathrm{Ga}^{2+}\right)^{\mathrm{II}}$ species for all investigated $\mathrm{Ga}^{+}$doping levels [81]. The structure of these two $\mathrm{Ga}^{2+}$ hole trap centres is assumed to be the same as in $\mathrm{RbBr}_{\mathrm{Ga}^{+}}$[80]. However, in contrast to $\mathrm{RbBr}: \mathrm{Ga}^{+}$, there is no clear replenishment observable in $\mathrm{CsBr}: \mathrm{Ga}^{+}$. It has therefore less complications compared to $\mathrm{RbBr}: \mathrm{Ga}^{+}$with the X-ray induced formation of PSL inactive $\left(\mathrm{Ga}^{2+}\right)^{\mathrm{II}}$ centres depending on the doping level (and possibly the way of $\mathrm{Ga}^{+}$doping). 


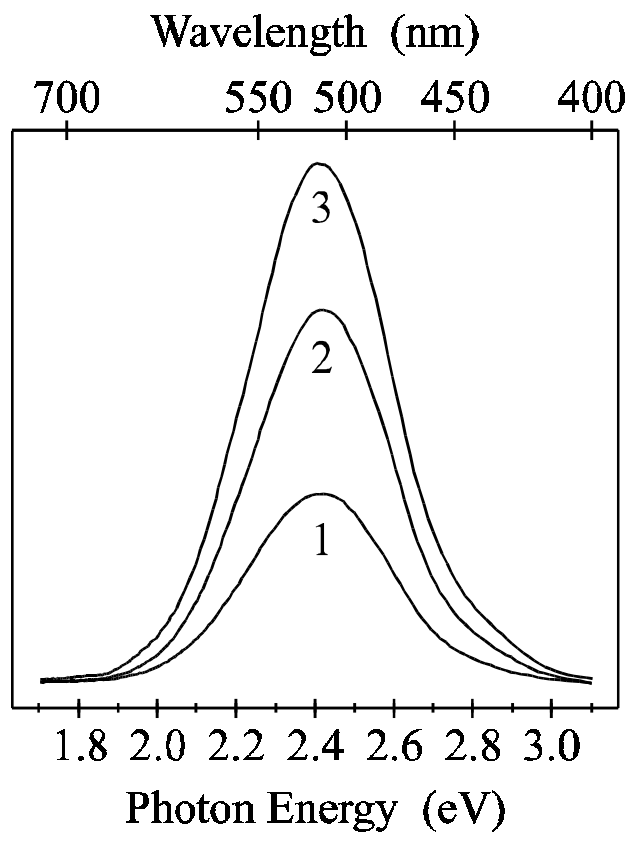

Figure 4.12 $\mathrm{Ga}^{+}$luminescence of $\mathrm{CsBr}: \mathrm{Ga}^{+}(3000 \mathrm{ppm}$, sample L) before (curve 1) and after an annealing/quenching procedure (curves 2 and 3). The annealing temperature was $340{ }^{\circ} \mathrm{C}$ (curve 2) and $520^{\circ} \mathrm{C}$ (curve 3), respectively [81].

\subsubsection{Optimal activator concentration and $\mathrm{Ga}^{+}$aggregation}

The $\mathrm{Ga}^{+}$concentration plays an important role in the hole trap centre formation, particularly in $\mathrm{RbBr}$, and decides whether $\left(\mathrm{Ga}^{2+}\right)^{\mathrm{I}}$ alone or additionally competing $\left(\mathrm{Ga}^{2+}\right)^{\mathrm{II}}$ centres are formed. In $\mathrm{KCl}: \mathrm{Ga}^{+}$a clear tendency of $\mathrm{Ga}^{+}$to form aggregates has been observed [91]. Thus, for the practical use of the systems $\mathrm{RbBr}: \mathrm{Ga}^{+}$and $\mathrm{CsBr}: \mathrm{Ga}^{+}$it is important to know whether the doped activator forms aggregates or not. The possible aggregate formation can be detected by measuring the UV excited $\mathrm{Ga}^{+}$luminescence as a function of the doping level. The luminescence was detected before and after an annealing/quenching procedure in order to see whether or not aggregates may have been formed which can be destroyed by the annealing/quenching step [92].

It turned out that in $\mathrm{RbBr}: \mathrm{Ga}^{+}$very high $\mathrm{Ga}^{+}$doping levels do not seem advantageous, since a $\mathrm{Ga}^{+}$aggregation occurs which could not be countered by the annealing and quenching treatment used. A somewhat surprising result came from the investigation of the PSL effect as a function of $\mathrm{Ga}^{+}$doping level. The highest PSL signal is obtained for a low $\mathrm{Ga}^{+}$concentration. This means, that apparently the formation of $\mathrm{Ga}^{+}$aggregates is 
negative for the PSL effect, while the formation of $\left(\mathrm{Ga}^{2+}\right)^{\mathrm{II}}$ centres seems not to affect the PSL efficiency. For practical purposes it seems that even a low concentration of $\left(\mathrm{Ga}^{2+}\right)^{\mathrm{I}}$ centres is sufficient, while too many aggregates seem negative. It remains to be investigated how the formation of $\left(\mathrm{Ga}^{2+}\right)^{\mathrm{II}}$ centres can be minimised compared to $\left(\mathrm{Ga}^{2+}\right)^{\mathrm{I}}$ centres. If $\mathrm{RbBr}: \mathrm{Ga}^{+}$is to be used in practical screens, an investigation of the effect of annealing should be carried out with a variation of annealing temperatures.

In $\mathrm{CsBr}: \mathrm{Ga}^{+}$a significant tendency of $\mathrm{Ga}^{+}$to aggregate was also found. Annealing (and subsequent quenching) destroys the aggregates. However, the annealing temperature has to be sufficiently high. Figure 4.12 shows that an annealing temperature of $340{ }^{\circ} \mathrm{C}$ was not high enough to break all the aggregates, whereas annealing up to $520{ }^{\circ} \mathrm{C}$ and subsequent quenching yielded an even larger increase in the $\mathrm{Ga}^{+}$luminescence. Note, that the melting temperature of $\mathrm{CsBr}$ is at $632{ }^{\circ} \mathrm{C}$. Re-aggregation under light takes place within about a day at RT. When the sample is kept in the dark, experiments on the reaggregation showed no significant difference between the signal measured directly after the annealing and subsequent quenching treatment within a day. Thus the $\mathrm{Ga}^{+}$reaggregation in this case lasts at least some days or weeks.

The PSL is also influenced by the $\mathrm{Ga}^{+}$aggregation, in particular for higher doping levels. If one wants to use $\mathrm{CsBr}: \mathrm{Ga}^{+}$as X-ray storage phosphor, it is certainly necessary to consider the $\mathrm{Ga}^{+}$aggregation. The cooling process has to be adjusted accordingly. 


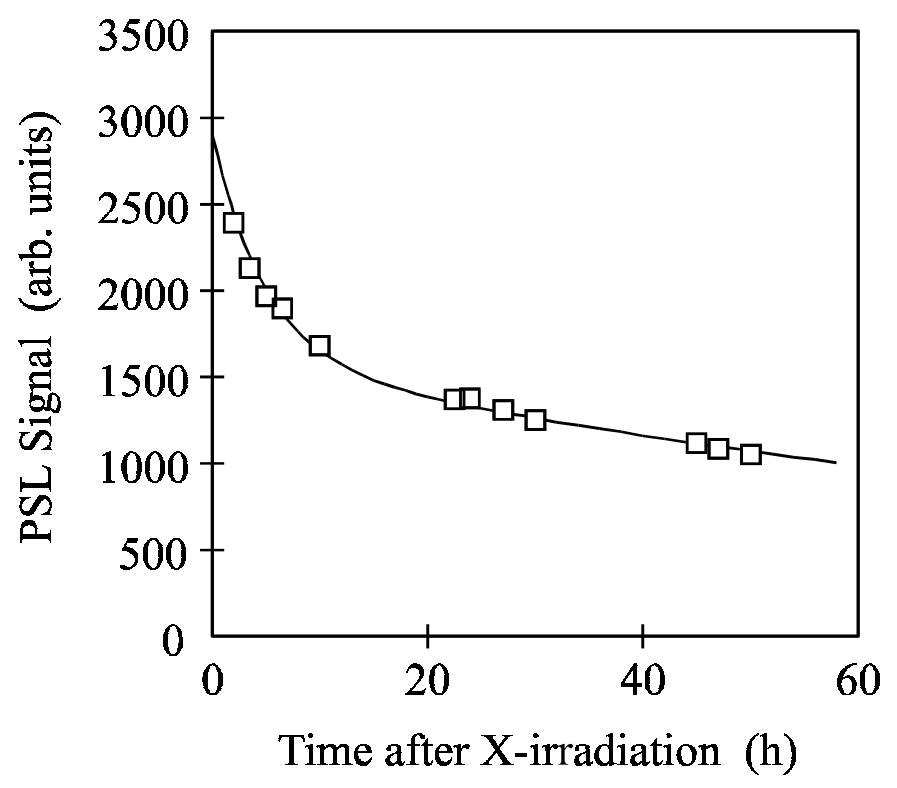

Figure 4.13 Fading of the PSL effect of $\mathrm{RbBr}: \mathrm{Ga}^{+}(200 \mathrm{ppm})$ in the dark at RT, excitation at $670 \mathrm{~nm}$, detection at $550 \mathrm{~nm}$ [92].

\subsubsection{PSL fading}

The fading of the PSL, i.e. the electron and hole recombination with time in the dark and thus the partial loss of the stored information, is an important feature for the application of $\mathrm{RbBr}: \mathrm{Ga}^{+}$or $\mathrm{CsBr}: \mathrm{Ga}^{+}$as X-ray storage phosphors. Figure 4.13 shows the fading of the stored information as a function of time measured for $\mathrm{RbBr}: \mathrm{Ga}^{+}$ (200 ppm) which revealed the best PSL performance. The sample was X-irradiated for $15 \mathrm{~min}(60 \mathrm{kV}, 15 \mathrm{~mA})$. The decay of the PSL with time was followed by stimulating the sample with $\mathrm{F}$ light $(670 \mathrm{~nm})$ and detecting the $\mathrm{Ga}^{+}$emission at $550 \mathrm{~nm}$ several times from directly after the X-ray exposure up to two days. The stimulating $670 \mathrm{~nm}$ light was very weak, such that the PSL signal measured twice within a few seconds showed no change in its magnitude. The measured PSL fading with time could be fitted by two exponential functions with $\tau_{1}=5 \mathrm{~h}$ and $\tau_{2}=125 \mathrm{~h}$. The initial PSL intensity is halved after approximately $14 \mathrm{~h}[92]$.

For $\mathrm{RbBr}: \mathrm{Ga}^{+}$the fading of the PSL was followed in the dark detecting the PSL intensity with weak stimulation light. In case of $\mathrm{CsBr}: \mathrm{Ga}^{+}$the investigation of the $\mathrm{F}$ centre fading by detecting its MCDA showed that after 20 hours one third of the initial F centre concentration is lost. 


\subsubsection{Red-shift of the PSL excitation}

It is known from previous work on alkali halides that doping with lighter alkali cations leads to the formation of perturbed $\mathrm{F}$ centres, so-called $\mathrm{F}_{\mathrm{A}}$ centres [62]. In these centres one of the nearest neighbour cations of the $\mathrm{F}$ centre is replaced by an alkali ion of smaller size, so that an F centre with reduced local symmetry is formed. Figure 4.14 shows the $\mathrm{F}_{\mathrm{A}}$ centre in $\mathrm{RbBr}$ (fcc lattice structure) doped with lithium and the corresponding absorption bands. In this configuration the $\mathrm{F}_{\mathrm{A}}$ centre absorption band splits into two bands one of which is red-shifted $\left(\mathrm{F}_{\mathrm{A} 1}\right)$, the other one only slightly different from the normal $\mathrm{F}$ band $\left(\mathrm{F}_{\mathrm{A} 2}\right)$. If the incident light is polarised along the $\mathrm{F}-\mathrm{Li}^{+}$direction, the so-called $\mathrm{F}_{\mathrm{A} 1}$ absorption band is measured which represents the more red-shifted one. Choosing the polarisation perpendicular to the $\mathrm{F}_{-} \mathrm{Li}^{+}$direction the $\mathrm{F}_{\mathrm{A} 2}$ band is observed. In table 4.2 the literature data of $\mathrm{F}_{\mathrm{A}}$ centres in $\mathrm{RbBr}$ and $\mathrm{CsBr}$ for several codopings are summarised. The $\mathrm{F}_{\mathrm{A} 1}$ absorption band is further red-shifted the lighter the doped alkali cation (note, that this simple rule generally applies to the alkali halides with fcc structure, not to those with bcc structure).

\begin{tabular}{lccc}
\hline \hline crystal & dopant & $\mathrm{F}_{\mathrm{A} 2}$ & $\mathrm{~F}_{\mathrm{A} 1}$ \\
\hline & & \multicolumn{2}{c}{$1.86 \mathrm{eV}(670 \mathrm{~nm})$} \\
$\mathrm{RbBr}$ & $\mathrm{Li}$ & $1.78 \mathrm{eV}(697 \mathrm{~nm})$ & $1.57 \mathrm{eV}(790 \mathrm{~nm})$ \\
& $\mathrm{Na}$ & - & - \\
& $\mathrm{K}$ & $1.85 \mathrm{eV}(671 \mathrm{~nm})$ & $1.67 \mathrm{eV}(742 \mathrm{~nm})$ \\
\hline & & $1.81 \mathrm{eV} / 685 \mathrm{~nm}$ \\
$\mathrm{CsBr}$ & $\mathrm{Li}$ & $1.78 \mathrm{eV}(697 \mathrm{~nm})$ & $1.60 \mathrm{eV}(775 \mathrm{~nm})$ \\
& $\mathrm{Na}$ & $1.83 \mathrm{eV}(678 \mathrm{~nm})$ & $1.65 \mathrm{eV}(751 \mathrm{~nm})$ \\
& $\mathrm{K}$ & $1.77 \mathrm{eV}(701 \mathrm{~nm})$ & $1.58 \mathrm{eV}(785 \mathrm{~nm})$ \\
& $\mathrm{Rb}$ & $1.75 \mathrm{eV}(709 \mathrm{~nm})$ & $1.66 \mathrm{eV}(747 \mathrm{~nm})$ \\
\hline \hline
\end{tabular}

Table 4.2 Optical absorption bands of several $\mathrm{F}_{\mathrm{A}}$ centres in $\mathrm{RbBr}$ and $\mathrm{CsBr}[62,93]$. 

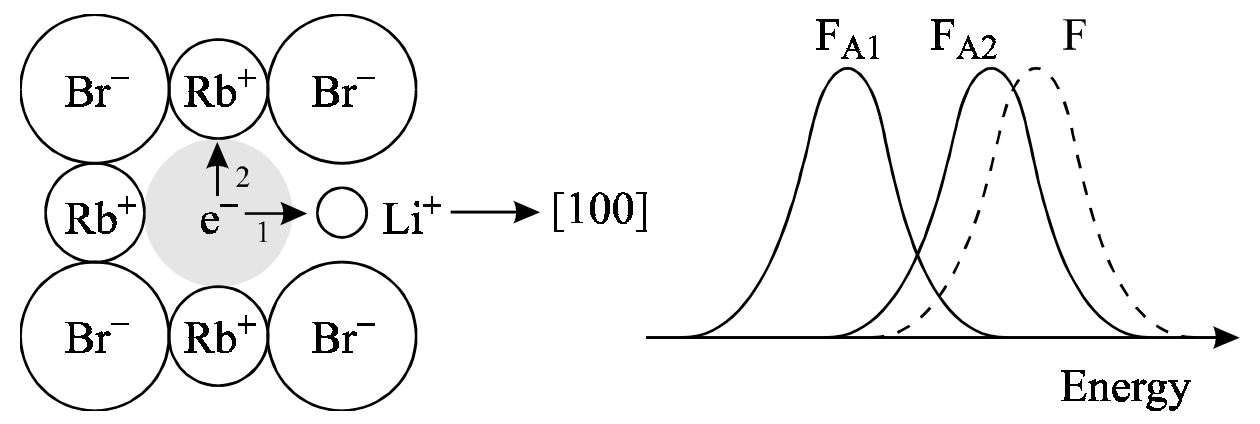

Figure 4.14 Schematic representation of the $\mathrm{F}_{\mathrm{A}}$ centres in $\mathrm{RbBr}$ (fcc structure) doped with $\mathrm{Li}^{+}$and the corresponding absorption spectra in comparison with the unperturbed $\mathrm{F}$ centre band [62].

What is known from the literature is the formation of $\mathrm{F}_{\mathrm{A}}$ centres using doping levels of the order of a few percent and additive coloration. Only a statistically small fraction of $\mathrm{F}$ centres is formed as the $\mathrm{F}_{\mathrm{A}}$ species. Upon bleaching into the $\mathrm{F}$ band at RT, a larger fraction (usually about $50 \%$ of $\mathrm{F}$ centres) is transformed into $\mathrm{F}_{\mathrm{A}}$ centres.

It is not clear a priori whether $\mathrm{F}_{\mathrm{A}}$ centres in alkali halide compounds are formed upon $\mathrm{X}$-irradiation at all, whether they are possibly preferentially formed compared to normal $\mathrm{F}$ centres and whether they contribute to the read-out process. Upon X-irradiation of BaFBr:Eu co-doped with $\mathrm{Ca}^{2+}$ or $\mathrm{Sr}^{2+}$, respectively, $\mathrm{F}_{\mathrm{A}}\left(\mathrm{Ca}^{2+}\right)$ or $\mathrm{F}_{\mathrm{A}}\left(\mathrm{Sr}^{2+}\right)$ centres were formed which generated the desired red-shift of the PSL excitation spectrum [51, 61].

According to table 4.2 $\mathrm{RbBr}$ doped with $\mathrm{Li}^{+}$should yield the largest red-shift of the $\mathrm{F}_{\mathrm{A}}$ centre absorption bands. Figure 4.15 shows the MCDA spectrum of $\operatorname{RbBr}:\left(0.1 \% \mathrm{Ga}^{+}\right.$, $1 \% \mathrm{Li}^{+}$) after $\mathrm{X}$-irradiation at $\mathrm{RT}$. Besides the strong $\mathrm{F}$ centre band an additional band with its maximum peaking at $1.57 \mathrm{eV}(790 \mathrm{~nm})$ appears. Corresponding to the data of table 4.2 this band is assigned to the $\mathrm{F}_{\mathrm{A} 1}$ transition of perturbed $\mathrm{F}$ centres due to the $\mathrm{Li}^{+}$doping. After bleaching into the F band at RT using a HeNe laser, a fraction of the F centres could be converted into $\mathrm{F}_{\mathrm{A}}$ centres. PSL excitation spectra of $\mathrm{RbBr}:\left(\mathrm{Ga}^{+}, \mathrm{Li}^{+}\right)$ proved that the $\mathrm{F}_{\mathrm{A}}$ centres are photostimulable in all their absorption bands and, therefore, permit read-out of stored X-ray information in the near infrared region [92]. 


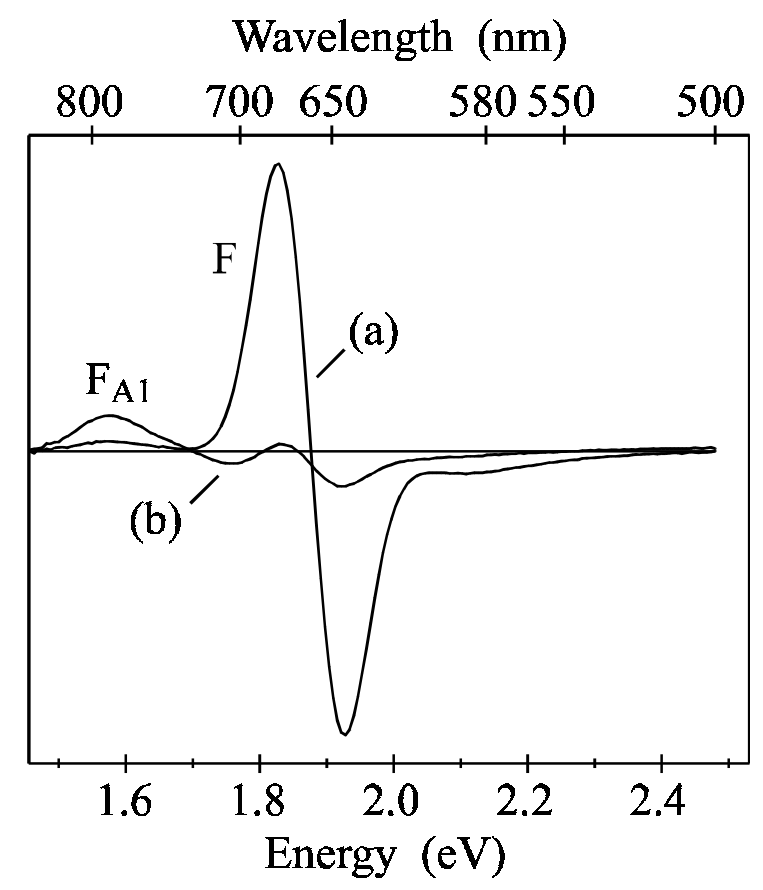

Figure 4.15 MCDA spectra of $\operatorname{RbBr}:\left(0.1 \% \mathrm{Ga}^{+}, 1 \% \mathrm{Li}^{+}\right)$, recorded at $1.5 \mathrm{~K}$ (a) immediately after X-irradiation at RT and (b) after $60 \mathrm{sec}$ bleaching (HeNe laser) at RT [92].

The dose dependence of the amount of the X-ray induced $F$ and $F_{A}$ centres was analysed by measuring the MCDA of both centres for X-ray doses from $40 \mathrm{mR}$ to $1400 \mathrm{mR}$ at $1.5 \mathrm{~K}$ in $1 \% \mathrm{Li}^{+}$-doped $\mathrm{RbBr}: \mathrm{Ga}^{+}$. The results are presented in figure 4.16: The magnitudes of the MCDA maxima of the $\mathrm{F}$ and $\mathrm{F}_{\mathrm{A}}$ centres (for the latter the $\mathrm{F}_{\mathrm{A} 1}$ maximum) are determined for each dose and plotted versus the $\mathrm{X}$-ray dose. In the high dose regime the $\mathrm{F}$ and $\mathrm{F}_{\mathrm{A}}$ bands increase approximately to the same degree, whereas in the low dose regime the $\mathrm{F}$ band increases faster than the $\mathrm{F}_{\mathrm{A} 1}$ band with increasing dose. For doses lower than $40 \mathrm{mR}$ the signal to noise ratio was too poor to clearly separate the $\mathrm{F}_{\mathrm{A} 1}$ MCDA band from the background.

Figure 4.17 presents the percentage of $\mathrm{F}_{\mathrm{A} 1} / \mathrm{F}$ versus the applied $\mathrm{X}$-ray dose, calculated from the data of figure 4.16. It is seen more clearly in this diagram that the $\mathrm{F}_{\mathrm{A}}$ formation is preferred when $\mathrm{X}$-irradiating with low doses, comparable to doses applied in medical diagnostics. The relative fraction of $\mathrm{F}_{\mathrm{A} 1} / \mathrm{F}$ increases to about $10 \%$ at $40 \mathrm{mR}$ for the investigated sample which exceeds the $6 \%$ statistical chance (6 next nearest neighbours) that an $\mathrm{F}$ centre is formed adjacent to a $\mathrm{Li}^{+}$cation. A disadvantage is that the $\mathrm{F}_{\mathrm{A}}\left(\mathrm{Li}^{+}\right)$ centres have a faster fading component compared to the $\mathrm{F}$ centres in $\mathrm{RbBr}: \mathrm{Ga}^{+}$. Espe- 


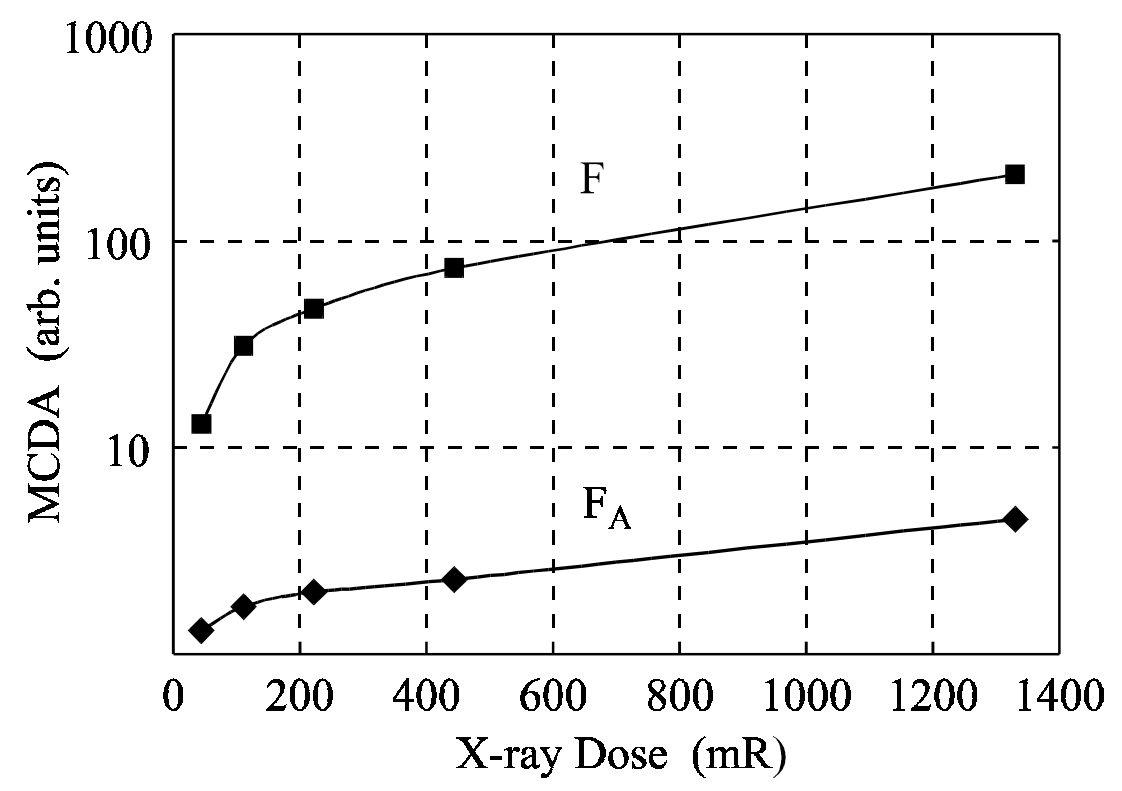

Figure 4.16 X-ray dose dependence of the intensity of the $F$ and $F_{A 1}$ MCDA bands in $1 \% \mathrm{Li}^{+}$-doped $\mathrm{RbBr}: \mathrm{Ga}^{+}$. The spectra were recorded at $1.5 \mathrm{~K}$ after $\mathrm{X}$ irradiation at RT [92].

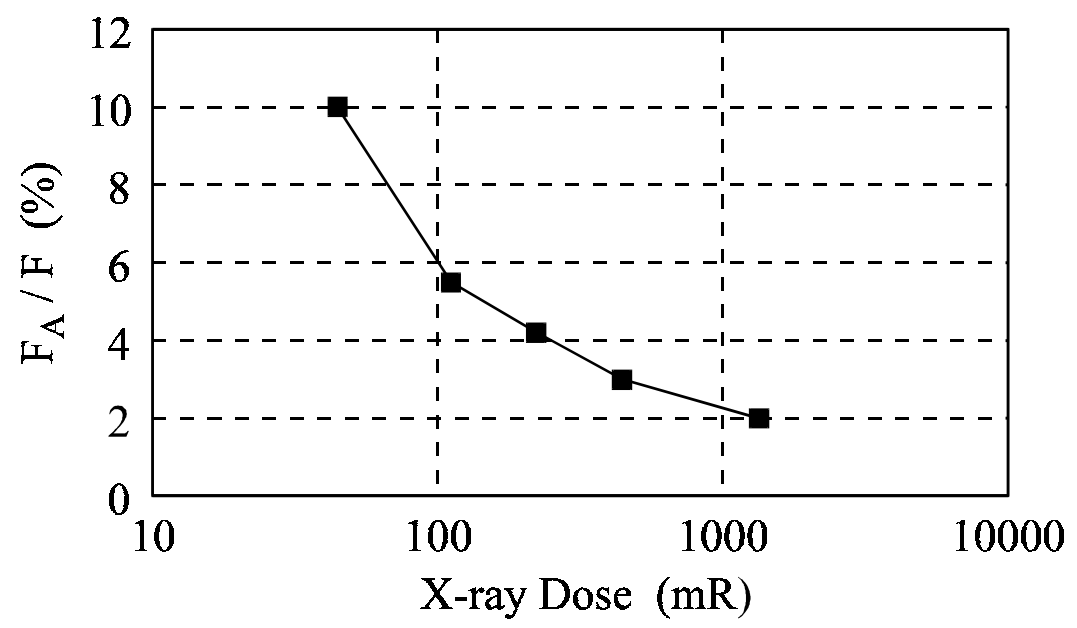

Figure 4.17 Relative amount of $\mathrm{F}_{\mathrm{A}}$ over $\mathrm{F}$ as a function of the $\mathrm{X}$-ray dose for $1 \% \mathrm{Li}^{+}-$ doped $\mathrm{RbBr}: \mathrm{Ga}^{+}$[92].

cially a high $\mathrm{Li}^{+}$doping level of $10 \%$ seems disadvantageous, since the half time of the $\mathrm{F}_{\mathrm{A}}$ centres is only 2 hours compared to the 14 hours of the $\mathrm{F}$ centres [92].

It was not possible to produce $\mathrm{F}_{\mathrm{A}}\left(\mathrm{K}^{+}\right)$centres in $\mathrm{RbBr}: \mathrm{Ga}^{+}$by $\mathrm{X}$-irradiation. However, $\mathrm{Na}^{+}$-doping leads to an $\mathrm{F}_{\mathrm{A} 1}\left(\mathrm{Na}^{+}\right)$band peaking at about $750 \mathrm{~nm}$, less red-shifted than that of $\mathrm{F}_{\mathrm{A}}\left(\mathrm{Li}^{+}\right) . \mathrm{F}_{\mathrm{A}}\left(\mathrm{Na}^{+}\right)$has not been followed further, since it seems less attractive. 
Co-doping $\mathrm{CsBr}: \mathrm{Ga}^{+}$with lighter alkali ions to achieve a red-shift of the PSL excitation seems less attractive. However, a red-shift of the PSL excitation is feasible even though it is not as much pronounced as in $\mathrm{RbBr}:\left(\mathrm{Ga}^{+}, \mathrm{Li}^{+}\right)$. Unfortunately, the $\mathrm{F}_{\mathrm{A} 1}$ band responsible for the red-shift could not be enhanced by a bleaching technique. Moreover, the creation of a red-shift of the PSL excitation in $\mathrm{CsBr}: \mathrm{Ga}^{+}$by co-doping with light alkali ions is disadvantageous regarding the PSL performance. Only a $\mathrm{Rb}^{+}$co-doping seems promising [92].

\subsection{RbBr: $\mathrm{Eu}^{2+}$ and $\mathrm{CsBr}: \mathrm{Eu}^{2+}$}

$\mathrm{CsBr}$ doped with $\mathrm{Eu}^{2+}$ has a figure of merit as high as $\mathrm{BaFBr}: \mathrm{Eu}^{2+}$ [22]. Although no UV excited photoluminescence of $\mathrm{Eu}^{2+}$ could be observed, there was a significant PSL effect after X-irradiation of $\mathrm{CsBr}: \mathrm{Eu}^{2+}$ at RT. It is known that $\mathrm{Eu}^{2+}$ doped into $\mathrm{CsBr}$ forms dipoles of $\mathrm{Eu}^{2+}$ and charge compensating cation vacancies $\left(\mathrm{v}_{\mathrm{c}}\right)$ which agglomerate very quickly to different types of aggregates [94]. The investigated $\mathrm{CsBr} \mathrm{Eu}^{2+}$ samples did not show any photoluminescence, but an intense X-ray luminescence (XL). The XL spectra comprised several luminescence bands which are probably due to different kinds of $\mathrm{Eu}^{2+}$ aggregates. After X-irradiation at RT the PSL spectra stimulated in the F centre absorption band reproduce the XL spectra quite well. It seems that all $\mathrm{Eu}^{2+}$ aggregates observed in XL participate in the PSL process. The radiative life time of these $\mathrm{Eu}^{2+}$ aggregates is about $1 \mathrm{~ms}$ [22] and thus much longer to the one of isolated $\mathrm{Eu}^{2+}$ $(\approx 1 \mu \mathrm{s})$.

After X-irradiation at RT there was also a PSL effect in $\mathrm{RbBr}: \mathrm{Eu}^{2+}$. Here, it was even possible to observe UV excited photoluminescence due to isolated $\mathrm{Eu}^{2+}-\mathrm{v}_{\mathrm{c}}$ dipoles and different $\mathrm{Eu}^{2+}$ aggregates [95]. MCDA investigations yielded several intense bands in the spectral range between 220 and $420 \mathrm{~nm}$. MCDA-detected EPR showed not only EPR lines from the [110] oriented $\mathrm{Eu}^{2+}-\mathrm{v}_{\mathrm{c}}$ dipole [96], but also from further $\mathrm{Eu}^{2+} \mathrm{ag}-$ gregates. 


\subsection{The elpasolites $\mathrm{Cs}_{2} \mathrm{NaYF}_{6}: \mathrm{Ce}^{3+}$ and $\mathrm{Cs}_{2} \mathrm{NaYF}_{6}: \mathrm{Pr}^{3+}$}

Elpasolites of type $\mathrm{Cs}_{2} \mathrm{NaYF}_{6}$ have a cubic crystal structure [97] (figure 4.18). The $\mathrm{Na}^{+}$ and $\mathrm{Y}^{3+}$ ions build a sublattice with $\mathrm{NaCl}$ structure. The $\mathrm{Cs}^{+}$ions occupy the centre of the unit cell of the $\mathrm{Na}^{+}-\mathrm{Y}^{3+}$ sublattice whereas the $\mathrm{F}^{-}$ions reside on the axis connecting $\mathrm{Na}^{+}$and $\mathrm{Y}^{3+}$. A trivalent activator, such as $\mathrm{Ce}^{3+}$ or $\mathrm{Pr}^{3+}$, substitutes for $\mathrm{Y}^{3+}$ in sites with octahedral symmetry.

Under X-ray or UV excitation Ce-doped $\mathrm{Cs}_{2} \mathrm{NaYF}_{6}$ shows a strong emission band at $3.44 \mathrm{eV}(360 \mathrm{~nm})$ arising from the allowed $5 d-4 f$ transition of $\mathrm{Ce}^{3+}$. Cs is a heavy ion, so the expectation is that if electron and hole trap centres can be formed, storage and PSL properties will be found. Indeed, it has been found that upon X-irradiation the luminescence of the activator $\mathrm{Ce}^{3+}$ at $3.44 \mathrm{eV}(360 \mathrm{~nm})$ can be photostimulated by excitation at about $2.25 \mathrm{eV}(550 \mathrm{~nm})$ at $300 \mathrm{~K}[2,9,98]$. The PSL decay time of $\mathrm{Ce}^{3+}$ is fast, namely $42 \mathrm{~ns}$ at RT, and is, within experimental error, identical with the $\mathrm{Ce}^{3+}$ radiative life time upon direct UV excitation. Thus, the bottleneck for the PSL decay time is the

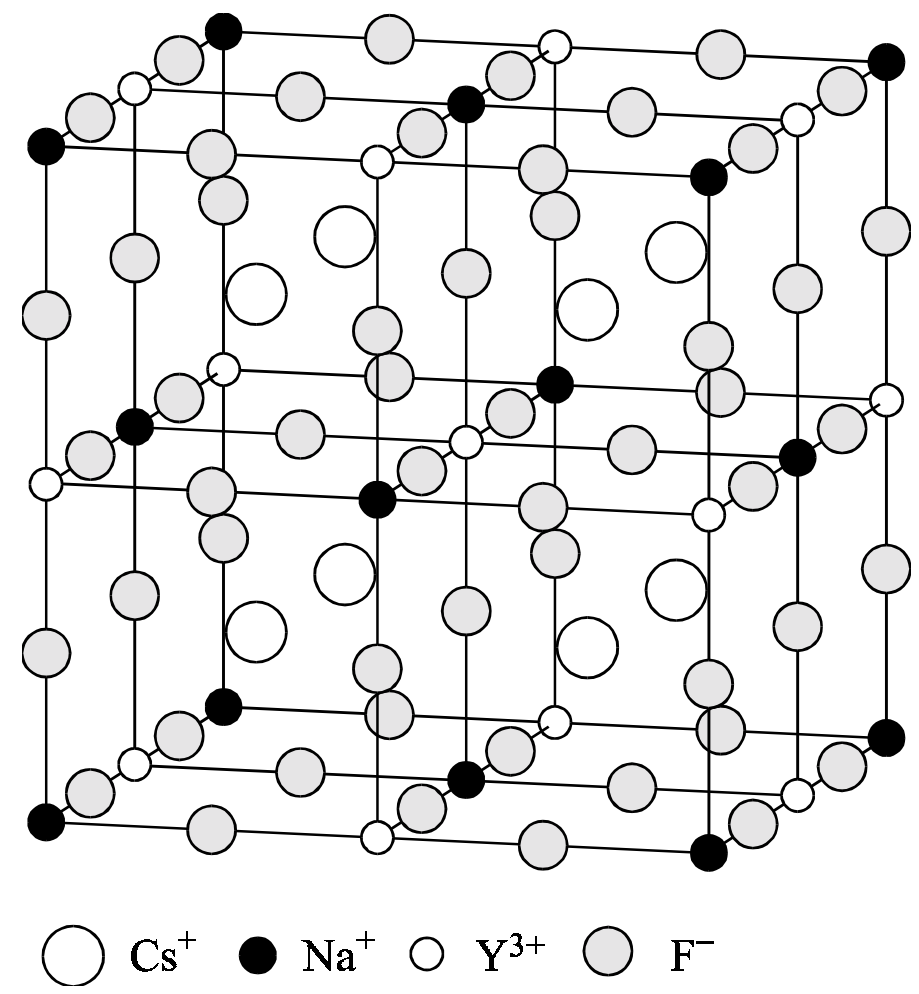

Figure 4.18 Crystal structure of the cubic elpasolite Cs NaYF . 
radiative life time of the activator $\mathrm{Ce}^{3+}$. One can assume that the electron-hole recombination process occurs via tunnelling and not via the conduction band. PSL has also been observed for $\mathrm{Pr}^{3+}$ as activator $[2,9,98]$. However, the radiative life time of the PSL is much longer, i.e. $4 \mathrm{~ms}$ at RT.

The maximum of the PSL stimulation of $\mathrm{Cs}_{2} \mathrm{NaYF}_{6}: \mathrm{Ce}^{3+}$ is at about $530 \mathrm{~nm}$, i.e. a frequency-doubled Nd-YAG $(533 \mathrm{~nm})$ would be ideal for photostimulation. For a stimulation at $633 \mathrm{~nm}$ (HeNe laser) the PSL efficiency is already reduced to $40 \%$. In comparison to $\mathrm{BaFBr}: \mathrm{Eu}^{2+}$ the PSL stimulation is shifted to shorter wavelength which makes the use of cheap semiconductor light emitting diodes (LED) as light sources for photostimulation impossible. Investigations on the stability of the photostimulable centres showed that the PSL efficiency is reduced to half its value after storing $\mathrm{X}$-irradiated $\mathrm{Cs}_{2} \mathrm{NaYF}_{6}: \mathrm{Ce}^{3+}$ in the dark at RT for $80 \mathrm{~min}$. This value is still acceptable for an X-ray storage phosphor. After $30 \mathrm{~h}$ the PSL efficiency decreases to a constant value of $15 \%$. The conversion efficiency (CE) of $\mathrm{Cs}_{2} \mathrm{NaYF}_{6}: \mathrm{Ce}^{3+}$ was determined to $15 \mathrm{pJ} / \mathrm{mm}^{2} / \mathrm{mR}$, i.e. comparable to $\mathrm{BaFBr}: \mathrm{Eu}^{2+}$, whereas the stimulation energy was $90 \mu \mathrm{J} / \mathrm{mm}^{2}$, i.e. somewhat higher, but still in the same order of magnitude as $\mathrm{BaFBr}: \mathrm{Eu}^{2+}$ [99].

MCDA and MCDA-EPR spectroscopy showed that the photostimulable electron trap centres are $\mathrm{F}$ centres. ENDOR measurements have shown that the $\mathrm{F}$ centres in this crystal are of lower symmetry than, for example, in the alkali halides or in $\mathrm{BaFBr}[100$, 101]. The hole trap centre is the activator, i.e. $\mathrm{Ce}^{3+}$ or $\mathrm{Pr}^{3+}$. The proof for this was established when examining diamagnetic $\mathrm{Pr}^{3+}$ as an activator, since after X-irradiation this turned into paramagnetic $\operatorname{Pr}^{4+}$, which could be detected by EPR. $\mathrm{Ce}^{3+}\left([\mathrm{Xe}] 4 f^{1}\right)$ is paramagnetic due to its unpaired $f$-electron, whereas $\operatorname{Pr}^{3+}\left([\mathrm{Xe}] 4 f^{2}\right.$ ) has no unpaired electron and is thus diamagnetic. After $\mathrm{X}$-irradiation $\mathrm{Ce}^{3+}$ captures a hole and is converted to diamagnetic $\mathrm{Ce}^{4+}([\mathrm{Xe}])$, but $\operatorname{Pr}^{3+}$ to paramagnetic $\operatorname{Pr}^{4+}\left([\mathrm{Xe}] 4 f^{1}\right)$. To check whether $\mathrm{Ce}^{4+}$ or $\mathrm{Pr}^{4+}$ is really the corresponding hole trap centre in the PSL process, it was easier to observe a rise of the $\operatorname{Pr}^{4+}$ EPR than a decrease of the very intense $\mathrm{Ce}^{3+}$ signal intensity.

$\mathrm{X}$-irradiation of undoped $\mathrm{Cs}_{2} \mathrm{NaYF}_{6}$ below $100 \mathrm{~K}$ creates mainly $\mathrm{F}$ and $\mathrm{V}_{\mathrm{K}}$ centres which are present in a comparable number. The $g$ tensor and the hyperfine tensor of the $\mathrm{V}_{\mathrm{K}}$ centre are very similar to those of the $\mathrm{V}_{\mathrm{K}}$ centre found in $\mathrm{NaF}$ [77]. The $\mathrm{V}_{\mathrm{K}}$ centre has two optical absorption bands, at $1.43 \mathrm{eV}$ and at $3.69 \mathrm{eV}$, which correspond to the $\Sigma_{\mathrm{u}}-\Pi_{\mathrm{g}}$ and the $\Sigma_{\mathrm{u}}-\Sigma_{\mathrm{g}}$ transition of the $\mathrm{X}_{2}{ }^{-}$molecule, respectively [77]. This assignment was confirmed by MCDA-EPR. The $\mathrm{V}_{\mathrm{K}}$ centre decays thermally at temperatures above 


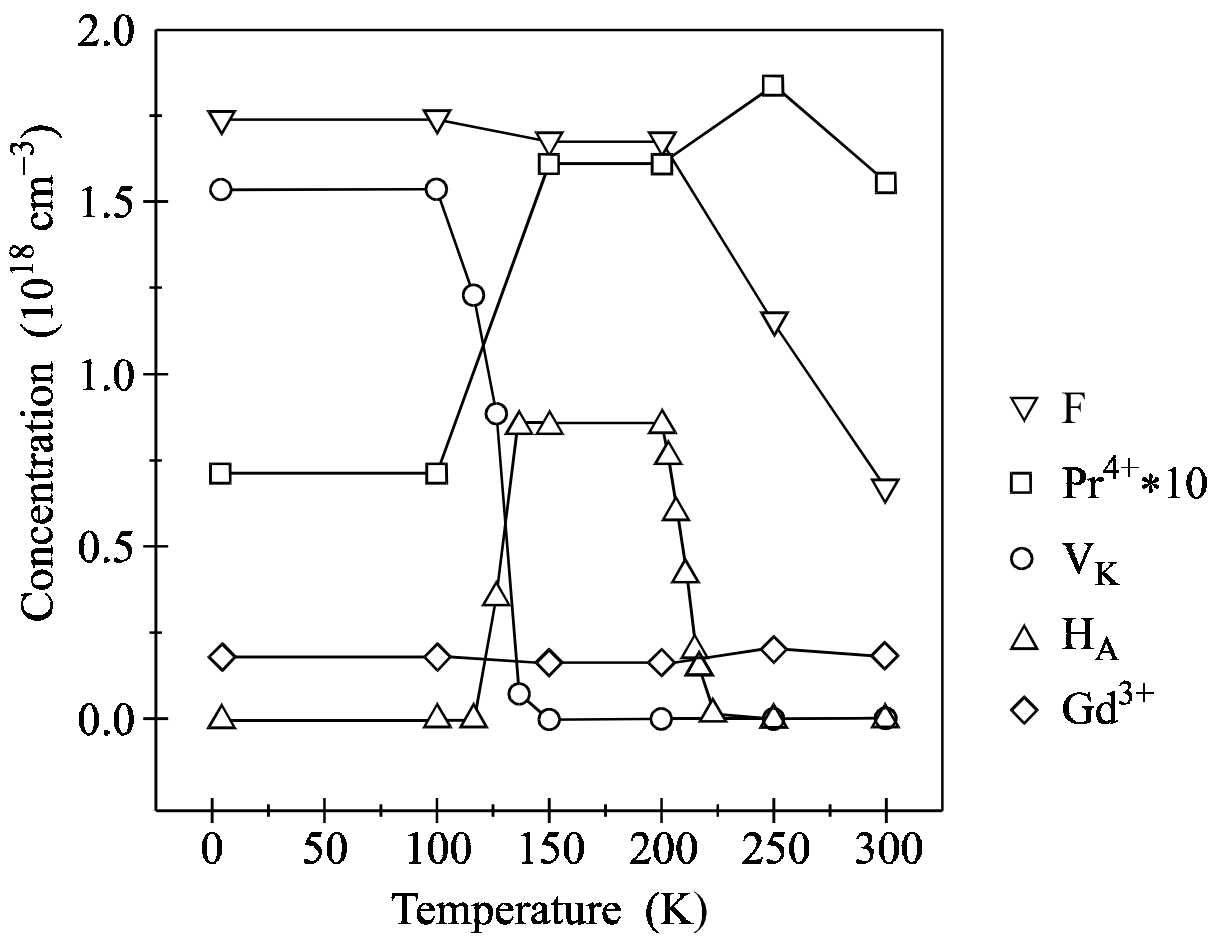

Figure 4.19 $\mathrm{F}$ and hole trap centre concentration in $\mathrm{Cs}_{2} \mathrm{NaYF}_{6}: \mathrm{Pr}^{3+}$ after $\mathrm{X}$-irradiation at $10 \mathrm{~K}$ and subsequent annealing steps up to $\mathrm{RT}$. $\mathrm{Gd}^{3+}$ was present as an unintended impurity [100].

$150 \mathrm{~K}$ whereby new hole trap centres of $\mathrm{X}_{2}^{-}$type appear which are not exactly aligned along [110] what is expected for an unperturbed alignment of these centres. It is assumed that they are $\mathrm{K}^{+}$- or $\mathrm{Rb}^{+}$-perturbed $\mathrm{H}$ centres $\left(\mathrm{H}_{\mathrm{A}}\right.$ centres) $[100,101]$. The optical absorption bands of the $\mathrm{H}_{\mathrm{A}}$ centre are shifted to higher energies compared to the $\mathrm{V}_{\mathrm{K}}$ centre, i.e. to $1.66 \mathrm{eV}$ and $3.86 \mathrm{eV}$, respectively. The $\mathrm{F}$ centre concentration is almost unaffected by this annealing step to $150 \mathrm{~K}$. The decay of the $\mathrm{H}_{\mathrm{A}}$ centre at about $230 \mathrm{~K}$ is accompanied by a significant decrease in the $\mathrm{F}$ centre concentration.

The $\mathrm{F}$ and hole trap centre concentration of $\mathrm{Cs}_{2} \mathrm{NaYF}_{6}: \mathrm{Pr}^{3+}$ after X-irradiation at $10 \mathrm{~K}$ and subsequent stepwise annealing to $\mathrm{RT}$ is shown in figure 4.19 . X-irradiation at $10 \mathrm{~K}$ generates not only $\mathrm{F}$ and $\mathrm{V}_{\mathrm{K}}$ centres, but also a small number of $\operatorname{Pr}^{4+}$ centres. Note, that in figure 4.19 the $\operatorname{Pr}^{4+}$ concentration is scaled up by a factor of 10 . The holes are liberated by the $\mathrm{V}_{\mathrm{K}}$ centre decay at $150 \mathrm{~K}$ and captured by interstitial fluorines forming $\mathrm{H}_{\mathrm{A}}$ centres. Some of the holes are captured by $\mathrm{Pr}^{3+}$ causing an increase of the $\mathrm{Pr}^{4+}$ concentration by a factor of 2 whereby the PSL efficiency is increased by the same amount. Annealing to $230 \mathrm{~K}$ leads to the $\mathrm{H}_{\mathrm{A}}$ centre decay and simultaneously to a partial decay 


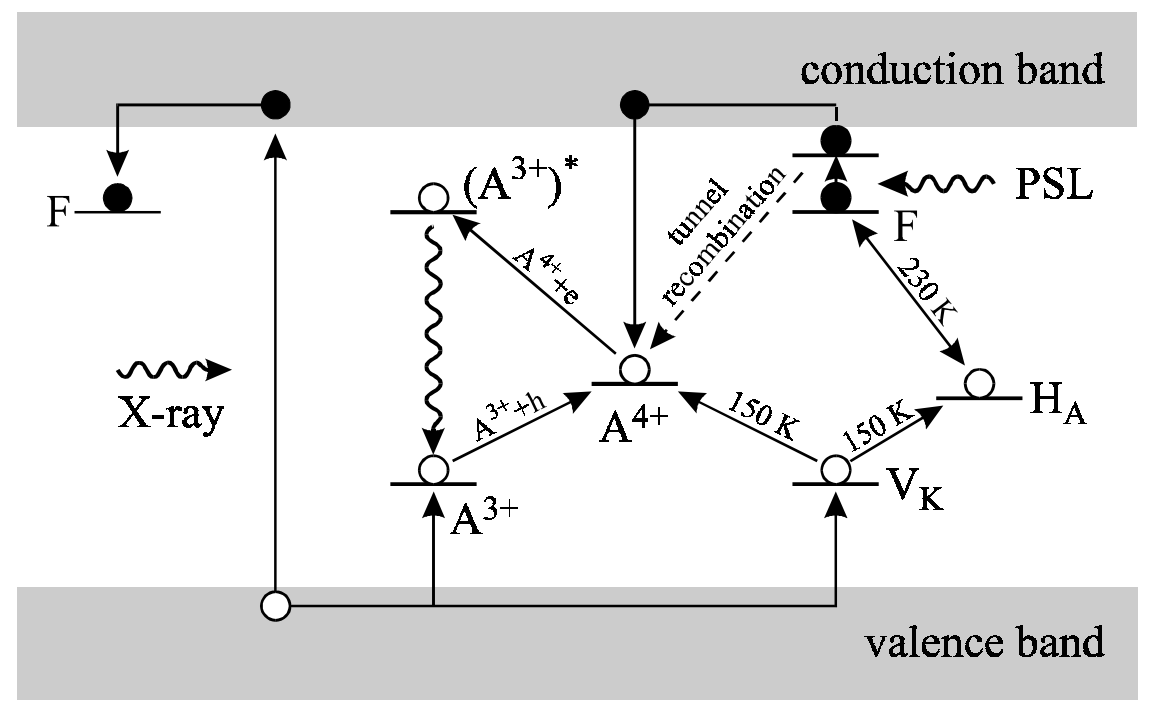

$$
\mathrm{A}=\mathrm{Ce}, \operatorname{Pr}
$$

Figure 4.20 Scheme of the PSL mechanism and the thermal conversion of the generated hole trap centres in X-irradiated Cs NaYF : $\mathrm{Ce}^{3+}, \operatorname{Pr}^{3+}[98]$.

of the F centres. The F centre concentration is reduced further by annealing to RT, which is probably due to a recombination with unidentified hole trap centres, whereas the $\mathrm{Pr}^{4+}$ concentration and the PSL efficiency remains unchanged.

Stimulation experiments have shown that about $50 \%$ of the PSL active $\mathrm{F}$ and $\mathrm{Pr}^{4+}$ centres are spatially correlated. This result was obtained by detecting the EPR signal of the paramagnetic $\operatorname{Pr}^{4+}$ after X-irradiation at RT. Stimulating at $10 \mathrm{~K}$ into the F centre absorption band reduces the $\operatorname{Pr}^{4+}$ concentration considerably in the first minutes, but reaches a constant value of about $50 \%$ upon continued stimulation. The initial exponential decrease indicates a tunnelling recombination of pairs of electron ( $F$ centre) and hole trap centres $\left(\operatorname{Pr}^{4+}\right)$ which are separated by definite distances having only a small variation. In $\mathrm{BaFBr}$ doped with the activator $\mathrm{Eu}^{2+}$ the PSL process occurs also via a tunnelling recombination between the created electron and hole trap centres [23]. A subsequent stimulation at RT destroys all the remaining $\operatorname{Pr}^{4+}$ centres. This observation can be explained by the assumption that $50 \%$ of the PSL-active $\mathrm{F}$ and $\mathrm{Pr}^{4+}$ centres, generated by X-irradiation at RT, are spatially correlated. It is possible to read them out even at $10 \mathrm{~K}$ by inducing a tunnelling recombination. The non-correlated centres are not PSL-active at low temperatures. Their recombination requires thermal activation. The optically excited electron of the F centre may then escape thermally from its relaxed excited state into the conduction band. Figure 4.20 shows the two proposed recombina- 
tion paths and the thermal conversion of the created defects. In $\mathrm{Cs}_{2} \mathrm{NaYF}_{6}: \mathrm{Ce}^{3+}$ the mechanism is considered to be analogue to the one in the $\operatorname{Pr}^{3+}$-doped elpasolite, i.e. $\mathrm{Ce}^{4+}$ plays here the role of the PSL-active hole trap centre [98]. 


\section{Chapter 5}

\section{Glasses and glass ceramics}

A continuing difficulty in the dimensional X-ray imaging is that in X-ray storage phosphor screens considerable scattering of the read-out light occurs, limiting the resolution to around 5 line pairs $/ \mathrm{mm}$. One possible improvement to this scattering problem would be a phosphor based on a cubic system as discussed in section 5 or a phosphor based on a glass. There have been reports of the observation of a weak PSL in Eu-doped fluoroaluminate glass [102], and in Ce- or Eu-doped borate based glasses [103, 104]. Unfortunately, the magnitude of the weak PSL effect was not stated. A glass phosphor would have the additional advantages of arbitrary shapes useful for applications in medicine and non-destructive testing.

In contrast to the literature it was reported [105] that in Eu- or Ce-doped fluoroaluminate glass, or in a Eu-doped borate glass no PSL was observed at RT. However, a significant PSL was seen in a modified $\mathrm{Eu}^{2+}$ doped fluorozirconate glass, where a substantial fraction $(5 \%)$ of the fluoride ions were replaced by bromide ions in the melt resulting in a glass ceramic containing small crystallites of a high-pressure phase of $\mathrm{BaBr}_{2}$.

\subsection{Production of fluorozirconate glasses and glass ceramics}

The well-known ZBLAN20 composition for fluorozirconate glasses was modified by replacing most of the $\mathrm{NaF}$ with $\mathrm{NaBr}$ so that the total number of $\mathrm{Br}^{-}$ions was $5 \%$ of the total number of anions, and by substituting some of the $\mathrm{LaF}_{3}$ with $\mathrm{YF}_{3}$ to improve the glass quality. The composition of the modified glass was then $53 \% \mathrm{ZrF}_{4}, 20 \% \mathrm{BaF}_{2}, 6 \%$ $\mathrm{NaF}, 14 \% \mathrm{NaBr}, 1.5 \% \mathrm{LaF}_{3}, 3 \% \mathrm{AlF}_{3}, 1 \% \mathrm{EuF}_{2}$ or $\mathrm{CeF}_{3}$ and $1.5 \% \mathrm{YF}_{3}$. The glass raw materials were first mixed and then melted in a glassy carbon crucible at about $750{ }^{\circ} \mathrm{C}$, 


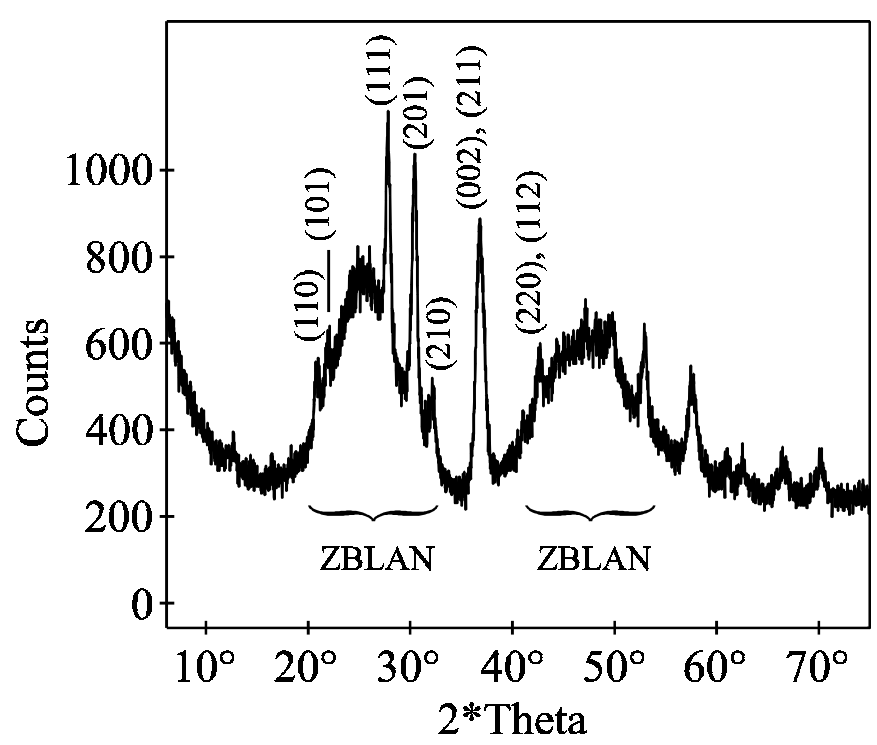

Figure 5.1 X-ray diffraction spectrum for $\mathrm{Cu} \mathrm{K} \alpha$ radiation of bromine-doped fluorozirconate glass, recorded at RT [106].

before being poured out into a brass mould at $220{ }^{\circ} \mathrm{C}$ and cooled to RT over 12 hours. The whole glass manufacture was done in an inert nitrogen atmosphere. There was evidence of crystallisation in all of the doped glasses, ranging from a near-transparent glass which was yellow in transmitted light but blue in scattered light, to one which was opaque and milky-white. These differences presumably reflect variations in crystallite size and concentration [105].

\subsection{X-ray diffraction of fluorozirconate glasses and glass ce- ramics}

X-ray diffraction of the base glass with no bromine doping showed no sharp peaks, just broad maxima at 26 and 47 degrees (for $\mathrm{Cu} \mathrm{K} \alpha$ radiation) typical for glasses close to the ZBLAN formulation. However, the bromine-doped glass (milky-white) showed a pattern of relatively sharp diffraction lines from an included crystalline phase superimposed on the broad glass background (figure 5.1). Almost all of the lines in the pattern could be attributed to the so-called high pressure form of $\mathrm{BaBr}_{2}$ which has the anti-Fe ${ }_{2} \mathrm{P}$ structure $[107,108]$. 


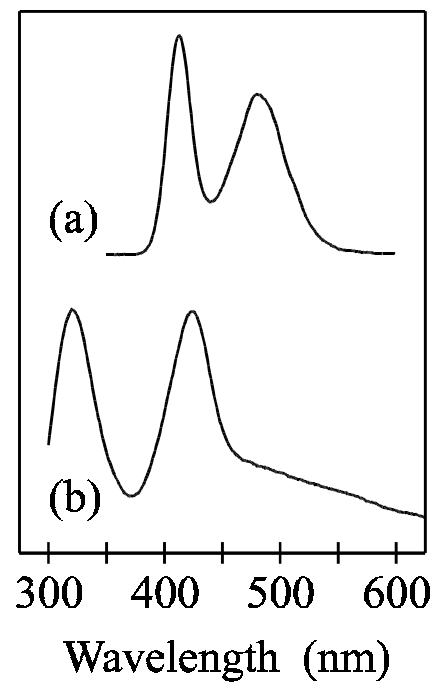

Figure 5.2 Photoluminescence spectra recorded at RT for (a) the $\mathrm{Eu}^{2+}$ doped glass ceramic and (b) the $\mathrm{Ce}^{3+}$ doped glass ceramic, excited at $270 \mathrm{~nm}$ [105].

\subsection{Photoluminescence and PSL of fluorozirconate glasses and glass ceramics}

The photoluminescence spectrum of the base glass, without bromine doping, showed no fluorescence from $\mathrm{Eu}^{2+}$ or $\mathrm{Ce}^{3+}$ ions, although it was clear from EPR and Mössbauer studies that $\mathrm{Eu}^{2+}$ was certainly present in the $\mathrm{Eu}^{2+}$ doped glass [109]. This quenching of the fluorescence has been tentatively ascribed to competing charge transfer processes involving the $\mathrm{Zr}^{4+}$ ions [109]. In contrast, the glass with bromine doping and either $\mathrm{Eu}^{2+}$ or $\mathrm{Ce}^{3+}$ co-doping each show two PL bands, at $413 \mathrm{~nm}$ and a broader band centred at $485 \mathrm{~nm}$ for $\mathrm{Eu}^{2+}$, and one band at $320 \mathrm{~nm}$ and a broader band at $425 \mathrm{~nm}$ for $\mathrm{Ce}^{3+}$, as shown in figure 5.2. Since $\mathrm{Eu}^{2+}$ and $\mathrm{Ce}^{3+}$ ions in the glass itself do not fluoresce, the observed emissions probably come from $\mathrm{Eu}^{2+}$ or $\mathrm{Ce}^{3+}$ in the crystallites. The bands were tentatively assigned to $5 d-4 f$ transitions of $\mathrm{Eu}^{2+}$ or $\mathrm{Ce}^{3+}$ ions at the two $\mathrm{Ba}^{2+}$ sites in the $\mathrm{BaBr}_{2}$ crystallites [105]. The PL spectrum which was observed in the $\mathrm{Eu}^{2+}$ glass ceramic is quite different from the single band observed in the low pressure form of $\mathrm{BaBr}_{2}$ doped with $\mathrm{Eu}^{2+}[110]$. However, the emissions could also come from $\mathrm{Eu}^{2+}$ or $\mathrm{Ce}^{3+}$ containing $\mathrm{Br}^{-}$aggregates in the glass. At present this is an open question.

Of the two luminescent peaks for $\mathrm{Eu}^{2+}$ only that at $413 \mathrm{~nm}$ shows a measurable PSL effect. For the $\mathrm{Ce}^{3+}$-doped glass ceramic, only the peak at $425 \mathrm{~nm}$ showed PSL. The 


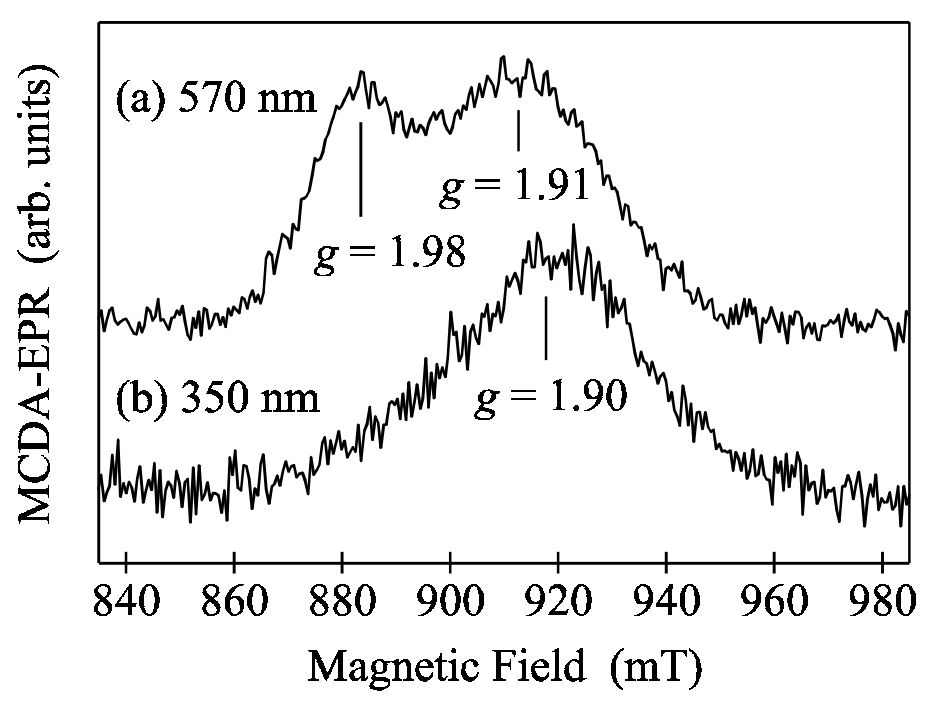

Figure 5.3 MCDA-detected EPR of Ce-doped fluorozirconate glass, detected at (a) $570 \mathrm{~nm}$ and (b) $350 \mathrm{~nm}$, recorded at $1.5 \mathrm{~K}$ after X-irradiation at RT applying $24 \mathrm{GHz}$ microwave frequency [114].

relative magnitudes of the effects were determined by performing identical spectroscopic measurements on a piece of crystalline $\mathrm{BaFBr}: \mathrm{Eu}^{2+}(1000 \mathrm{ppm}$ europium) and the glass ceramic (milky-white), except for a longer exposure time in the latter case. This comparison showed that the PSL effect in the glass ceramic was approximately 4000 times weaker in the case of $\mathrm{Eu}^{2+}$ and 2000 times weaker in the case of $\mathrm{Ce}^{3+}$ compared to BaFBr:Eu ${ }^{2+}$, after the longer exposure time was compensated for. The excitation spectrum for the PSL, being the luminescence intensity at $413 \mathrm{~nm}$ for $\mathrm{Eu}^{2+}$ and at $425 \mathrm{~nm}$ for $\mathrm{Ce}^{3+}$ as a function of the photostimulation wavelength, comprises a broad peak centred at about $570 \mathrm{~nm}$, with a similar spectral shape in both cases.

\subsection{Electron and hole trap centres}

It is known from other X-ray storage phosphors such as elpasolites (e.g. [9]) that $\mathrm{Ce}^{3+}$ acts as a very efficient hole trap centre being converted to $\mathrm{Ce}^{4+}$. Assuming that the diamagnetic $\mathrm{Ce}^{4+}$ is the hole trap centre, magnetic resonance methods allow the investigation of the complementary electron trap centres.

The MCDA of a $\mathrm{Ce}^{3+}$-doped fluorozirconate glass showed an intense paramagnetic band peaking at $285 \mathrm{~nm}$, which can be assigned to the $\mathrm{Ce}^{3+}$ absorption [111], and a second one between 300 and $550 \mathrm{~nm}$ with its maximum at $310 \mathrm{~nm}$ having opposite sign. 


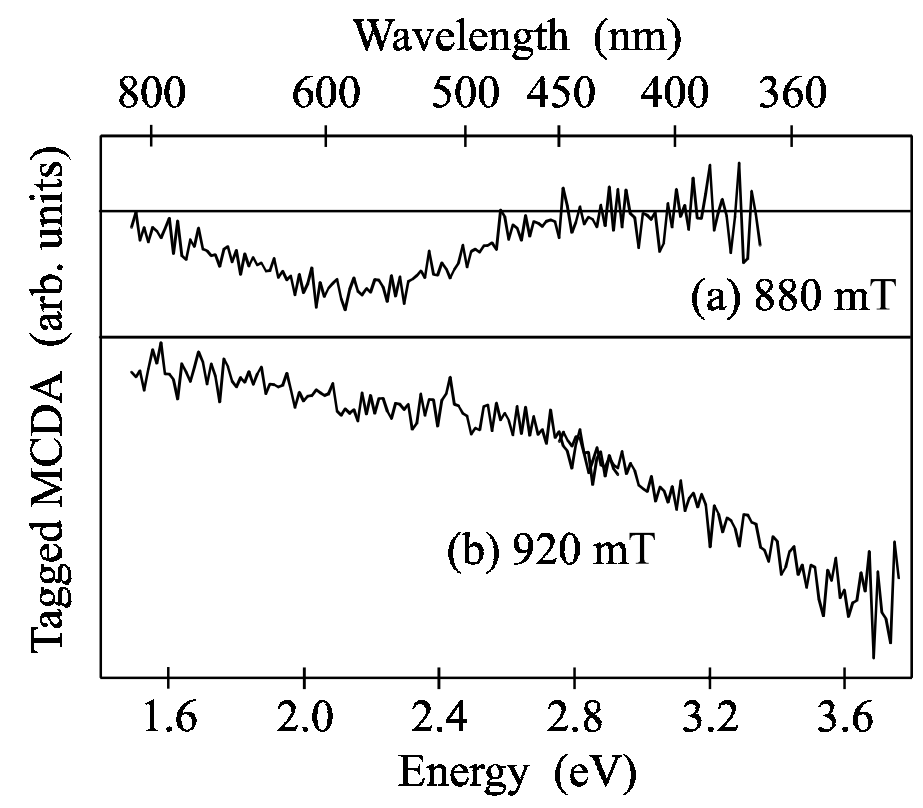

Figure 5.4 "Tagged" MCDA spectra of Ce-doped fluorozirconate glass, detected at (a) $880 \mathrm{mT}$ and (b) $920 \mathrm{mT}$, recorded after X-irradiation at $1.5 \mathrm{~K}$ applying $24 \mathrm{GHz}$ microwave frequency. For the sake of clarity the spectra are vertically displaced [114].

MCDA-detected EPR on the band peaking at $285 \mathrm{~nm}$ yielded a single line which can be simulated using the theoretical $g$ tensor $g_{\perp}=18 / 7$ and $g_{\|}=6 / 7$ for the $J=5 / 2$ ground state of the $4 f^{1}$ electron of $\mathrm{Ce}^{3+}[112]$. Note, that in a powder or glass sample all angular orientations are represented with equal probability. The effect of this angular averaging can be mathematically simulated, leading to the calculation of "powder pattern". In general, paramagnetic centres in a glass will be characterised by a statistical distribution in the spin Hamiltonian parameters as a consequence of vitreous disorder. This contrasts with powdered crystalline materials where discrete sets of parameters pertain [113].

After X-irradiation at RT the MCDA spectrum showed a new band at approximately $570 \mathrm{~nm}$ in addition to an increased paramagnetic signal in the range from 300 to $700 \mathrm{~nm}$ which corresponds to the maximum of the stimulation of the PSL [105]. EPR detected in the MCDA at $570 \mathrm{~nm}$ (figure 5.3a) yielded a double-structured line with peaks at $g=1.98 \pm 0.01$ and at $g=1.91 \pm 0.01$, whereas MCDA-detected EPR at $350 \mathrm{~nm}$ (figure 5.3b) showed only a single line at $g=1.90 \pm 0.01$. The $g$ values of these resonances, being smaller than $g_{\mathrm{e}}$ for the free electron, indicate that electron trap centres have been formed (see e.g., [10]). These lines did not appear before X-irradiation. "Tagged" 
MCDA measurements showed that the low field line at $g=1.98$ (detected at $880 \mathrm{mT}$ ) belongs to the new paramagnetic band at $570 \mathrm{~nm}$ (figure 5.4a) whereas the high field lines having $g=1.90-1.91$ (detected at $920 \mathrm{mT}$ ) belong to the band between 300 and $700 \mathrm{~nm}$ (figure 5.4b). Probably X-irradiation creates two defect centres having different MCDA bands. One centre has a $g$ value of $g=1.98$ whereas the second one has $g=1.90$. The double-structured line measured in the MCDA band at $550 \mathrm{~nm}$ is thus a superposition of two EPR lines since both show MCDA there. 


\section{Summary}

The investigation of the information storage and read-out processes in the X-ray storage phosphor $\mathrm{BaFBr}: \mathrm{Eu}^{2+}$ showed that it is necessary to distinguish between stoichiometric and non-stoichiometric BaFBr. It turned out that the stoichiometric material is always contaminated with oxygen whereas no oxygen contamination was found in the nonstoichiometric one.

For stoichiometric as well as for non-stoichiometric BaFBr, the PSL active electron trap centres are $\mathrm{F}\left(\mathrm{Br}^{-}\right)$and $\mathrm{F}\left(\mathrm{F}^{-}\right)$centres. In stoichiometric $\mathrm{BaFBr}$, "impurity" sites (e.g. oxygen or the activator) are preferred sites for the radiation-induced electron-hole centre generation. The F centre (electron trap) generation is significantly influenced by the incorporated oxygen impurities which provide the necessary anion vacancies for the $\mathrm{F}$ centres. The electron-hole pairs are obviously not created via a F-H process. In spite of thorough research by optically-detected magnetic resonance techniques no $\mathrm{H}$ centres ( (halogen $)_{2}^{-}$molecules occupying single halide sites) have been observed. The F centre generation seems thus to be impurity-limited. The hole centre taking part in the photostimulated luminescence process is still unknown.

It was shown by magic angle spinning nuclear magnetic resonance that in nonstoichiometric $\mathrm{BaFBr}, 10 \%$ fluorine "antisites" (fluorines on bromine sites) are present. The $\mathrm{F}$ centre generation occurs via a F-H process between the $\mathrm{F}^{-}$and $\mathrm{Br}^{-}$sublattices whereas no F-H process within one sublattice was observed. This is in agreement with the observations in stoichiometric $\mathrm{BaFBr}$ where no $\mathrm{H}$ centres have been found either. The existence of fluorine antisites enables the F centre generation. In non-stoichiometric $\mathrm{BaFBr}$ it is thus not impurity limited as in stoichiometric BaFBr. This feature is very promising for the use of non-stoichiometric $\mathrm{BaFBr}$ as X-ray storage phosphors for very high doses.

The spatial resolution of X-ray storage phosphor screens based on the optically anisotropic $\mathrm{BaFBr}$ is limited by the scattering of the read-out light. The scattering can proba- 
bly be reduced by using optically isotropic crystal systems instead. The search for such $\mathrm{X}$-ray storage phosphors, which have also comparable figures of merit as $\mathrm{Eu}^{2+}$-doped $\mathrm{BaFBr}$, yielded the alkali halides $\mathrm{RbBr}: \mathrm{Ga}^{+}$and $\mathrm{CsBr}: \mathrm{Ga}^{+}$as best candidates, as well as $\mathrm{CsBr}: \mathrm{Eu}^{2+}$. The elpasolite $\mathrm{Cs}_{2} \mathrm{NaYF}_{6}: \mathrm{Ce}^{3+}$ is also very promising whereas $\mathrm{KBr}: \mathrm{In}^{+}$and $\mathrm{RbI}: \mathrm{Tl}^{+}$are not so interesting for the practical applications.

The information storage and read-out process in $\mathrm{RbBr}: \mathrm{Ga}^{+}$and $\mathrm{CsBr}: \mathrm{Ga}^{+}$can be explained by a simple pair mechanism: Upon $\mathrm{X}$-irradiation $\mathrm{F}$ centres are generated as electron trap centres and $\mathrm{Ga}^{2+}$ centres as complementary hole trap centres. Two different types of $\mathrm{Ga}^{2+}$ hole trap centres were observed: $\left(\mathrm{Ga}^{2+}\right)^{\mathrm{I}}$ and $\left(\mathrm{Ga}^{2+}\right)^{\mathrm{II}}$ centres. Type $\mathrm{I}$ is an isolated $\mathrm{Ga}^{2+}$ on $\mathrm{ab}^{+}$or $\mathrm{Cs}^{+}$site, whereas type II is a complex between $\mathrm{Ga}^{2+}$ on $\mathrm{Rb}^{+}$or $\mathrm{Cs}^{+}$site and a nearest neighbouring cation vacancy. Only the type $\mathrm{I} \mathrm{Ga}^{2+}$ centres are taking part in the PSL process. In $\mathrm{RbBr}: \mathrm{Ga}^{+}$a sufficient high $\mathrm{Ga}^{+}$concentration suppresses the $\left(\mathrm{Ga}^{2+}\right)^{\mathrm{II}}$ generation. In $\mathrm{CsBr}: \mathrm{Ga}^{+}$the $\left(\mathrm{Ga}^{2+}\right)^{\mathrm{I}}$ centres clearly dominate over the PSL-inactive $\left(\mathrm{Ga}^{2+}\right)^{\mathrm{II}}$ centres for all $\mathrm{Ga}^{+}$doping levels.

For practical use, it is advantageous to red-shift the PSL-excitation to the near-infrared in order to use low cost, but high intensity laser diodes as stimulation light sources in the read-out process. BaFBr:Eu ${ }^{2+}$ as well as the two alkali halides $\mathrm{RbBr}: \mathrm{Ga}^{+}$and $\mathrm{CsBr}: \mathrm{Ga}^{+}$can be co-doped with smaller cations, leading to the formation of perturbed electron trap centres $\left(\mathrm{F}_{\mathrm{A}}\right.$ centres) the absorption bands of which are clearly red-shifted. It turned out that these sites are preferred sites for the electron-hole centre generation. Especially for low $\mathrm{X}$-ray doses the ratio between the perturbed $\mathrm{F}_{\mathrm{A}}$ and unperturbed $\mathrm{F}$ centres is clearly in favour of the perturbed one. This is in analogy to the red-shift of the PSL excitation in BaFBr:Eu ${ }^{2+}$ : The PSL excitation can be made sensitive to stimulation further into the infrared by additional $\mathrm{Ca}^{2+}$ or $\mathrm{Sr}^{2+}$ doping. Upon $\mathrm{X}$-irradiation $\mathrm{F}_{\mathrm{A}}\left(\mathrm{Br}^{-}\right.$, $\mathrm{Ca}^{2+}$ or $\mathrm{Sr}^{2+}$ ) centres are formed preferentially as photostimulable centres electron traps.

The energy storage and read-out processes in the alkali halides $\mathrm{KBr}: \mathrm{In}^{+}$and $\mathrm{RbI}: \mathrm{Tl}^{+}$and in the elpasolites $\mathrm{Cs}_{2} \mathrm{NaYF}_{6}: \mathrm{Ce}^{3+}$ and $\mathrm{Cs}_{2} \mathrm{NaYF}_{6}: \mathrm{Pr}^{3+}$ are completely understood assuming a simple pair model of an $\mathrm{F}$ centre as electron trap centre and the activator itself as complementary hole trap centre.

The observation that upon X-irradiation the electron and hole trap centres are always created with a spatial correlation to the activator is of particular interest for the functioning of the corresponding materials as storage phosphors. The reason for this spatial correlation is still an open question. A possible explanation for this phenomenon could be a lattice distortion around the activator due to an ionic radius misfit. However, an 
electron nuclear double resonance investigation of $\mathrm{Eu}^{2+}$ in $\mathrm{BaFBr}$ yielded that such a lattice distortion would only be very small (below $2 \%$ ).

Another approach to reduce the scattering of the read-out would be a phosphor based on a glass. It was shown that a fluorozirconate glass ceramic doped with $\mathrm{Eu}^{2+}$ or $\mathrm{Ce}^{3+}$ shows a significant PSL effect after X-irradiation at RT. The application of such glass ceramics as X-ray storage phosphors will depend upon optimising the crystallite size and dopant concentration so as to maximise efficiency and minimise scattering. The development of such systems is still at its beginning. 


\section{References}

[1] M. Sonoda, M. Takano, J. Miyahara, and H. Kato, Radiology 148, 833 (1983)

[2] J.-M. Spaeth, Th. Hangleiter, F.-K. Koschnick, and Th. Pawlik, Radiat. Eff. Defects Solids 135, 499 (1995)

[3] A. R. Lakshmanan, phys. stat. sol. (a) 153, 3 (1996)

[4] H. von Seggern, Brazilian Journal of Physics 29, 254 (1999)

[5] J.-M. Spaeth, Proceedings ICDIM2000 (Johannesburg-Midrand, South Africa, 2000), to be published in Radiation Effects and Defects in Solids

[6] A. Kalnins, I. Plavina, L. Trinkler, and M. Trinkler, Proceedings LUMDETR'91 (University of Latvia, Riga, 1991), p. E18

[7] M. Thoms, H. von Seggern, A. Winnacker, J. Appl. Phys. 76 (3), 1800 (1994)

[8] Th. Hangleiter, U. Rogulis, C. Dietze, J.-M. Spaeth, P. Willems, L. Struye, P. J. R. Leblans, Proceedings SCINT'95 (Delft University Press, The Netherlands)

[9] Th. Pawlik and J.-M. Spaeth, Proceedings SCINT'95 (Delft University Press, The Netherlands, 1995), p. 392

[10] J.-M. Spaeth, J. R. Niklas, and B. H. Bartram, Structural Analysis of Point Defects in Solids, Springer Series in Solid State Sciences 43 (Springer, Berlin, 1992)

[11] L. F. Mollenauer and S. Pan, Phys. Rev. B 6 (3), 772 (1972)

[12] F. Lüty and J. Mort, Phys. Rev. Letters 12, 45 (1964)

[13] C. P. Slichter, Principles of Magnetic Resonance, Springer Series in Solid State Sciences 1, 3rd Edition (Springer, Berlin, 1989) 
[14] N. Bloembergen, S. Shapiro, P. S. Pershan, and J. O. Artman, Phys. Rev. 114, 445 (1959)

[15] F.-K. Koschnick, Doctoral Thesis, Paderborn (1991)

[16] H. Seidel, Z. Phys. 165, 239 (1961)

[17] K. W. H. Stevens, Proc. Phys. Soc. 65, 209 (1952)

[18] S. Schweizer and J.-M. Spaeth, J. Phys. Chem. Solids 58 (6), 859 (1997)

[19] A. Meijerink, G. Blasse, and L. Struye, Mater. Chem. Phys. 21, 261 (1989)

[20] R. C. Gonzalez and P. Wintz, Digital Image Processing (Addison Wesley, Massachusetts, 1977)

[21] P. P. Dendy and B. Heaton, Physics for Radiologists (Blackwell Scientific Publications, Oxford, 1987)

[22] P. Willems, Private Communication (Agfa-Gevaert, Mortsel, Belgium)

[23] H. von Seggern, T. Voigt, W. Knüpfer, and G. Lange, J. Appl. Phys. 64, 1405 (1988)

[24] M. Thoms, H. von Seggern, A. Winnacker, Phys. Rev. B 44, 9240 (1991)

[25] G. Blasse, Journal of Alloys and Compounds 192, 17-21 (1993)

[26] B. W. Liebich and D. Nicollin, Acta Cryst. B33, 2790 (1977)

[27] H. P. Beck, Z. anorg. allg. Chem. 451, 73 (1979)

[28] K. Takahashi, J. Miyahara and Y. Shibahara, J. Electrochem. Soc. 132, 1492 (1985)

[29] H. H. Rüter, H. von Seggern, R. Reiniger and V. Saile, Phys. Rev. Letters 65, 2438 (1990)

[30] K. S. Song and R. T. Williams, Self-trapped Excitons, Springer Series in Solid State Sciences 105, 2nd Edition (Springer, Berlin, 1993)

[31] J.-M. Spaeth, W. Meise, and K. S. Song, J. Phys.: Condens. Matter 6, 18011814 (1994)

[32] Th. Hangleiter, F.-K. Koschnick, J.-M. Spaeth, R. H. D. Nuttall, and R. S. Eachus, J. Phys.: Condens. Matter 2, 6837 (1990) 
[33] Th. Hangleiter, F.-K. Koschnick, J.-M. Spaeth, and R. S. Eachus, Radiation Effects and Defects in Solids 119-121, 615 (1991)

[34] F.-K. Koschnick, Th. Hangleiter, J.-M. Spaeth, and R. S. Eachus, J. Phys.: Condens. Matter 4, 3001 (1992)

[35] R. S. Eachus, F.-K. Koschnick, J.-M. Spaeth, R. H. D. Nuttall and W. G. McDugle, Proceedings Intern. Conf. on Defects in Insulating Materials, Nordkirchen, Germany, ed. O. Kanert and J.-M. Spaeth, World Scientific (Singapore) p. 267

[36] R. S. Eachus, R. H. D. Nuttall, W. G. McDugle, F.-K. Koschnick and J.-M. Spaeth, Proceedings Intern. Conf. on Defects in Insulating Materials, Nordkirchen, Germany, ed. O. Kanert and J.-M. Spaeth, World Scientific (Singapore) p. 1172

[37] R. S. Eachus, W. G. McDugle, R. H. D. Nuttall, M. T. Olm, F.-K. Koschnick, Th. Hangleiter, and J.-M. Spaeth, J. Phys.: Condens. Matter 3, 9327 and 9339 (1991)

[38] R. S. Eachus, R. H. D. Nuttall, M. T. Olm, W. G. McDugle, F.-K. Koschnick, Th. Hangleiter, and J.-M. Spaeth, Phys. Rev. B 52, 3941 (1995)

[39] S. Schweizer and J.-M. Spaeth, J. Phys.: Condens. Matter 11, 1723 (1999)

[40] F.-K. Koschnick, J.-M. Spaeth, R. S. Eachus, W. G. McDugle and R. H. D. Nuttall, Phys. Rev. Letters 67, 3571 (1991)

[41] R. U. Bauer, J. R. Niklas and J.-M. Spaeth, phys. stat. sol. (b) 118, 557 (1983)

[42] K. Takahashi, K. Kohda, J. Miyahara, Y. Kanemitsu, K. Amitani, S. Shionoya, J. Luminescence 31 \& 32, 266 (1984)

[43] Y. Iwabuchi, C. Umemoto, K. Takahashi, and S. Shionoya, Journal of Luminescence 48 \& 49, 481 (1991)

[44] A. Meijerink and G. Blasse, J. Phys. D 24, 626 (1991)

[45] D. M. De Leeuw, T. Kovats and S. P. Herko, J. Electrochem. Soc. 134, 491 (1987)

[46] F.-K. Koschnick, J.-M. Spaeth, and R. S. Eachus, J. Phys.: Condens. Matter 4, 8919 (1992) 
[47] Y. Kondo, T. Tezuka, and Y. Iwabuchi, Proceedings ICDIM2000 (Johannesburg-Midrand, South Africa, 2000), to be published in Radiation Effects and Defects in Solids

[48] R. J. Klee, J. Phys. D: Appl. Phys. 28, 2529 (1995)

[49] F. K. Koschnick, T. Hangleiter, K. S. Song, and J.-M. Spaeth, J. Phys.: Condens. Matter 7, 6925 (1995)

[50] E. Radzhabov and V. Otroshok, J. Phys. Chem. Solids 56, 1 (1995)

[51] C. Dietze, Th. Hangleiter, P. Willems, R. J. R. Leblans, L. Struye, and J.-M. Spaeth, J. Appl. Phys. 80, 1074 (1996)

[52] S. Schweizer, J.-M. Spaeth and T. J. Bastow, J. Phys.: Condens. Matter 10, 9111 (1998)

[53] M. H. Cohen and F. Reif, Solid State Physics 5, 321 (1957)

[54] N. Boden, P. K. Kahal, A. Mee, M. Mortimer, and G. N. Peterson, Journal of Magnetic Resonance 54, 419 (1983)

[55] R. W. Vaughan, D. D. Elleman, W.-K. Rhim, and L. M. Stacey, Journal of Chem. Phys. 57, 5383 (1972)

[56] F.-K. Koschnick, J.-M. Spaeth, and R. S. Eachus, J. Phys.: Condens. Matter 4, 3015 (1992)

[57] W. Hayes, Crystals with the fluoride structure (Clarendon, Oxford, 1974)

[58] R. C. Baetzold, J. Chem. Phys. Solids 50, 915 (1989)

[59] R. C. Baetzold, Phys. Rev. B 36, 9182 (1987)

[60] W. Meise, U. Rogulis, F.-K. Koschnick, K. S. Song, and J.-M. Spaeth, J. Phys.: Condens. Matter 6, 1815 (1994)

[61] S. Schweizer, P. Willems, P. J. R. Leblans, L. Struye, J.-M. Spaeth, J. Appl. Phys. 79, 4157 (1996)

[62] Physics of Color Centres, edited by W. B. Fowler (Academic Press, New York and London, 1968)

[63] D. Nicollin and H. Bill, J. Phys. C 11, 4803 (1978)

[64] S. Assmann, S. Schweizer, and J.-M. Spaeth, phys. stat. sol. (b) 212, 325 (1999) 
[65] H. von Seggern, A. Meijerink, T. Voigt, and A. Winnacker, J. Appl. Phys. 66, 4418 (1989)

[66] P. F. Braslavets, A. Kalnins, I. Plavina, A. I. Popov, B. I. Rapoport, A. Tale, phys. stat. sol. (b) 170, 395 (1992)

[67] F. J. Ahlers, F. Lohse, Th. Hangleiter, J.-M. Spaeth, and R. H. Bartram, J. Phys. C: Solid State Phys. 17, 4877 (1984)

[68] U. Rogulis, I. Tale, Th. Hangleiter, and J.-M. Spaeth, J. Phys.: Condens. Matter 7, 3129 (1995)

[69] A. Fukuda, Phys. Rev. B 1, 4161 (1970)

[70] I. Plavina, I. Tale, and A. Tale, Proceedings LUMDETR'91 (University of Latvia, Riga, 1991), p. D4

[71] L. E. Trinkler, M. F. Trinkler and A. I. Popov, phys. stat. sol. (b) 180, K31 (1993)

[72] A. Kalnins, I. Plavina, and A. Tale, Nuclear Instruments and Methods in Physics Research B 84, 95-101 (1994)

[73] C. J. Delbecq, W. Hayes, and P. H. Yuster, Phys. Rev. B 121, 1043 (1961)

[74] U. Rogulis, K. S. Song, and J.-M. Spaeth, J. Phys.: Condens. Matter 7, 7699 (1995)

[75] B. J. Faraday and W. D. Compton, Phys. Rev. A 138, 893 (1965)

[76] U. Rogulis, C. Dietze, Th. Pawlik, Th. Hangleiter, and J.-M. Spaeth, J. Appl. Phys. 80, 2430 (1996)

[77] D. Schoemaker, Phys. Rev. B 7, 786 (1973)

[78] U. Rogulis, J.-M. Spaeth, I. Cabria, M. Moreno, I. A. Aramburu, and M. T. Barriuso, J. Phys.: Conden. Matter 10, 6473 (1998)

[79] I. Cabria, M. Moreno, I. A. Aramburu, M. T. Barriuso, U. Rogulis, and J.-M. Spaeth, J. Phys.: Conden. Matter 10, 6481 (1998)

[80] U. Rogulis, S. Schweizer, S. Assmann, and J.-M. Spaeth, J. Appl. Phys. 84, 4537 (1998)

[81] U. Rogulis, S. Schweizer, S. Assmann, and J.-M. Spaeth, J. Appl. Phys. 87, 207 (2000) 
[82] C. Dietze, Diploma Thesis, Paderborn (1995)

[83] Yu. V. Kolk and A. Ch. Lushchik, Sov. Phys. Solid State 28, 805 (1986)

[84] J. J. Pilloud and C. Jaccard, phys. stat. sol. (b) 92, 233 (1979)

[85] F.-K. Koschnick, K.-H. Wietzke, and J.-M. Spaeth, Phys. Rev. B 58 (12), 7707 (1998)

[86] P. G. Baranov and V. A. Khramtsov, Sov. Phys. Solid State 20, 1080 (1978)

[87] C. J. Delbecq, R. Hartford, D. Schoemaker, and P. H. Yuster, Phys. Rev. B 31, 3631 (1976)

[88] F. van Steen and D. Schoemaker, Phys. Rev. B 19, 55 (1979)

[89] E. Goovaerts, J. Andriessen, S. V. Nistor, and D. Schoemaker, Phys. Rev. B 24, $29(1981)$

[90] D. K. Rowell and M. J. L. Sangster, J. Phys. C: Solid State Phys. 14, 2909-2921 (1981)

[91] F. J. Ahlers, Doctoral Thesis, Paderborn (1985)

[92] S. Assmann, Doctoral Thesis, Paderborn (2000)

[93] S. Radhakrishna, N. N. Nigam and V. S. Sivasankar, Phys. Rev. B 15, 1187 (1977)

[94] V. P. Savelev, V. P. Avdonin, L. D. Dugarova, A. P. Nadashkovskii, and B. T. Plachenov, Soviet Physics Solid State 16, 700 (1974)

[95] C. P. Medrano, H. S. Murrieta, and J. O. Rubio, Journal of Luminescence 29, 223 (1984)

[96] E. P. Munoz, J. O. Rubio, H. S. Murrieta, G. S. Aguilar, and J. O. Boldu, J. Chem. Phys. 62, 3416 (1975)

[97] D. Babel, Mater. Res. Bull. 8, 1371 (1973)

[98] Th. Pawlik and J.-M. Spaeth, J. Appl. Phys. 82 (9), 4236 (1997)

[99] Th. Pawlik, Doctoral Thesis, Paderborn (1996)

[100] Th. Pawlik and J.-M. Spaeth, Material Science Forum 239-241, 287 (1997)

[101] Th. Pawlik and J.-M. Spaeth, phys. stat. sol. (b) 203, 43 (1997) 
[102] J. Qiu, Y. Shimizugawa, Y. Iwabuchi, and K. Hirao, Appl. Phys. Lett. 71, 759 (1997)

[103] J. Qiu, Y. Shimizugawa, Y. Iwabuchi, and K. Hirao, Appl. Phys. 71, 43 (1997)

[104] J. Qiu, Y. Shimizugawa, N Sugimoto, and K. Hirao, J. Non-Cryst. Solids 222, 290-295 (1997)

[105] A. Edgar, J.-M. Spaeth, S. Schweizer, S. Assmann, P. J. Newman, and D. R. MacFarlane, Appl. Phys. Lett. 75, 2386 (1999)

[106] S. Schweizer, S. Assmann, A. Edgar, and J.-M. Spaeth, Nuclear Instruments and Methods in Physics Research B 166-167, 508-510 (2000)

[107] Joint Committee on Powder Diffraction Standards, (Swarthmore, USA, 1996), Powder Diffraction File entry \#45-1314

[108] G. Liu and H. A. Eick, Journal of Less Common Metals 149, 47 (1989)

[109] D. R. MacFarlane, P. J. Newman, J. D. Cashion, and A. Edgar, J. Non-Cryst. Solids 257, 53-58 (1999)

[110] N. Iwase, S. Tadaki, S. Hidaka and N. Koshino, Journal of Luminescence 60 \& 61, 618 (1994)

[111] G. M. Williams, T.-E. Tsai, C. I. Merzbacher, and E. J. Friebele, Journal of Lightwave Technology 15, 1357 (1997)

[112] A. Abragam and B. Bleaney, Electron Paramagnetic Resonance of Transition Ions (Dover Publications, New York, 1986)

[113] D. L. Griscom, J. Non-Cryst. Solids 40, 211-272 (1980)

[114] S. Schweizer, S. Assmann, A. Edgar, and J.-M. Spaeth, Nuclear Instruments and Methods in Physics Research B 166-167, 505-507 (2000) 
Mein Dank geht an erster Stelle an Herrn Prof. Dr. J.-M. Spaeth, der mich in allen Phasen meiner wissenschaftlichen Laufbahn stets unterstützt und gefördert hat. Er hat mir mit zahlreichen Diskussionen und persönlichen Gesprächen ganz wesentlich bei der Anfertigung dieser Arbeit geholfen.

Im weiteren möchte ich mich bei Herrn Dr. S. Assmann und Herrn Dr. U. Rogulis für die ausgezeichnete Zusammenarbeit bedanken.

Für die problemlose Versorgung mit flüssigem Helium danke ich Herrn Dr. F. Lohse und Herrn J. Pauli. Weiterhin möchte ich mich bei den Kollegen des Kristallzuchtlabors Herrn Dr. Th. Hangleiter, Herrn D. Niggemeier und Herrn R. Winterberg bedanken.

Allen namentlich nicht erwähnten Mitgliedern der Arbeitsgruppe danke ich für die angenehme Arbeitsatmosphäre. 